\title{
Flexural behavior of reinforced masonry panels
}

\author{
Juliana T. Oliveira, Joaquim O. Barros \\ Paulo B. Lourenço, Everaldo Bonaldo
}

Report 02-DEC/E-10

\begin{abstract}
The present research has been carried out under contract GROW-1999-70420 "ISO-BRICK” from the European Commission
\end{abstract}

Date: Abril 2003

No. of pages: 70

Keywords:
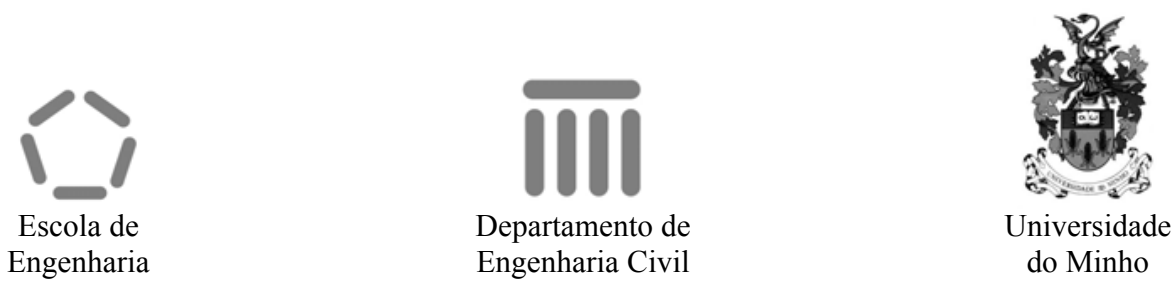


\section{Contents}

1 Introduction ................................................................................................................... 4

2 Characterization of the Materials......................................................................4

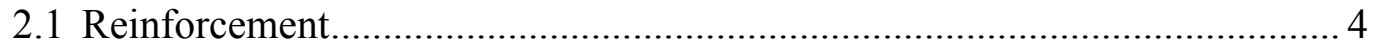

2.2 Welded wire mesh ............................................................................... 7

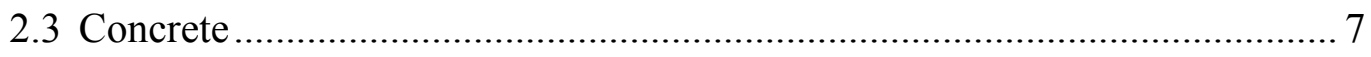

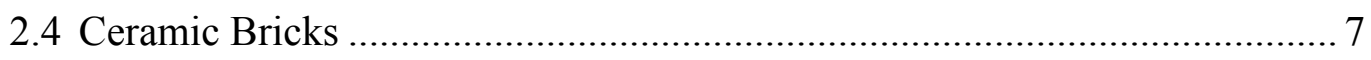

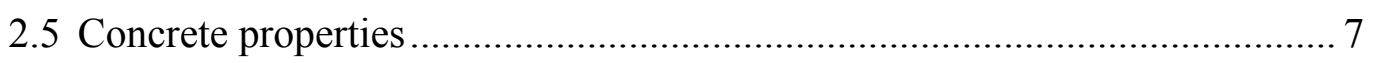

3 Masonry Specimens....................................................................................... 9

4 Test Results ..................................................................................................

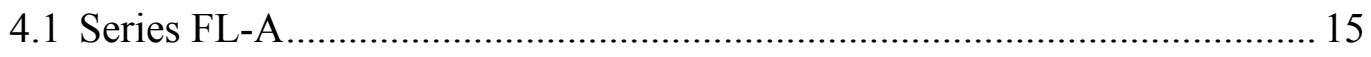

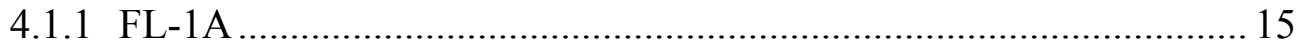

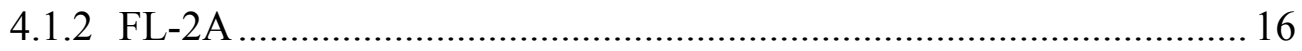

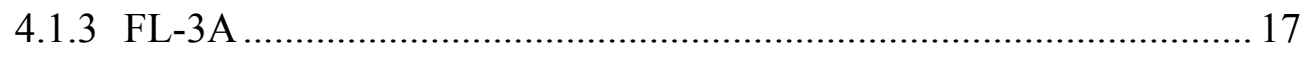

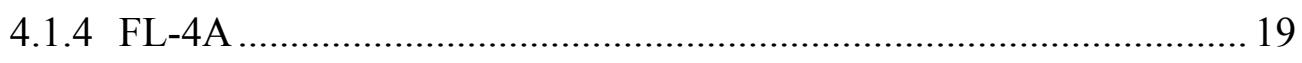

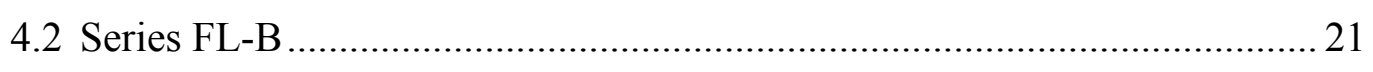

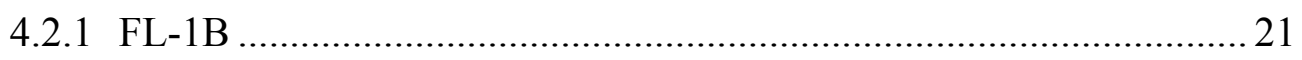

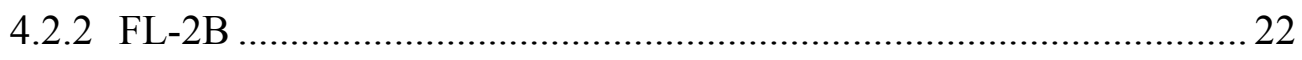

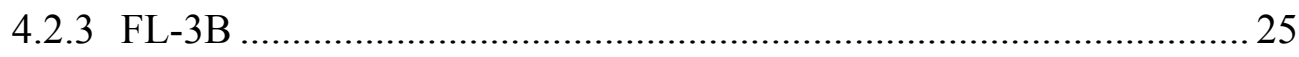

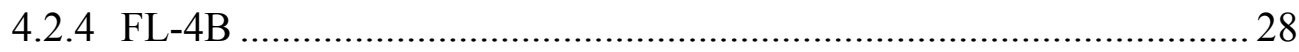

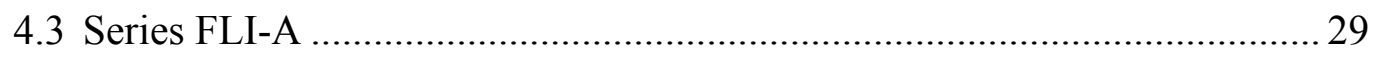

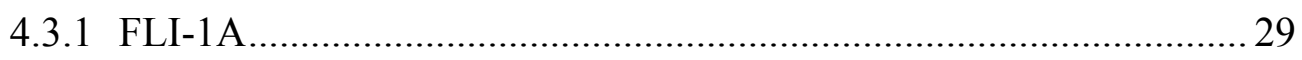

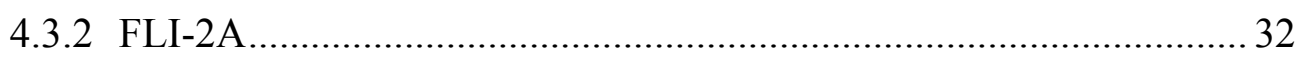

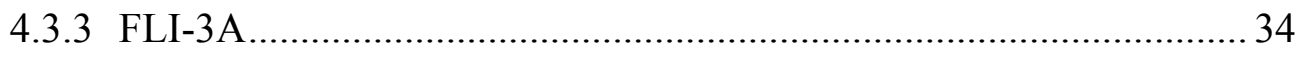

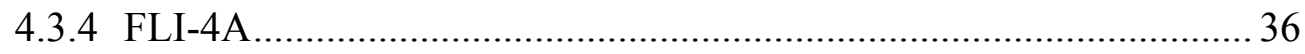

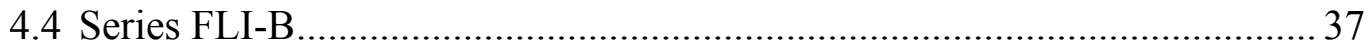

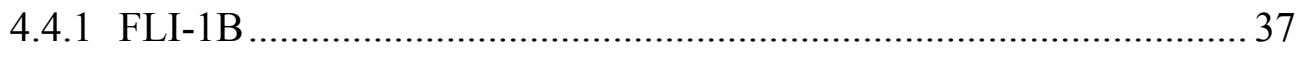

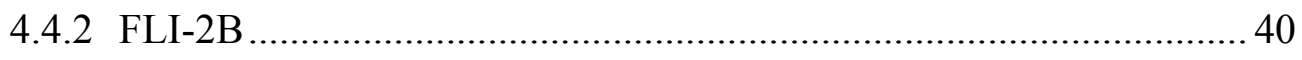

Flexural Tests in masonry Panels/GROW-1999-70420 "ISO-BRICK" - 2/2 


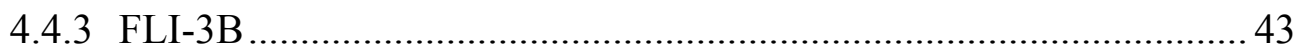

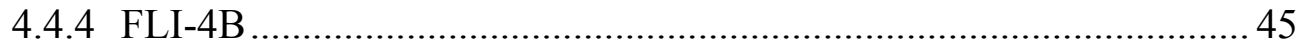

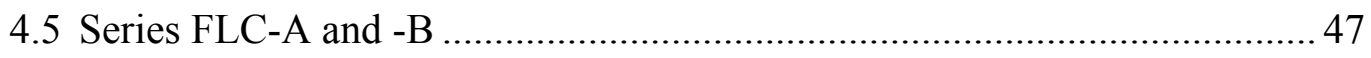

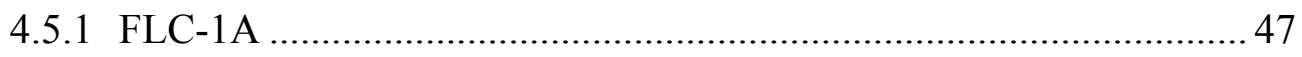

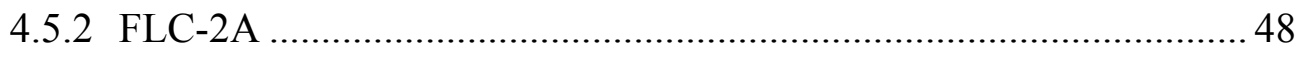

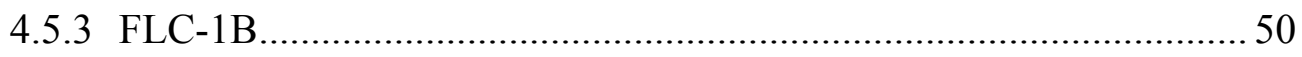

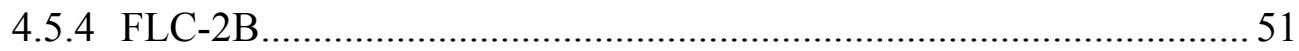

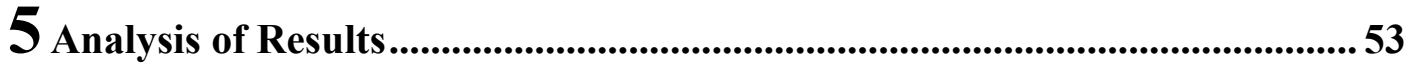

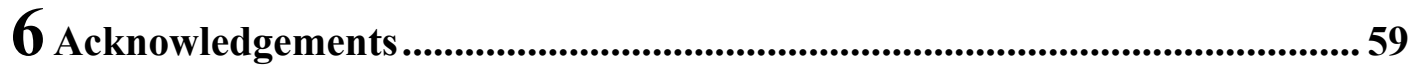

7 Bibliography............................................................................................60 


\section{Introduction}

To assess the flexural behavior of reinforced masonry panels, series of four point bending tests were carried out according to EN 1052-2 - "Methods of test for masonry Part 2: Determination of flexural strength" (EN 1052-2 2000). The properties of the intervening materials (bricks, concrete and reinforcement) were also determined from experimental tests.

In his report the tests are described and the results are presented and analyzed.

\section{Characterization of the Materials}

\subsection{Reinforcement}

The concrete joints of the masonry panels had $25 \mathrm{~mm}$ thick. The concrete joints in orthogonal and in parallel directions to brick holes were reinforced with steel bars of $8 \mathrm{~mm}$ and $6 \mathrm{~mm}$ diameter, respectively.

To evaluate the tensile behavior of this reinforcement, four and six specimens of $6 \mathrm{~mm}$ and $8 \mathrm{~mm}$ diameter, respectively, were tested according to EN 10 002-1 - Tensile Testing, 1990, Part 1: method of test (EN 10002-1 1990). Due to high dispersion of the results registered in specimens of $6 \mathrm{~mm}$ diameter, larger number of specimens was tested in this series. The stress-displacement relationships and the main representative results are included in Annex 1.

The specimens were tested in direct tension using a DARTEC universal testing machine equipped with a load cell of $600 \mathrm{kN}$ maximum load bearing capacity. To evaluate the elongation at the rupture of the specimens, marks at $30 \mathrm{~mm}$ and $40 \mathrm{~mm}$ of distance were made on the central zone of the specimens of $6 \mathrm{~mm}$ and $8 \mathrm{~mm}$ diameter, respectively. In some specimens this elongation was not measured because the rupture occurred outside the marked zones.

A clip-gauge was used to measure the displacements up to the estimated material limit of proportionality, LOP, see Figure 1. For avoiding the damage of the clip 
gauge during the test, it was removed when the stress attained the LOP value. To do that, the load was maintained constant during the period of time necessary to remove the clip gauge. Up to LOP the strain was evaluated from the displacements registered in the clip-gauge, using its measuring length that was taken equal to five times the bar diameter. This strain is representative of the specimen deformation, and is designated by "true" strain. After LOP, the strain was derived from the machine internal displacement transducer, using a reference length of $280 \mathrm{~mm}$. This is an apparent strain because, beyond the specimen deformation, the machine internal displacement transducer also registers parasitic movements.

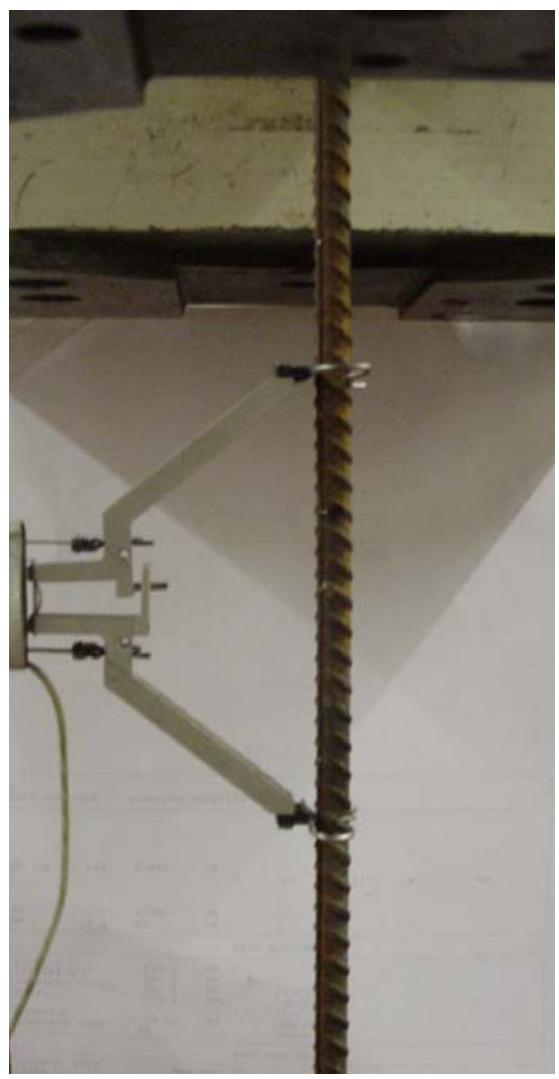

Figure 1 - Device used for measuring the strain of the steel bar specimen.

The stress at $0.2 \%$ of elongation, the strength (maximum stress), the "true" and "apparent" strains and the ratio between these two strains are included in Tables 2.1 and 2.2. From the results in these Tables and using the recommendations of the European Norm EN 10 002-1 (EN 10002-1 1990), both steel bars can be considered of steel class A500. The strains at $0.2 \%$ for steel bars of $8 \mathrm{~mm}$ diameter and $6 \mathrm{~mm}$ diameter are $2.62 \times 10^{-3}$ and $3.31 \times 10^{-3}$, respectively. 
Table 2.1 - Characterization of steel bars of $8 \mathrm{~mm}$ diameter.

\begin{tabular}{|c|c|c|c|c|}
\hline$\varnothing 8 \mathrm{~mm}$ & $\mathbf{A}_{1}$ & $\mathbf{A}_{2}$ & $\mathbf{A}_{3}$ & $\mathbf{A}_{4}$ \\
\hline $\begin{array}{l}\text { Tensile stress at } 0.2 \% \\
\text { (MPa) }\end{array}$ & 537 & 526 & 548 & 486 \\
\hline $\begin{array}{l}\text { Tensile Strength } \\
\text { (MPa) }\end{array}$ & 625 & 613 & 627 & 589 \\
\hline $\begin{array}{c}\text { Elongation on } \\
\mathrm{L}_{0}=40 \mathrm{~mm}(\%)\end{array}$ & 26.25 & - & - & 21.95 \\
\hline $\begin{array}{c}\text { Elongation on } \\
\mathbf{L}_{0}=280 \mathrm{~mm}(\%)\end{array}$ & 14 & 14.5 & 11.5 & 13.0 \\
\hline $\begin{array}{l}\text { Ratio Elongation }\left(\mathrm{L}_{0}=40 \mathrm{~mm}\right) /(\text { Elongation } \\
\left.\qquad \mathbf{L}_{0}=280 \mathrm{~mm}\right)(\%)\end{array}$ & 87 & - & - & 69 \\
\hline
\end{tabular}

Table 2.2 - Characterization of steel bars of $6 \mathrm{~mm}$ diameter.

\begin{tabular}{|c|c|c|c|c|c|c|}
\hline$\varnothing 6 \mathrm{~mm}$ & $\mathbf{A}_{1}$ & $\mathbf{A}_{2}$ & $\mathbf{A}_{3}$ & $\mathbf{A}_{4}$ & $\mathbf{A}_{5}$ & $\mathbf{A}_{6}$ \\
\hline Tensile stress at $0.2 \%$ (MPa) & 739 & 660 & 651 & - & 717 & 573 \\
\hline $\begin{array}{l}\text { Tensile Strength } \\
\text { (MPa) }\end{array}$ & 791 & 685 & 678 & 634 & 781 & 620 \\
\hline $\begin{array}{c}\text { Elongation on } \mathrm{L}_{0}=40 \mathrm{~mm} \\
(\%)\end{array}$ & 13 & - & - & 13.3 & 10.3 & - \\
\hline $\begin{array}{c}\text { Elongation } \\
\text { on } \mathrm{L}_{\mathbf{0}}=\mathbf{2 8 0 \mathrm { mm }} \\
(\%)\end{array}$ & 5.5 & 4.5 & 3.5 & 5.5 & 6.0 & - \\
\hline $\begin{array}{c}\text { Ratio Elongation } \\
\left(\mathrm{L}_{0}=40 \mathrm{~mm}\right) /\left(\text { Elongation } L_{0}=280 \mathrm{~mm}\right) \\
(\%)\end{array}$ & 236 & - & - & 242 & 172 & \\
\hline
\end{tabular}




\subsection{Welded wire mesh}

A welded wire mesh A500 with the tradename of CQ30 was used to reinforce the concrete layer of the masonry panels. The wire mesh was placed at the brickconcrete layer interface. This mesh was composed by wires of $3 \mathrm{~mm}$ diameter forming a square grid of $150 \mathrm{~mm}$ edge. As the desired wire spacing was $75 \mathrm{~mm}$, two over-crossed CQ30 meshes were applied for reinforcing the concrete layer (see Figure 2).

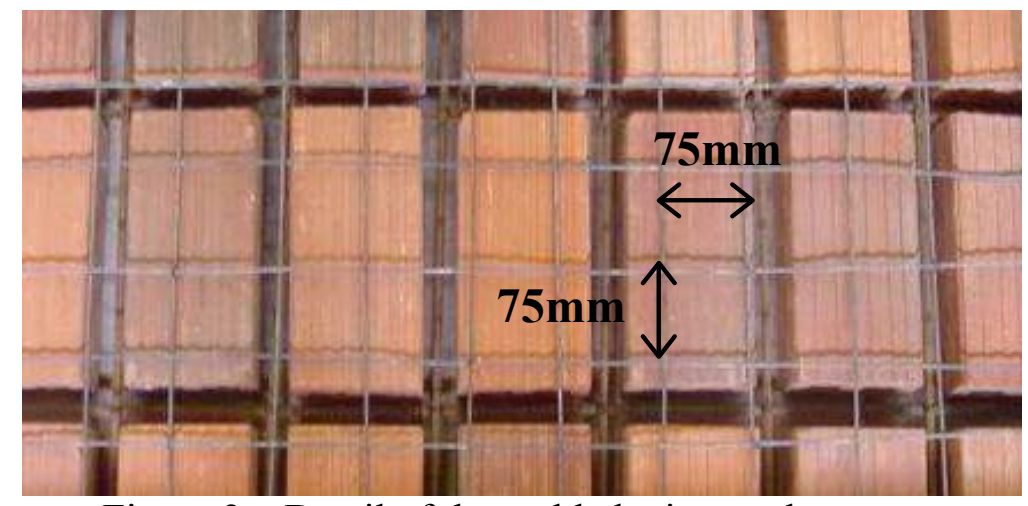

Figure 2 - Detail of the welded wire mesh.

\subsection{Concrete}

The concrete was composed by $300 \mathrm{Kg} / \mathrm{m}^{3}$ of cement $52.5 \mathrm{R}$ of high initial strength, $654.70 \mathrm{Kg} / \mathrm{m}^{3}$ of sand $0.3-0.6 \mathrm{~mm}, 279.32 \mathrm{Kg} / \mathrm{m}^{3}$ of sand $0.6-5 \mathrm{~mm}$, and $805.79 \mathrm{Kg} / \mathrm{m}^{3}$ of gravel $5-10 \mathrm{~mm}$. The sieve curves of these aggregates are presented in Annex 2. Rebuilt ${ }^{\circledR} 1000$ superplasticizer was used in a content of $2.5 \%$ of the cement content. The water/cement ratio was 0.55 .

\subsection{Ceramic Bricks}

The brick had dimensions of $215 \mathrm{~mm}$ length, $100 \mathrm{~mm}$ width and $65 \mathrm{~mm}$ height, and had two holes of $25 \mathrm{~mm} \times 25 \mathrm{~mm}$, see Figure 3 . Polystyrene pieces were introduced in the extremities of the brick holes to avoid excessive concrete penetration.
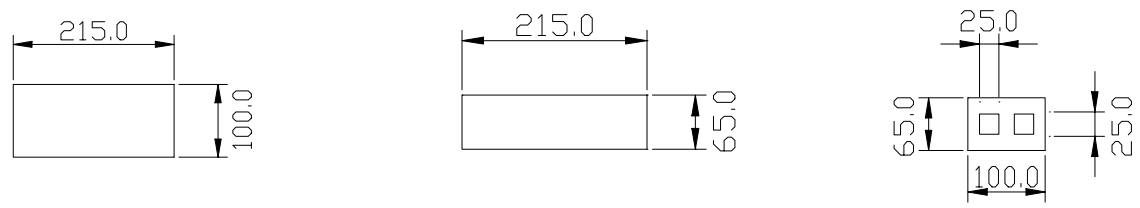

Figure 3 - Geometry of clay bricks. 


\subsection{Concrete properties}

For evaluating the pre- and the post-peak flexural behavior of the concrete used on the masonry panels, three-point bending tests were carried out with notched beams, according to the recommendations of RILEM TC 50-FMC (RILEM 1985). Table 2.3 includes the results obtained, where $\mathrm{f}_{\mathrm{fct}, \mathrm{fl}}$ is the flexural tensile strength, $\mathrm{f}_{\mathrm{fct}, \mathrm{ax}}$ is the axial tensile strength, and $\mathrm{f}_{\mathrm{c}}$ is the compression strength determined in cylindrical specimens of $150 \mathrm{~mm}$ diameter and $300 \mathrm{~mm}$ height.

Table 2.3 - Results obtained from three point bending tests with notched beams.

\begin{tabular}{c|c|c|c|c}
\hline Specimens & $\begin{array}{c}\text { Age } \\
(\mathbf{d a y s})\end{array}$ & $\begin{array}{c}\mathbf{f}_{\text {fct,fl }} \\
(\mathbf{M P a})\end{array}$ & $\begin{array}{c}\mathbf{f}_{\text {fct,ax }} \\
(\mathbf{M P a})\end{array}$ & $\begin{array}{c}\mathbf{f}_{\mathbf{c}} \\
(\mathbf{M P a})\end{array}$ \\
\hline FL-1A & 100 & 3.98 & 1.59 & 36.75 \\
FL-2A & 100 & 3.98 & 1.59 & 36.75 \\
FL-3A & 101 & 3.98 & 1.59 & 36.75 \\
FL-4A & 102 & 3.98 & 1.59 & 36.75 \\
\hline Average & - & $\mathbf{3 . 9 8}$ & $\mathbf{1 . 5 9}$ & $\mathbf{3 6 . 7 5}$ \\
\hline FL-1B & 103 & 4.26 & 1.70 & 45.29 \\
FL-2B & 103 & 4.26 & 1.70 & 45.29 \\
FL-3B & 104 & 4.26 & 1.70 & 45.29 \\
\hline FL-4B & 101 & 4.18 & 1.67 & 32.84 \\
\hline Average & - & $\mathbf{4 . 2 4}$ & $\mathbf{1 . 6 9}$ & $\mathbf{4 2 . 1 8}$ \\
FLI-1A & 70 & 5.04 & 2.02 & 39.93 \\
FLI-2A & 70 & 5.04 & 2.02 & 39.93 \\
FLI-3A & 71 & 5.04 & 2.02 & 39.93 \\
FLI-4A & 71 & 5.04 & 2.02 & 39.93 \\
\hline \hline Average & - & $\mathbf{5 . 0 4}$ & $\mathbf{2 . 0 2}$ & $\mathbf{3 9 . 9 3}$ \\
\hline \hline FLI-1B & 98 & 4.11 & 1.64 & 36.23 \\
FLI-2B & 98 & 4.80 & 1.92 & 40.55 \\
FLI-3B & 99 & 4.80 & 1.92 & 40.55 \\
FLI-4B & 99 & 4.11 & 1.64 & 36.23 \\
\hline \hline Average & - & $\mathbf{4 . 4 6}$ & $\mathbf{1 . 7 8}$ & $\mathbf{3 8 . 3 9}$ \\
\hline \hline FLC-1A & 115 & 3.98 & 1.59 & 36.75 \\
FLC-2A & 80 & 5.04 & 2.02 & 39.93 \\
FLC-1B & 100 & 4.11 & 1.64 & 36.23 \\
FLC-2B & 107 & 4.18 & 1.67 & 32.84 \\
\hline \hline Average & - & - & - & - \\
\hline \hline
\end{tabular}


The $f_{\text {fct,ax }}$ parameter was evaluated from the $f_{\text {fct,fl }}$ values and using the recommendations of CEB-FIP 1993 (CEB-FIP 199). The average values for each series are also indicated $\left(f_{\text {fctm,fl }}, f_{\text {fctm,ax }}, f_{c m}\right)$, as well as, the age of the specimens when tested.

\section{Masonry Specimens}

A masonry specimen was composed by ceramic bricks, concrete joints, concrete layer, welded wire mesh and steel bars. A masonry panel had the dimensions of $975 \mathrm{~mm}$ length, $455 \mathrm{~mm}$ width and $95 \mathrm{~mm}$ thickness. The panel entire thickness was composed by the brick thickness $(65 \mathrm{~mm})$ plus the concrete layer thickness $(30 \mathrm{~mm})$. The force was applied by two line loads in the specimen's width, distanced $187.5 \mathrm{~mm}$ from the middle of the panel. In two series this distance was increased, in order to force the occurrence of shear failure. The external supports were distanced $437.5 \mathrm{~mm}$ and $420 \mathrm{~mm}$ from the panel center (see Figures 4, 5 and 6).

Five displacement transducers (LVDTs), placed according to Figure 4 (a) and (b), were used for measuring the panel deformability. In panels of series -A, a LVDT was placed at mid span (LVDT1), two LVDTs near the line loads and distanced $215 \mathrm{~mm}$ from the panel center (LVDT2 and LVDT3), and two LVDTs near the external supports, distanced $415 \mathrm{~mm}$ from the panel center (LVDT4 and LVDT5). In panels of series -B, a LVDT was placed at panel mid span (LVDT1), two LVDTs near the line loads and distanced $220 \mathrm{~mm}$ from the panel center (LVDT2 and LVDT3) and two LVDTs near the external supports and distanced $380 \mathrm{~mm}$ from the panel center (LVDT4 and LVDT5). The differences in the positions of the LVDTs in series $-\mathrm{A}$ and $-\mathrm{B}$ are due to the different length of the corresponding panels. The tests were grouped in the following series:

- Series FL-A: 4 panels tested with the concrete layer turned upward and the load applied directly on the concrete layer, in the direction of the brick holes (see Figures 5 and 7);

- Series FL-B: 4 panels tested with the concrete layer turned upward and the load applied directly on concrete topping, perpendicular to the direction of the brick holes (see Figures 6 and 7);

- Series FLI-A: 4 panels similar to the series FL-A, but tested with the concrete layer turned downward;

Flexural Tests in masonry Panels/GROW-1999-70420 "ISO-BRICK" - 9/9 
- Series FLI-B: 4 panels similar to the series FL-B, but tested with the concrete layer turned downward;

- Series FLC-A and FLC-B: 2 panels of series FL-A and 2 panels of series FL-B with a loading configuration consisted by two line load distanced $262.5 \mathrm{~mm}$ from the panel center.

The loading arrangement of series FLC was defined with the purpose of induce shear failure mode. Details of series -A and -B are represented in Figures 5 and 6 . The test layout is shown in Figure 7.

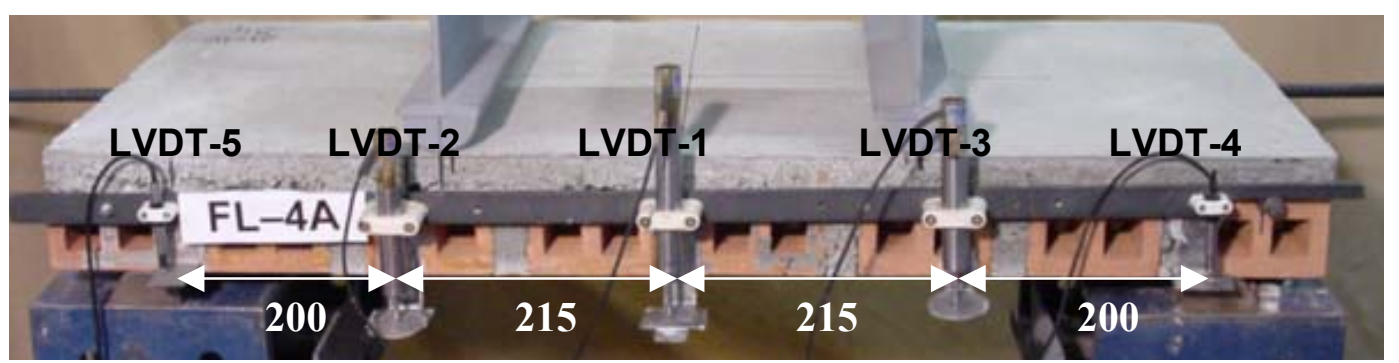

(a)

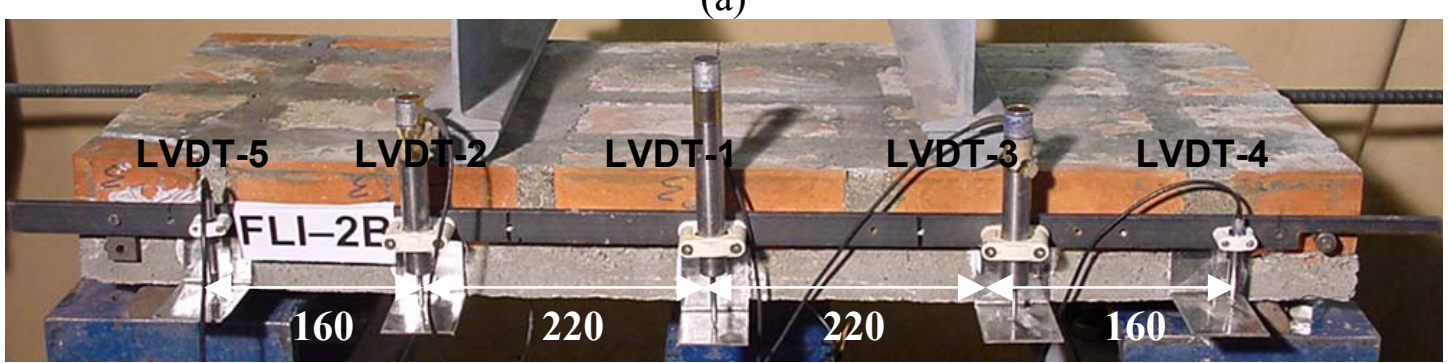

(b)

Figure 4 - Arrangement of the displacements transducers (LVDT) in the panels of series FL-A (a) and FLI-B (b). Dimensions in mm. 

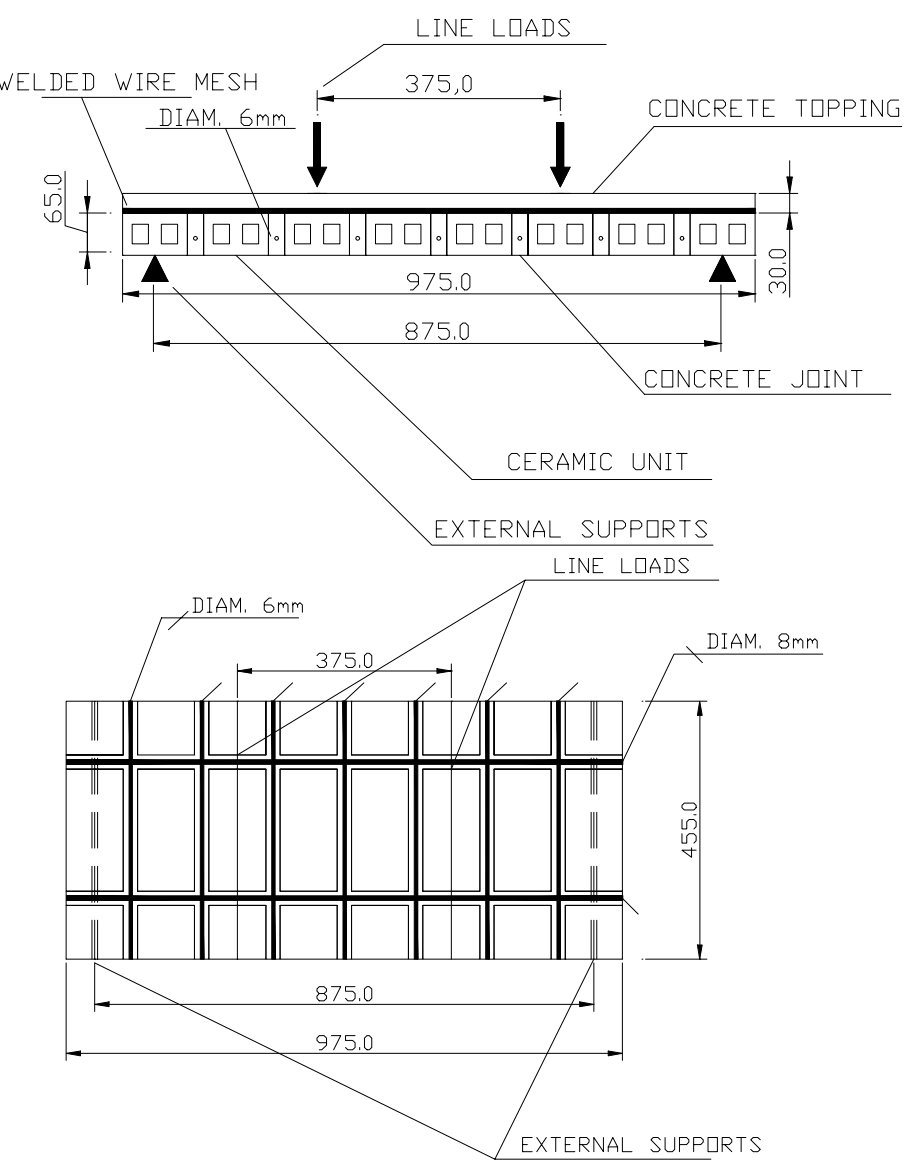

Figure 5 - Panel dimensions, loading arrangement and support conditions on panels of series A.
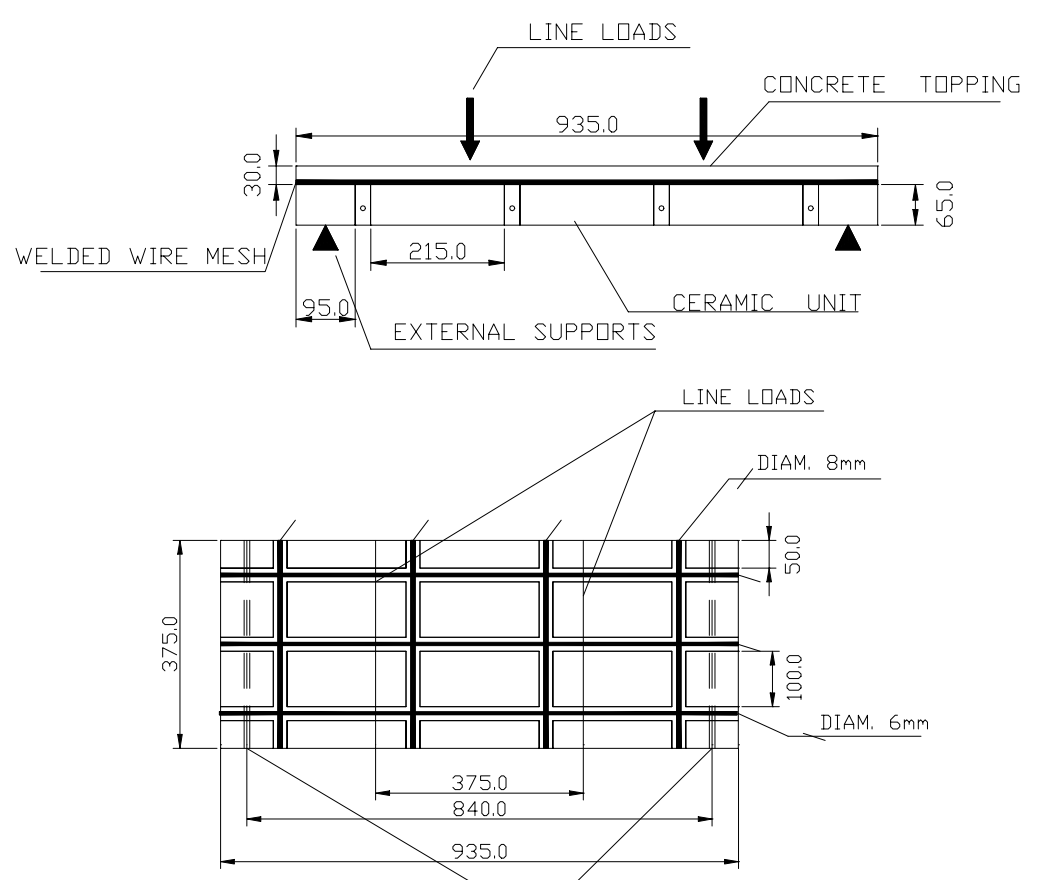

Figure 6 - Panel dimensions, loading arrangement and support conditions on panels of series B. 

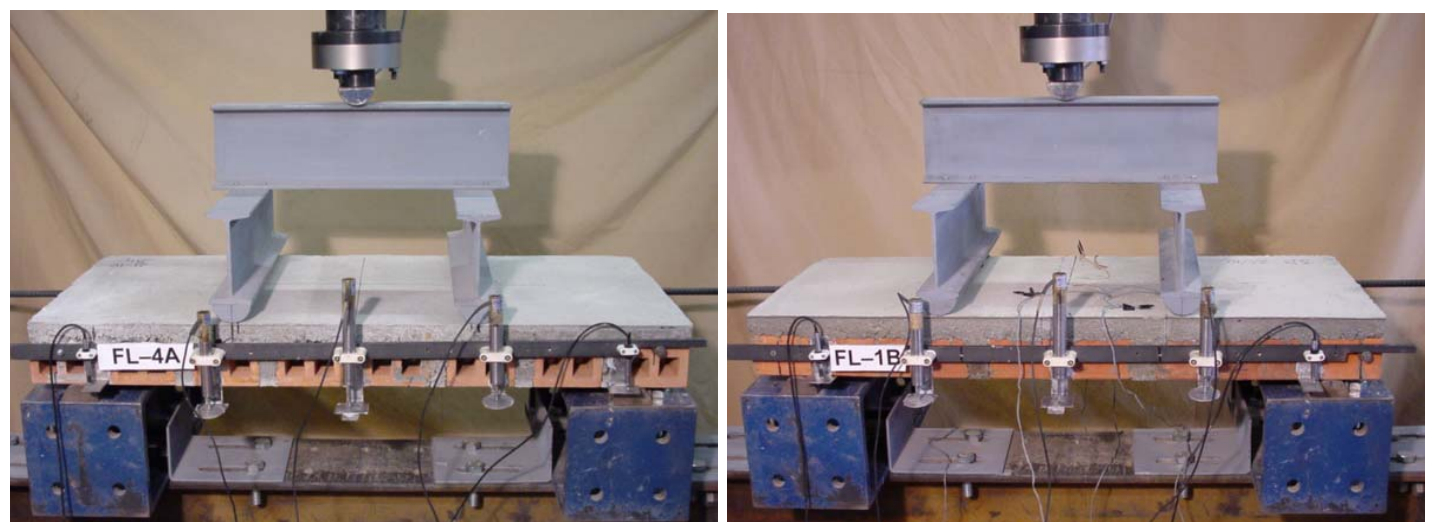

Figure 7 - Test system for panels of series -A and -B.

To obtain information about the deformational behavior of the steel bars reinforcing the masonry panels, strain gauges of $120 \Omega$ resistance were glued to some bars, according to the scheme represented in Figures 8 and 9.

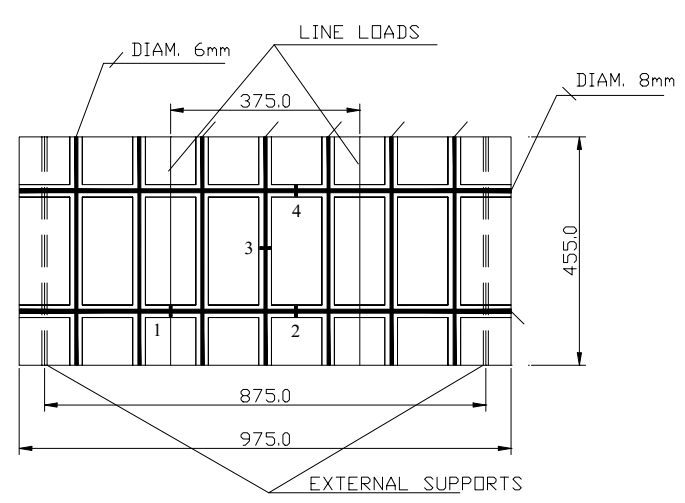

(a) Model 1

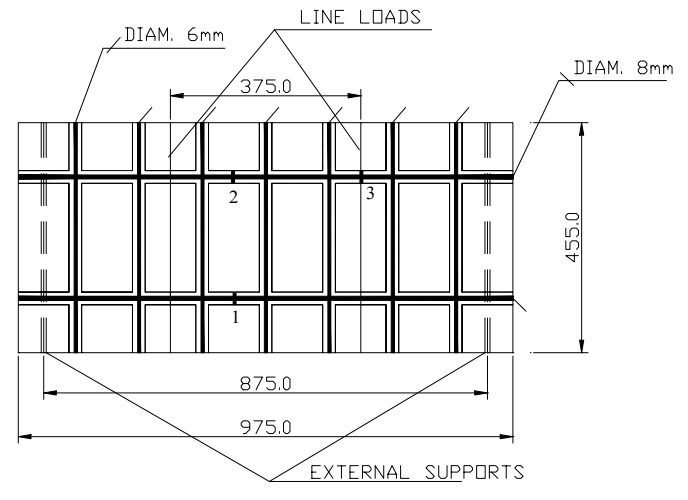

(b) Model 2

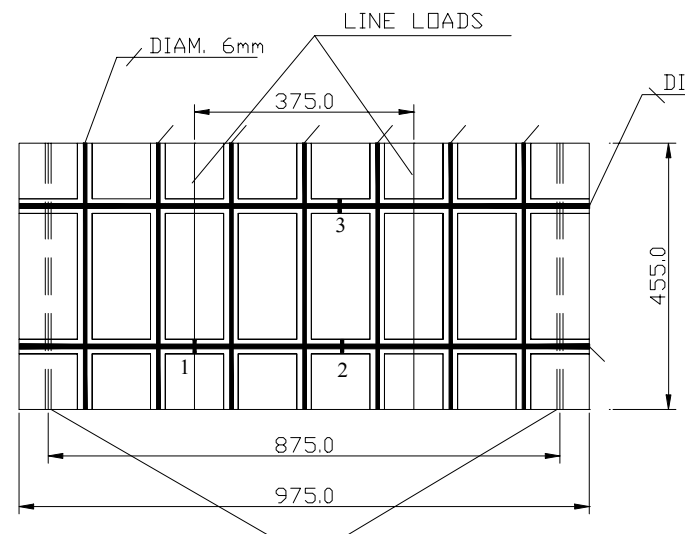

(c) Model 3

Figure 8 - Positions of the strain gauges used in series FL-A and FLI-A. 


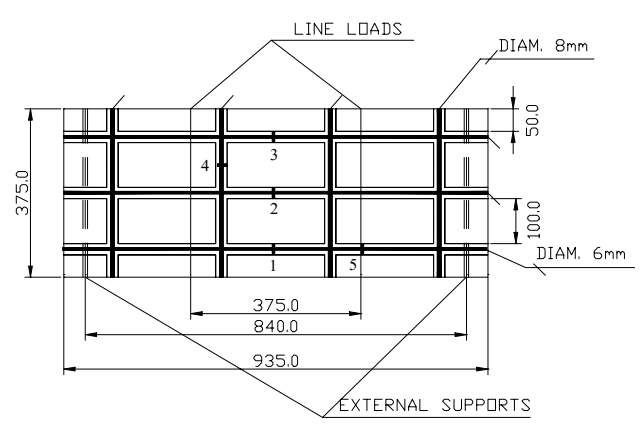

(a) Model 1

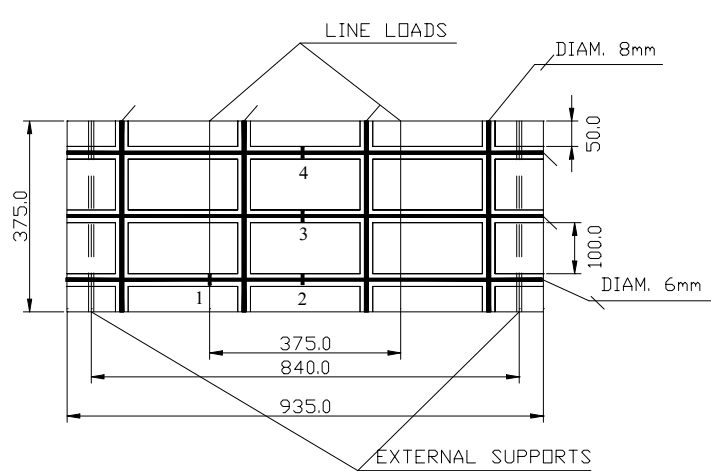

(c) Model 3

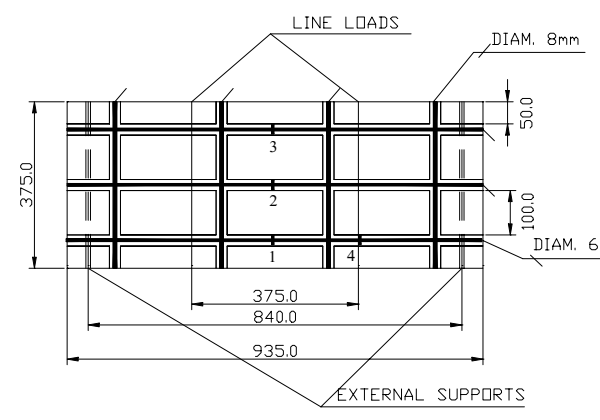

(b) Model 2

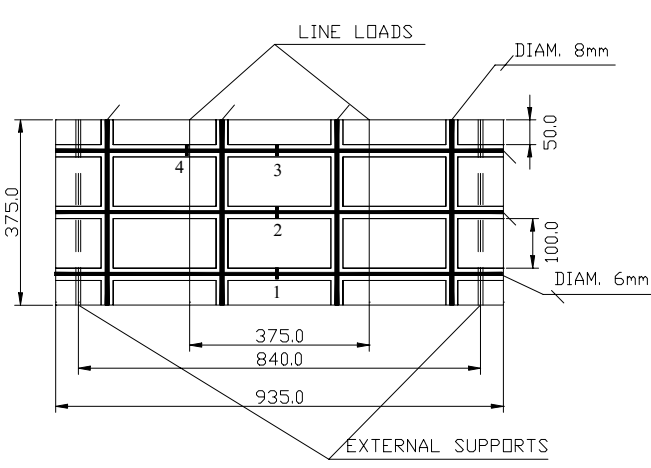

(d) Model 4

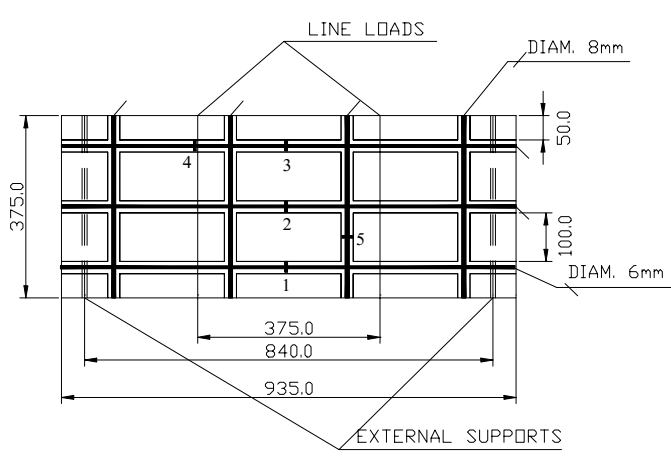

(e) Model 5

Figure 9 - Positions of the strain gauges used in series FL-B and FLI-B.

A correspondence between each panel and the corresponding model of strain gauge arrangement is given in Table 3.1. Panels FL-4A, FL-4B, FLI-4A and FLI-4B were not instrumented with strain gauges because it was assumed that the data obtained from three panels will be sufficient to assess the reinforcement behavior. Due to deficient operation of the data system acquisition, the strains in the panels FL-1A and FL-2A were not registered. 
Table 3.1 - Models of strain gauge arrangement.

\begin{tabular}{c|c}
\hline Panel reference & Configuration of strain gauges \\
\hline FL-3A & Model 2 (Figure 8) \\
FL-1B & Model 2 (Figure 9) \\
FL-2B & Model 4 (Figure 9) \\
FL-3B & Model 5 (Figure 9) \\
FLI-1A & Model 2 (Figure 8) \\
FLI-2A & Model 1 (Figure 8) \\
FLI-1B & Model 1 (Figure 9) \\
FLI-2B & Model 2 (Figure 9) \\
FLI-3B & Model 3 (Figure 9) \\
\hline
\end{tabular}

The tests were carried out under displacement control, at a displacement ratio of $15 \times 10^{-6} \mathrm{~m} / \mathrm{s}$. The displacement transducer placed at panel mid span (LVDT1) was used to control the test. The actuator had a maximum load bearing capacity of $300 \mathrm{kN}$. 


\section{Test Results}

\subsection{Series FL-A}

\subsubsection{FL-1A}

At a load of about $34 \mathrm{kN}$, the six fissures depicted in Figure 10 have arisen almost simultaneously at the concrete/brick interface. After this load level and during the crack opening process of the fissures, the welded wire mesh began rupturing. Fissure 2 was the failure crack, and a crack opening of $15 \mathrm{~mm}$ was attained on the brick base, and $10 \mathrm{~mm}$ on the brick/concrete layer interface. At a load of $44 \mathrm{kN}$ fissure 2 crossed the concrete layer and the panel load bearing capacity began decreasing, as Figure 11 shows.

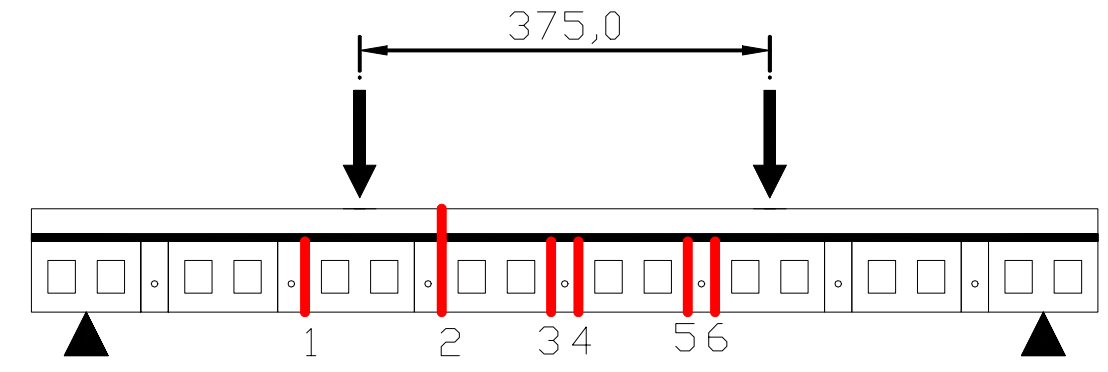

Figure 10 - Crack pattern in FL-1A.

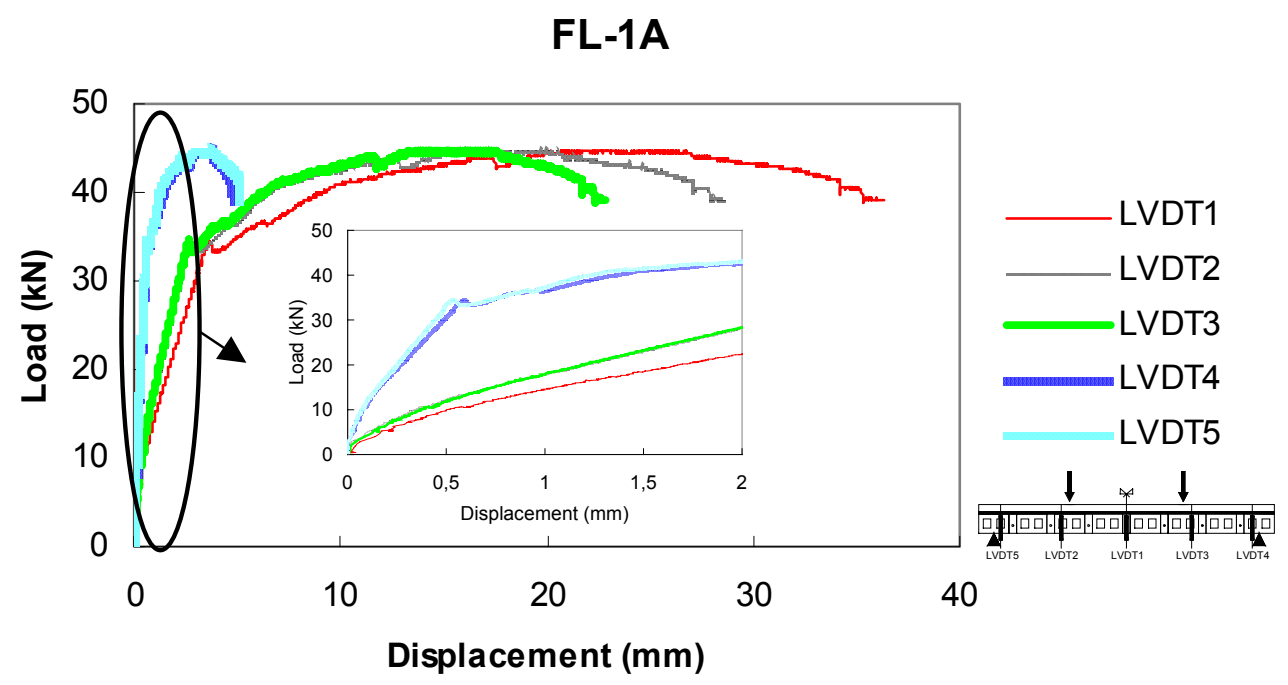

Figure 11 - Force-displacements relationship for all LVDTs. 
In spite of LVDT2 and LVDT3 are symmetrically placed (see Figure 4), LVDT 2 registered larger displacements because it is located nearest the failure crack. The displacements near the external supports of the panel were similar. Figure 12 shows the panel at the moment of its failure. The concrete above fissure 2 (failure crack) has crushed.
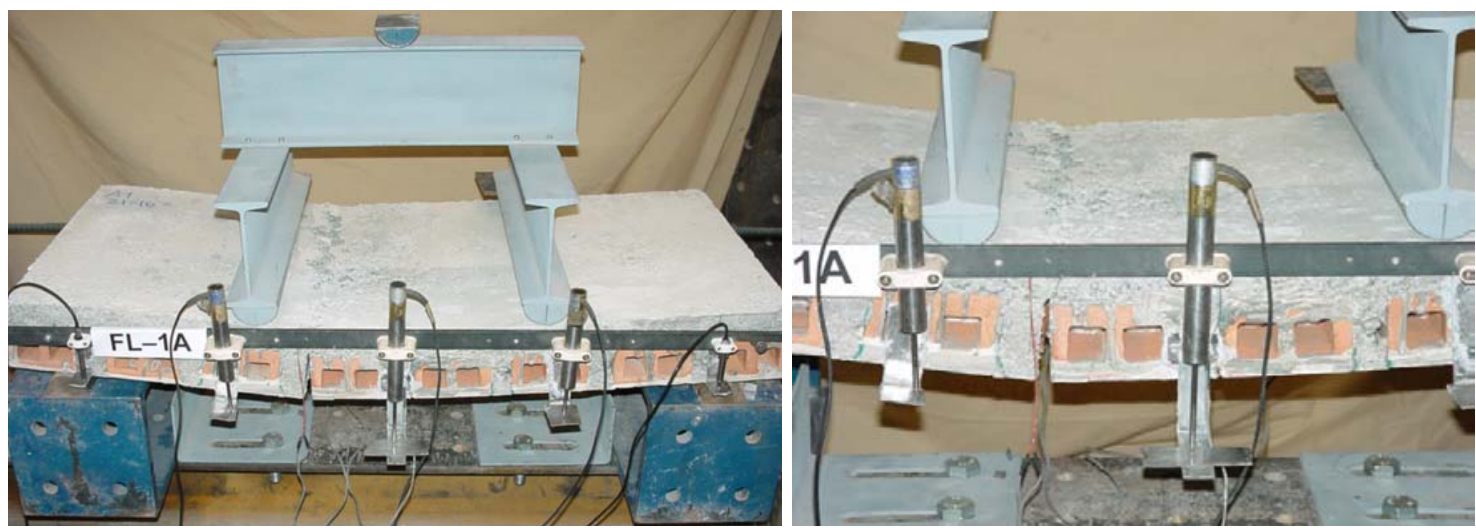

Figure 12 - Aspect of the panel FL-1A after have been tested.

\subsubsection{FL-2A}

Fissures 1, 1'and 1"(see Figure 13), at brick/concrete interface, appeared at a load of about $30 \mathrm{kN}$. The others fissures occurred at a load of about $40 \mathrm{kN}$. The fissures occurred in the alignment of the brick hole (fissure 1'), and at concrete joint/brick interface. At failure and at panel bottom surface, fissures 1'and 2' had an average crack opening of $7 \mathrm{~mm}$.

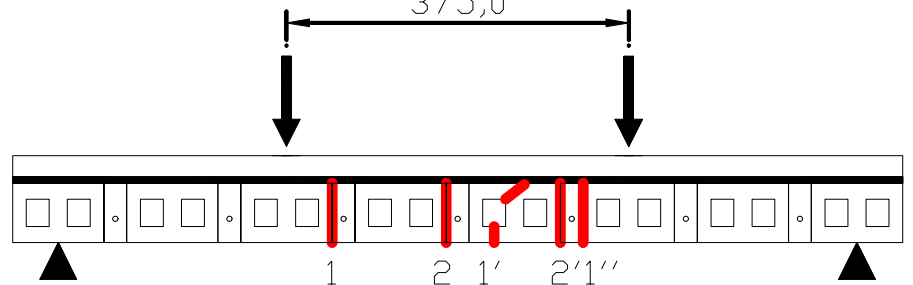

Figure 13 - Crack pattern in FL-2A.

Due to a problem with the data acquisition system, the displacements measured by the LVDTs were not recorded. However, the behavior of this panel was similar to the panel FL-1A, except concrete crushing that was not occurred in panel FL-2A. A view of the panel after have been tested can be seen in Figure 14 . 

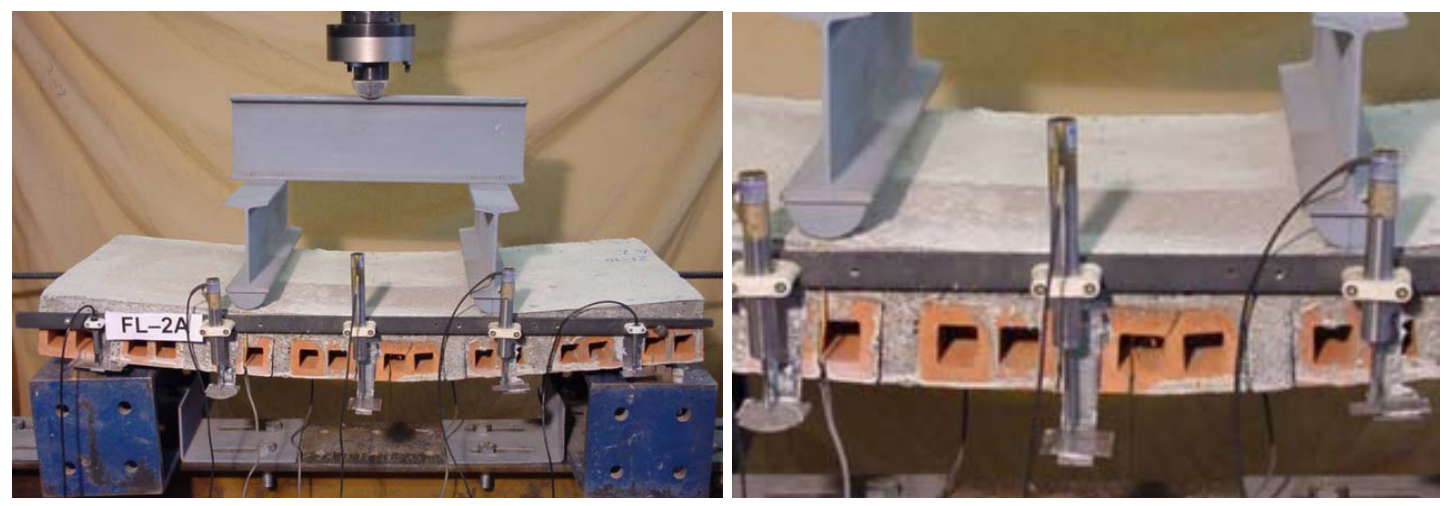

Figure 14 - Aspect of the panel FL-2A after have been tested.

\subsubsection{FL-3A}

Fissure 1, in the alignment of a brick's hole, was the first fissure to appear, at a load of $8 \mathrm{kN}$, see Figure 15. Fissures 2, 2', 2" and 2"' occurred simultaneously at a load of about $34 \mathrm{kN}$, see Figure 16. The major crack opening was observed in fissures 1 and 2 "'. At the end of the panel test it was measured the crack opening of fissure 2 "' at panel bottom surface, having registered a value of $7 \mathrm{~mm}$ in panel back side and $3 \mathrm{~mm}$ in panel front side. In this case, the panel was more loaded in its back side. This fact can be also verified by the values registered in strain gauges, see Figures 18 and 19. Strain gauge 2 (see model 2, Figure 8), placed in panel rear zone, measured larger strains than strain gauge 1 , placed in panel front zone.

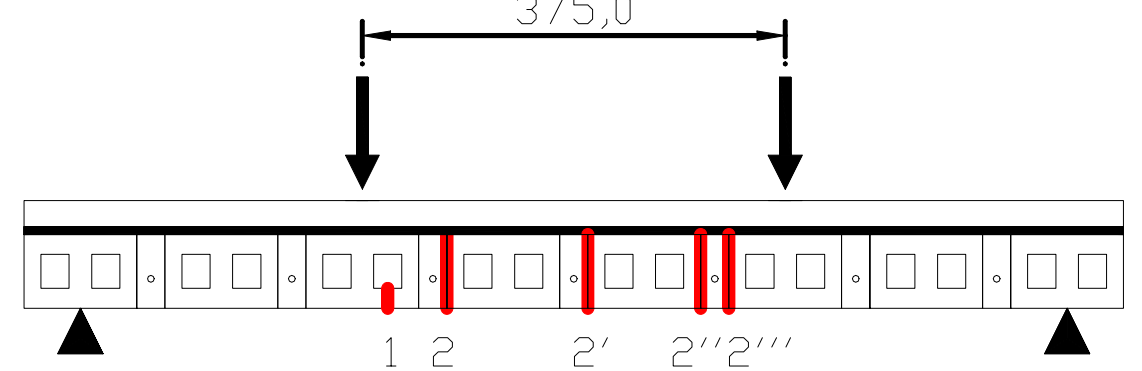

Figure 15 - Crack pattern in FL-3A.

Due to a quasi-symmetric distribution of the fissures, LVDTs 2 and 3 registered similar displacements, see Figure 16. However, as fissure 2"' developed the larger crack opening, LVDT3 registered displacements slightly higher than LVDT2. LVDTs near the supports measured similar displacements. The panel appearance after have been tested is shown in Figure 17. 


\section{FL-3A}

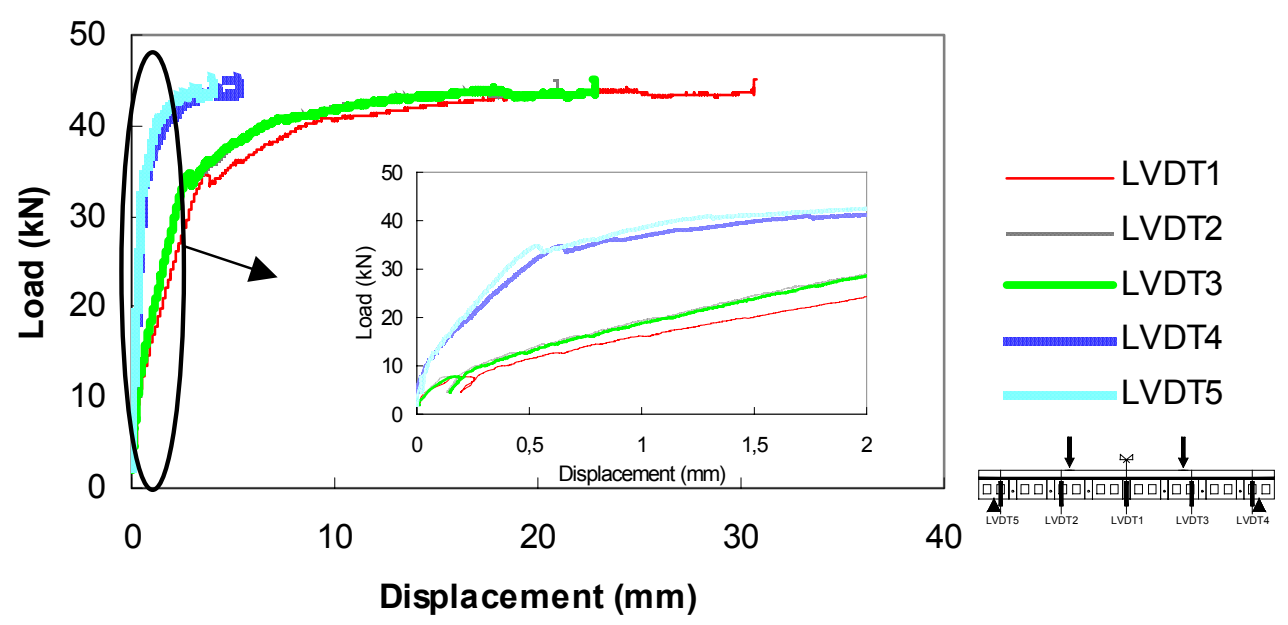

Figure 16 - Force-displacements relationship for all LVDTs.
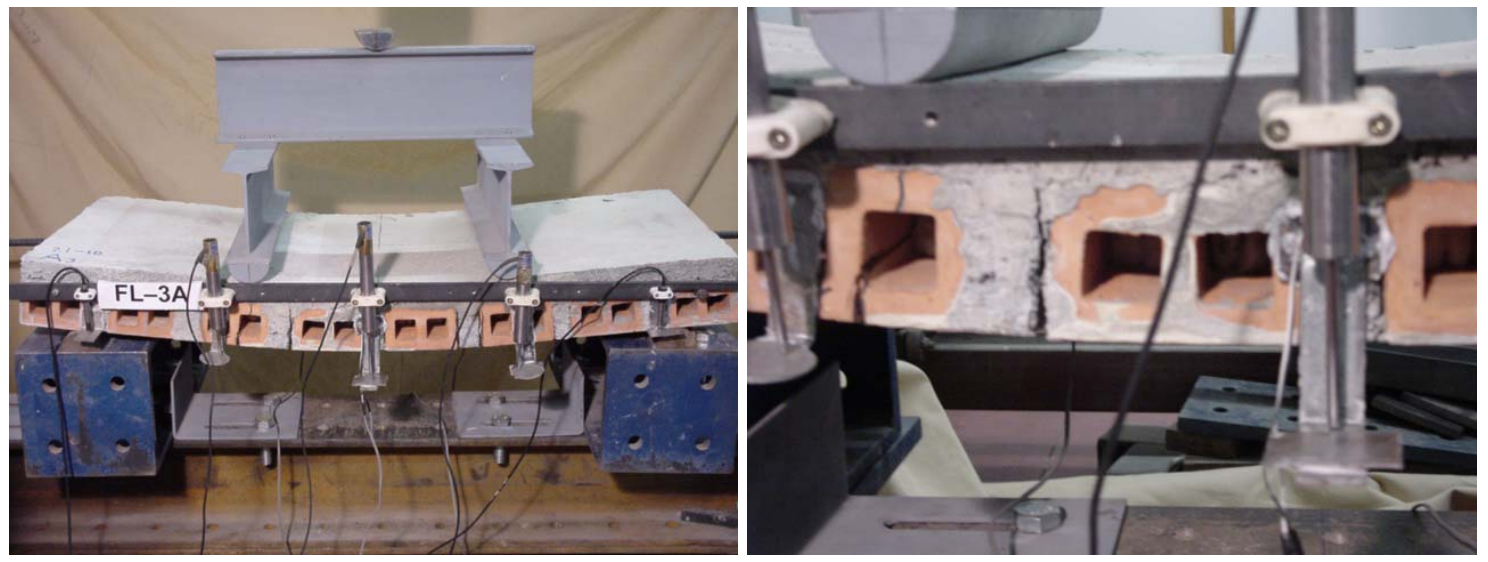

Figure 17 - Aspect of the panel FL-3A after have been tested.

Analyzing Figure 18 it is verified that longitudinal steel bars have yielded at a strain of about $2.6 \times 10^{-3}$, in agreement with the yield value registered in uniaxial tensile tests (see Annex 1). Taking the force values corresponding to the yield initiation of longitudinal bars it is verified that the longitudinal bar at panel rear zone has yielded before the bar at panel front zone. 


\section{FL-3A}

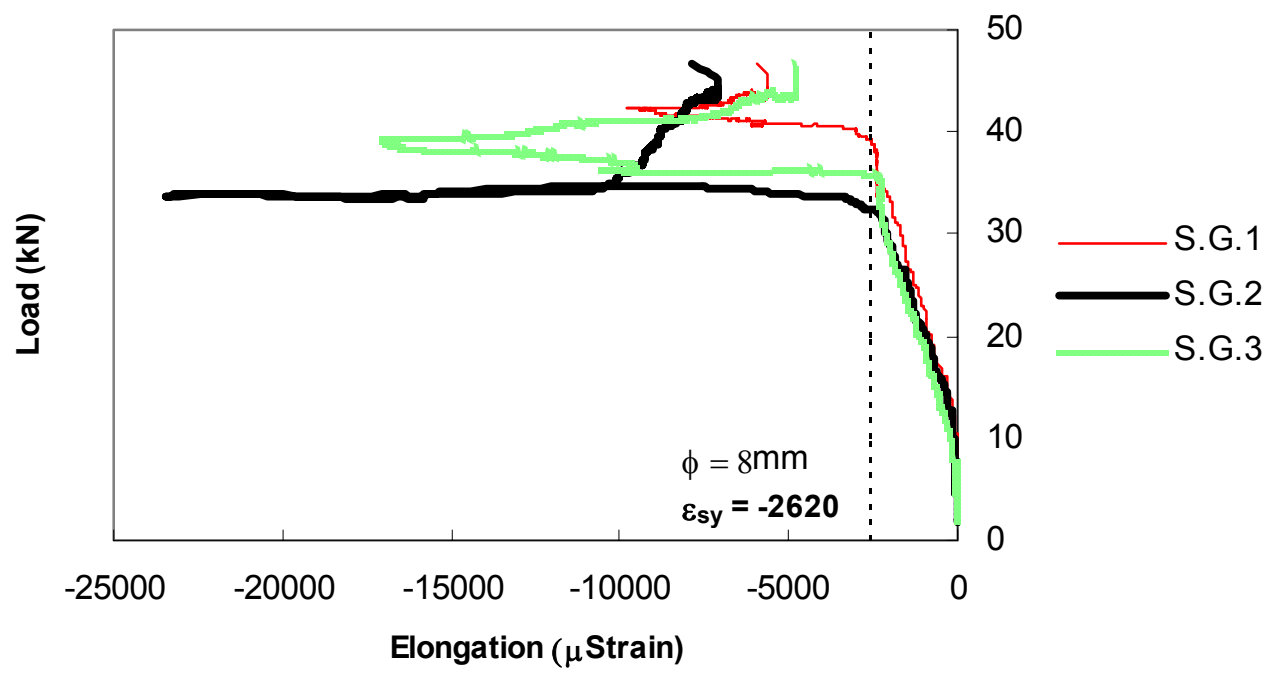

Figure 18 - Force-strain relationship for all strain gauges.

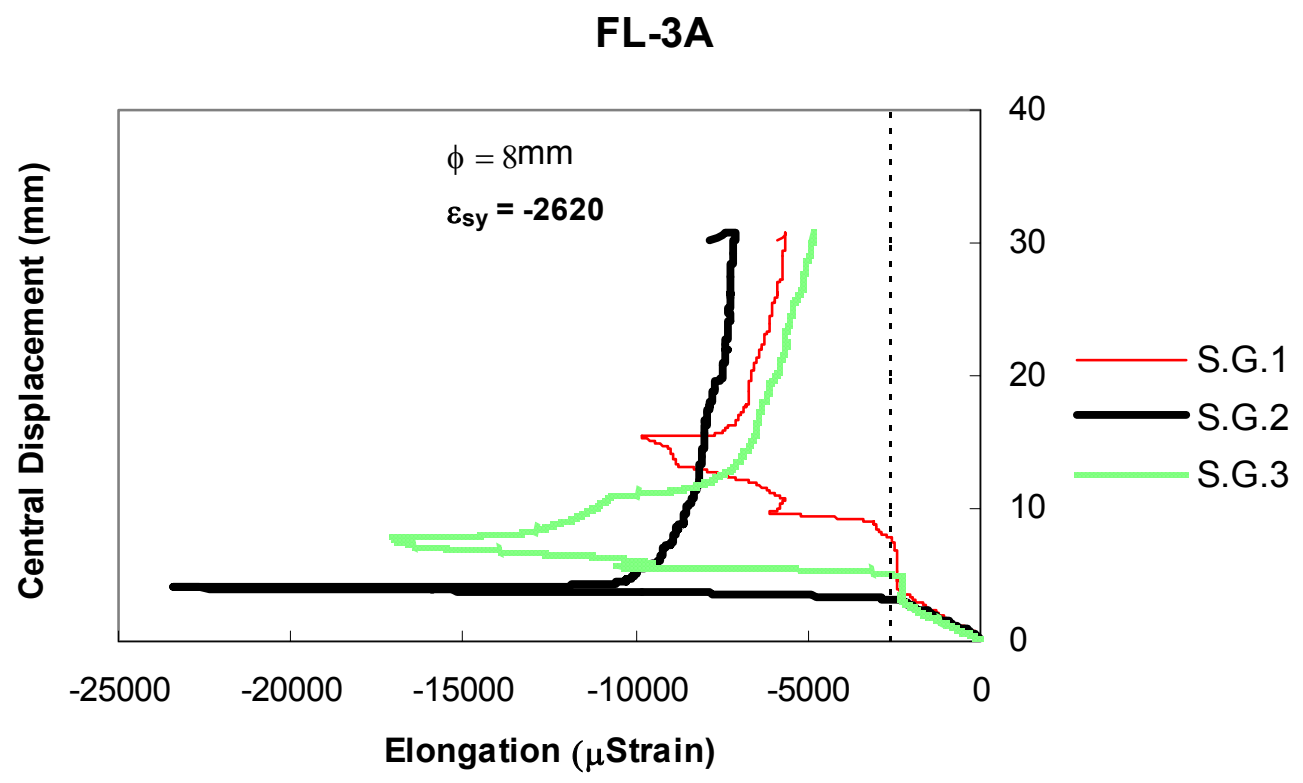

Figure 19 - Relationship between the deflection at panel mid span and the strains at strain gauges.

\subsubsection{FL-4A}

The first fissure (fissure 1) occurred at a load for about $7 \mathrm{kN}$. Fissures 2 and 3 appeared almost simultaneously at a load of about $17 \mathrm{kN}$, while fissures 4 and 5 occurred at a load of $38 \mathrm{kN}$, see Figure 20 and graphic presented in Figure 21. Finally, fissure 6 appeared at a load of about $50 \mathrm{kN}$ and became the failure crack. The crack 
opening process of fissures 4 and 6 developed simultaneously reaching a maximum value of $5 \mathrm{~mm}$ at panel bottom surface. Due to the regular crack pattern, LVDTs 2 and 3 registered similar displacements. The displacements near the supports were almost the same. At a load of $52 \mathrm{kN}$ the crack-mouth of fissure 4 attained the panel top surface. It was firstly visible on the panel back side, but soon it was extended to the total width of the panel. The aspect of the panel after have been tested is shown in Figure 22.

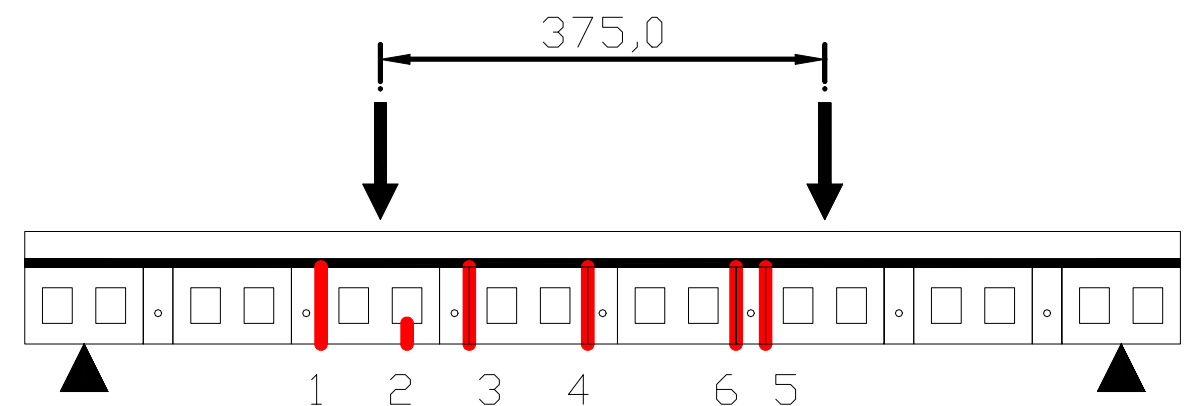

Figure 20 - Crack pattern in FL-4A.

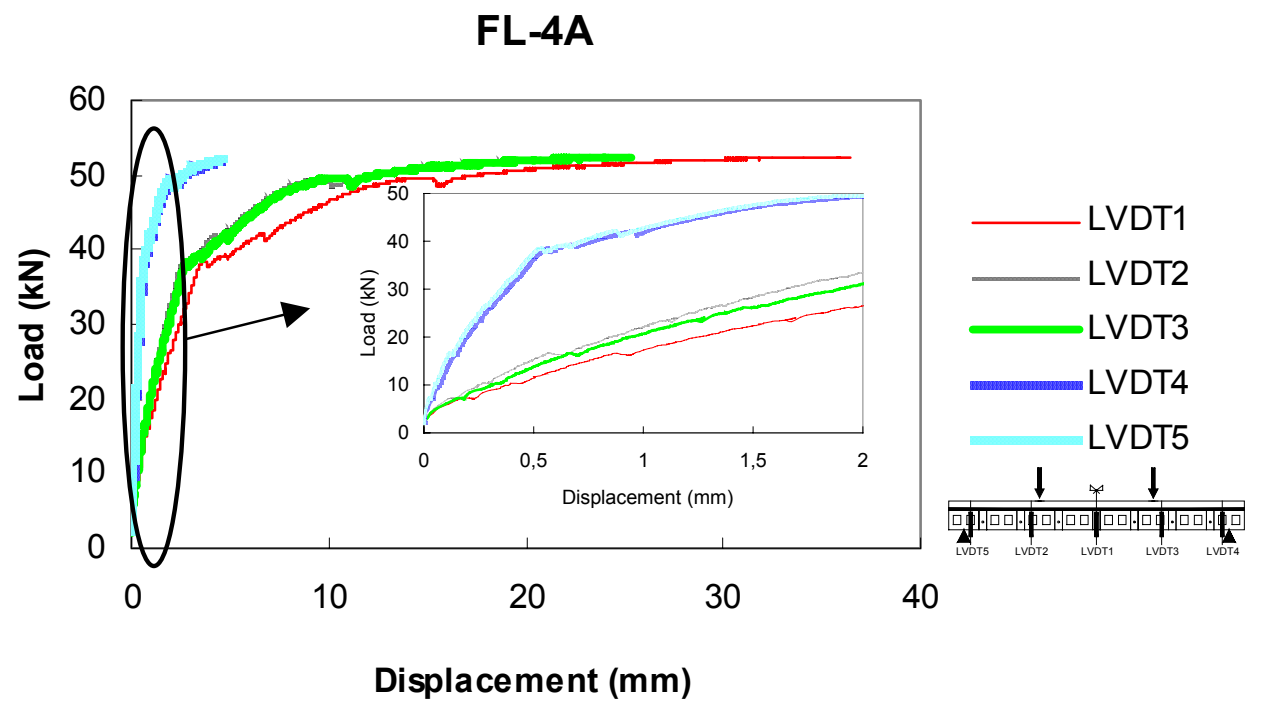

Figure 21 - Force-displacements relationship for all LVDTs. 

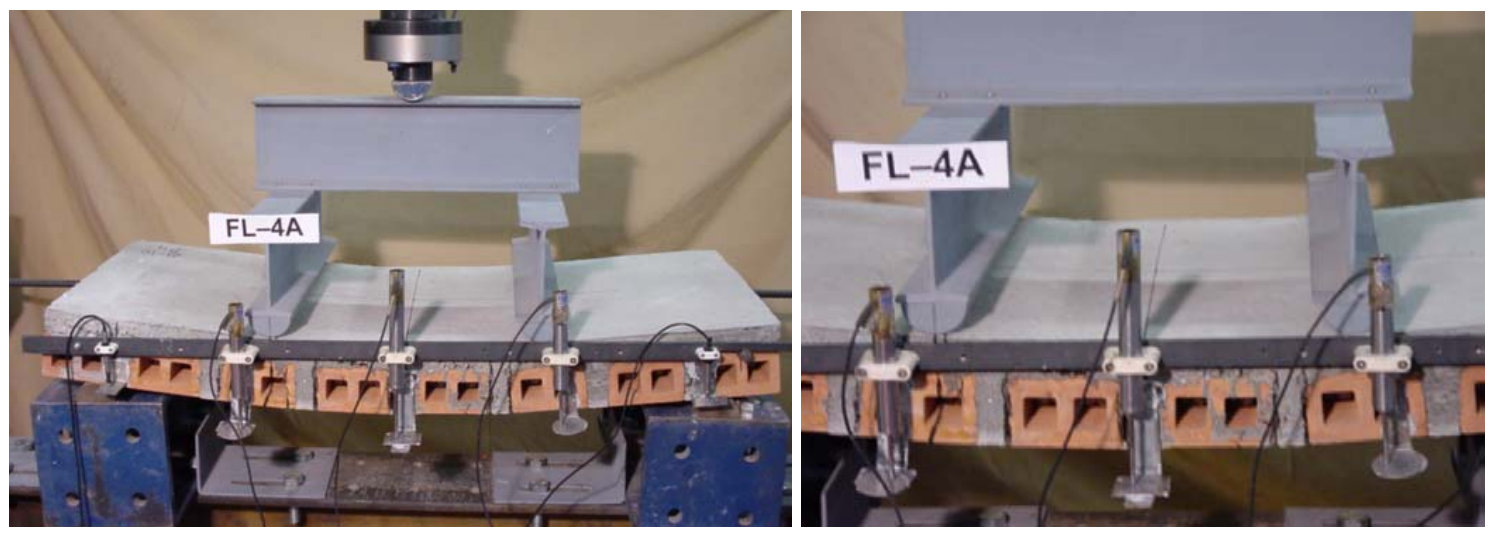

Figure 22 - Aspect of the panel FL-3A after have been tested.

\subsection{Series FL-B}

\subsubsection{FL-1B}

The first fissure observed in this panel occurred in the brick at panel mid span (fissure 1), at a load of $24 \mathrm{kN}$, see Figure 23. This fissure has crossed the panel width. Fissures 2 and 3 occurred in sequence, at brick/joint interface at a load of about $36 \mathrm{kN}$ and $43 \mathrm{kN}$, respectively. At a load of $52 \mathrm{kN}$ fissure 1 (the failure crack) has opened significantly.

At a load of $54 \mathrm{kN}$ the longitudinal reinforcement have ruptured in the failure crack, see Figure 24. At this moment deep load decay occurred. When crack mouth attained the wire mesh, the load was increased up to the moment when the wire mesh has ruptured.

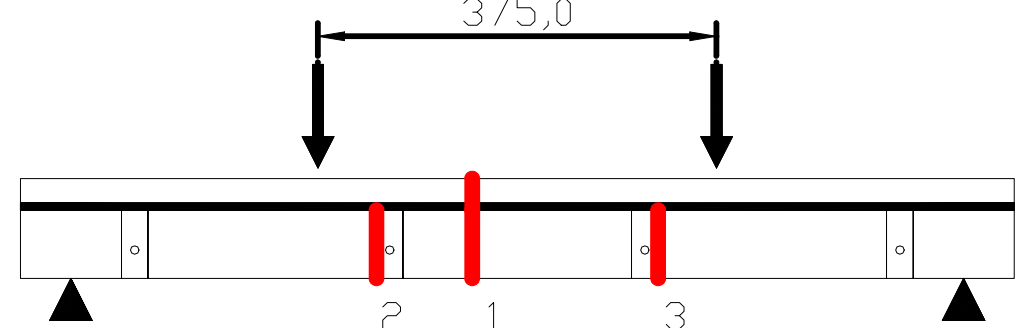

Figure 23 - Crack pattern in FL-1B.

The largest deflection was measured by the LVDT1. The LVDTs placed symmetrically registered similar displacements, see Figure 24. Figure 25 illustrates the aspect of the panel after have been tested. 
In this panel, four strain gauges were placed according to the model 2 for panels FL-B (see Figure 9). As failure crack was positioned near panel mid span, just in the area where the strain gauges were installed, they were damaged and strains were not registered.

In comparison to the failure modes of series FL-A, this panel failed by a more brittle mode.

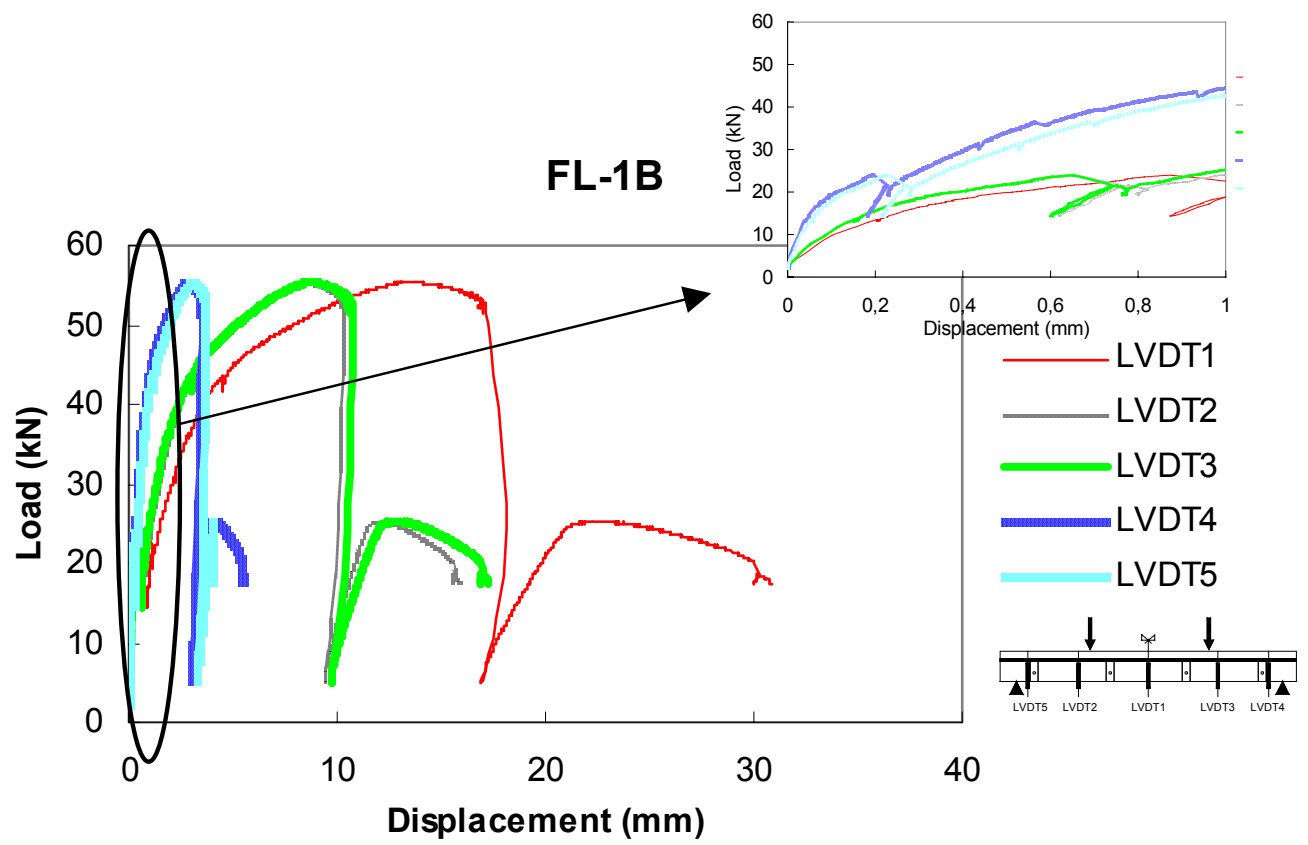

Figure 24 - Force-displacements relationship for all LVDTs.
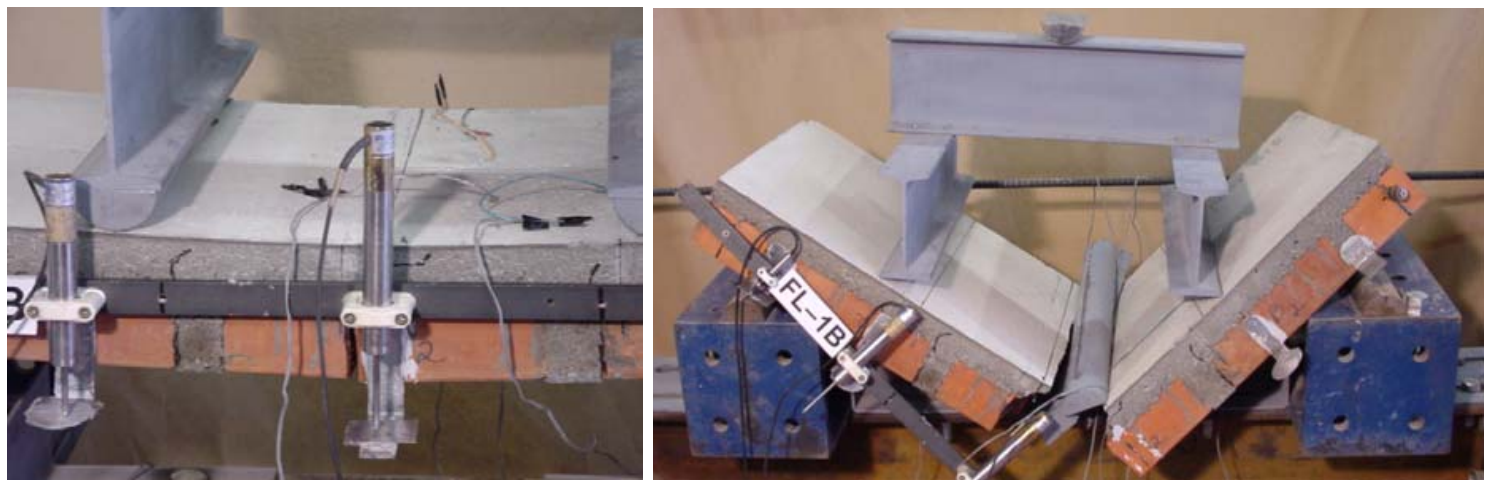

Figure 25 - Aspect of the panel FL-1B after have been tested.

\subsubsection{FL-2B}

In this panel four fissures occurred, positioned according to the scheme represented in Figure 26. Fissures 1 and 2 became visible at brick/joint interface at a 
load of about $16 \mathrm{kN}$, while the other two fissures have crossed the brick unities. At a load of $23 \mathrm{kN}$ fissure 3 occurred and became the failure crack. At a load of $26 \mathrm{kN}$ the crack opening of fissure 3 increased significantly. At this load level fissure 4 appeared, crossing the brick placed in the panel left shear span, near the line load. At about $40 \mathrm{kN}$ the longitudinal reinforcement (6 mm diameter) started to yield. Considering the force values when strain gauges registered the yield initiation (see Figure and Figure), it can be concluded that central bar was the first one to yield. At a load about $52 \mathrm{kN}$ the crack opening of fissure 3 was $10 \mathrm{~mm}$ and $2 \mathrm{~mm}$ at panel bottom surface and at concrete layer bottom surface, respectively. At panel back side the corresponding values of crack opening were $7 \mathrm{~mm}$ and $2 \mathrm{~mm}$. At this load level the longitudinal reinforcement crossing this fissure has ruptured. The displacements of the LVDTs positioned symmetrically were similar.

In this panel four strain gauges were applied according to the model 4 , see Figure 9. The longitudinal reinforcement had linear behavior until an elongation near $3.31 \times 10^{-3}$ (see Figures 28 and 29), which is in agreement with the results obtained in tensile tests carried out with steel bars of $6 \mathrm{~mm}$ diameter. When fissure 3 has occurred, at about $23 \mathrm{kN}$, a significant increase of strain was registered in strain gauges 1, 2 and 3, placed at panel middle span, glued to longitudinal bars. At about $43 \mathrm{kN}$ these strain gauges registered a decrease of strain when the load was increasing. This was due to the occurrence of slip between the longitudinal bars and concrete, at fracture process zones.

Figure shows the aspect of the panel after have been tested.

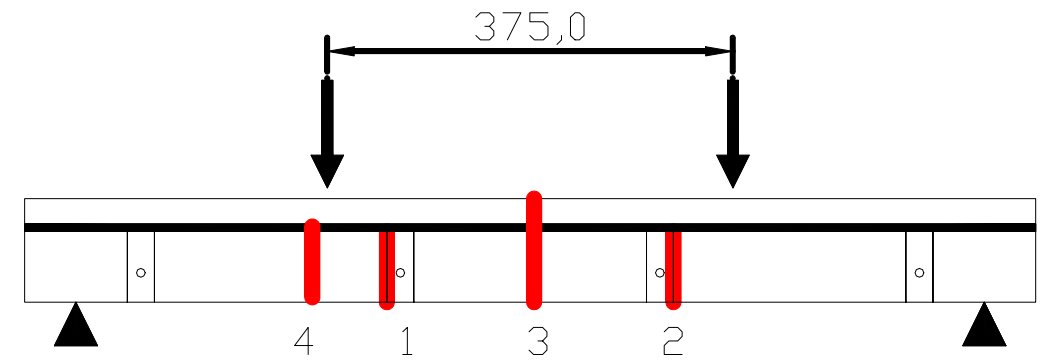

Figure 26 - Crack pattern in FL-2B. 


\section{FL-2B}

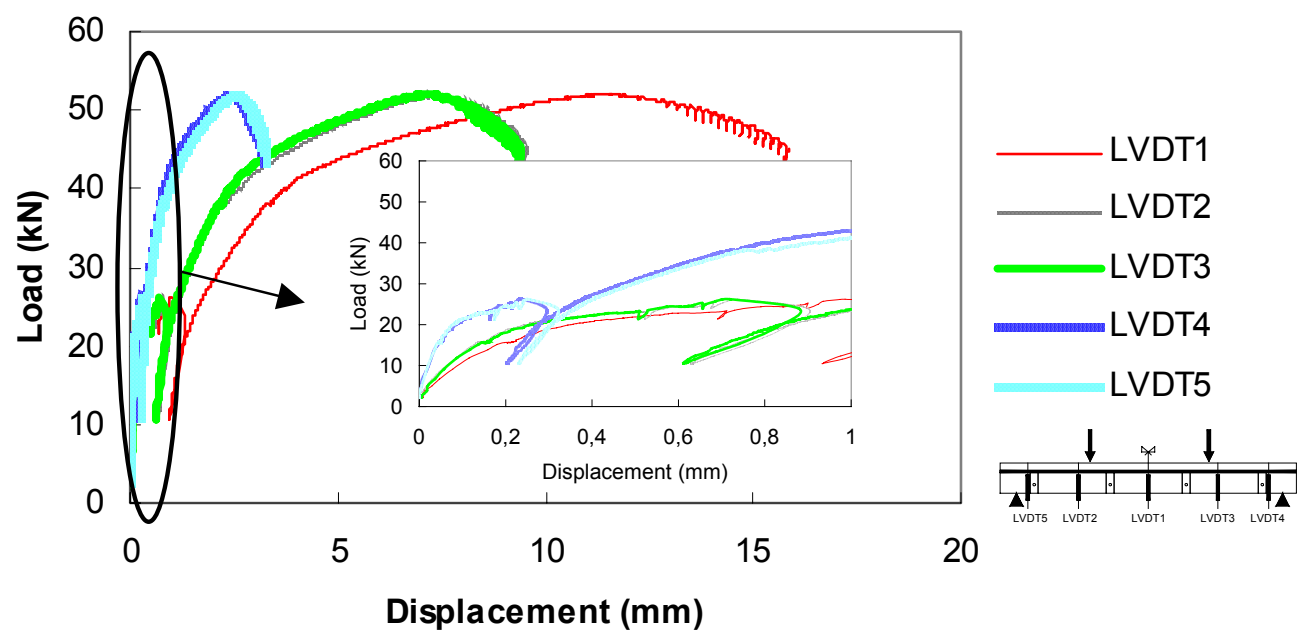

Figure 27 - Force-displacements relationship for all LVDTs.

\section{FL-2B}

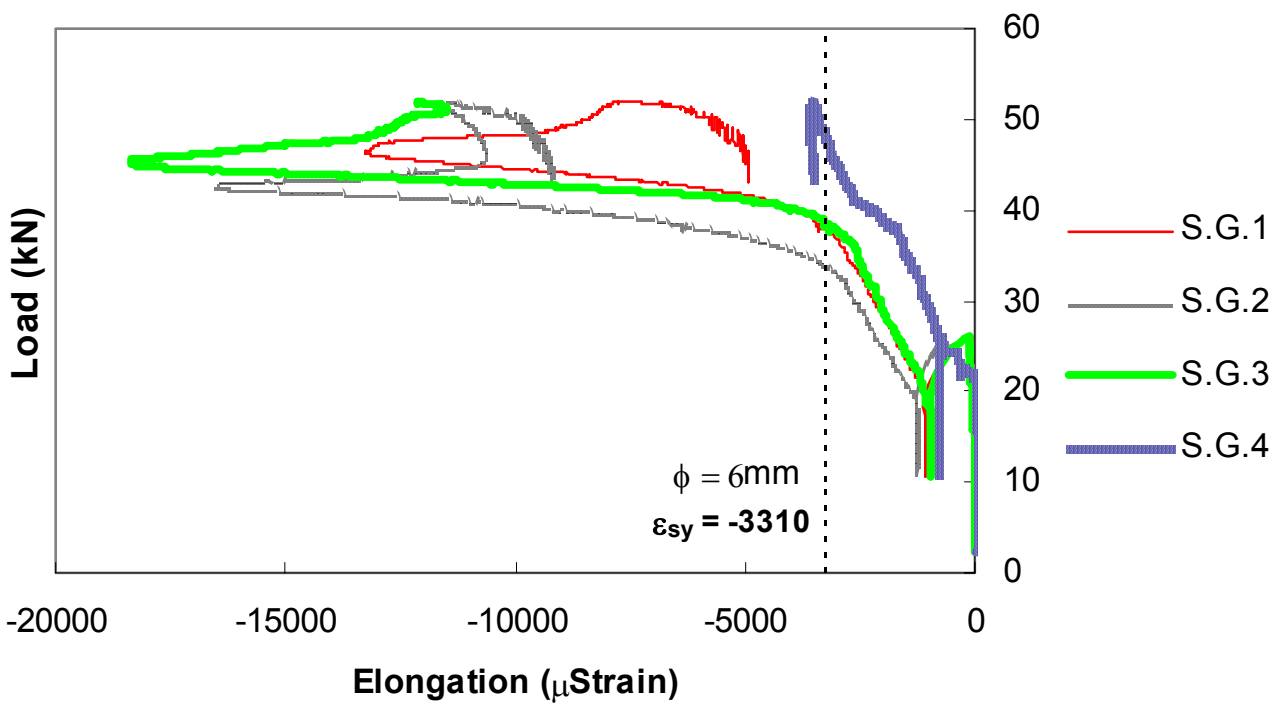

Figure 288 - Force-strain relationship for all strain gauges. 
FL-2B

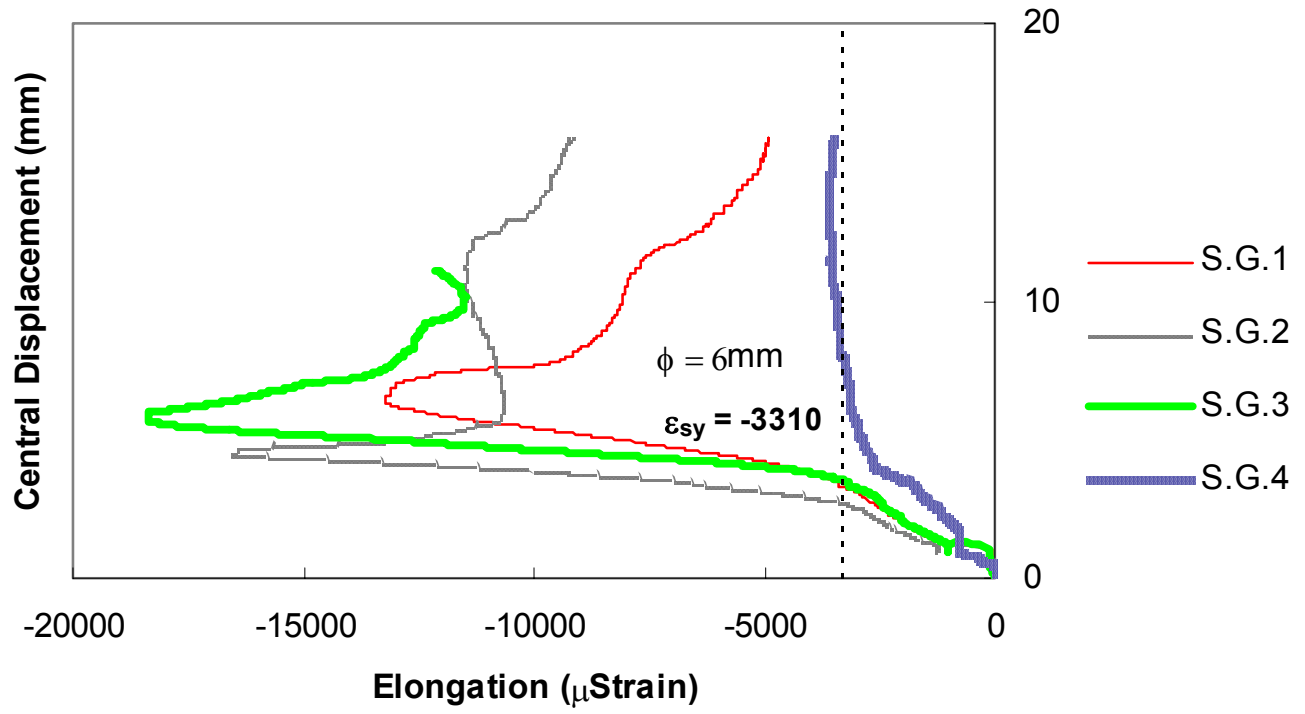

Figure 29 - Relationship between the deflection at panel mid span and the strains at strain gauges.
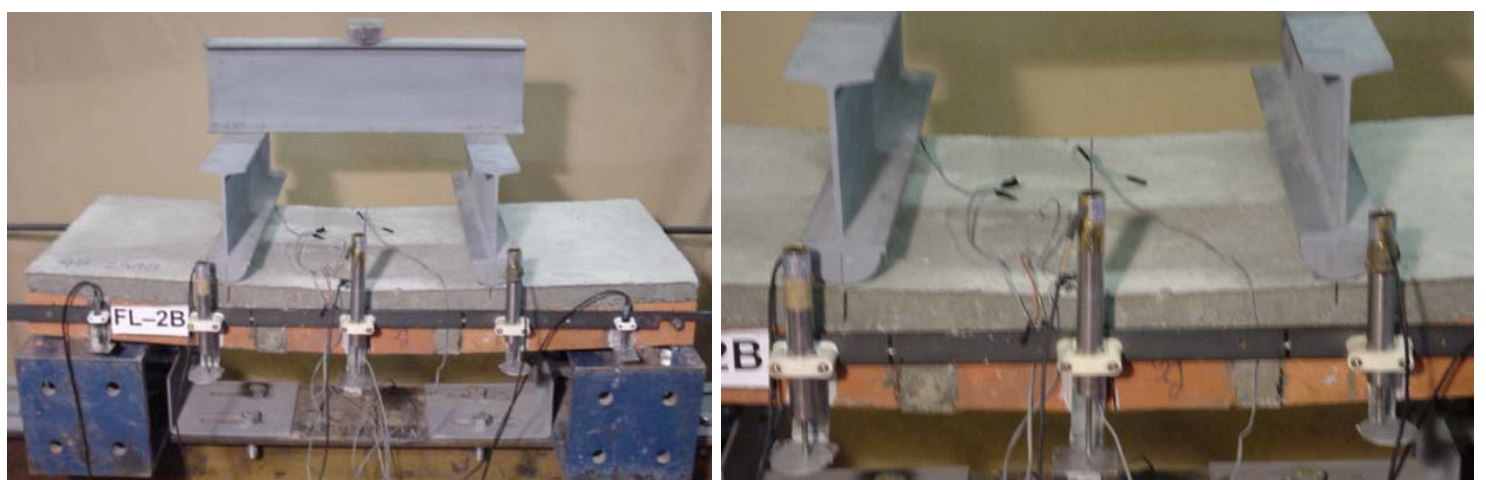

Figure 30 - Aspect of the panel FL-2B after have been tested.

\subsubsection{FL-3B}

In this panel, the first fissure (n. 1, see Figure 29) became visible at panel mid span for a load of $27 \mathrm{kN}$ having induced a load decay. Fissures 2 and 2' appeared simultaneously at brick/concrete interface at a load of $42 \mathrm{kN}$. While fissure 1 was widening, a shear crack arose in the brick at the left shear span of the panel (fissure 4), at a load of $49 \mathrm{kN}$. The occurrence of this crack has dropped the panel load bearing capacity to a load of $38 \mathrm{kN}$. The final configuration of the fissures is represented in Figure 29. 
As Figure 30 reveals, the displacements registered in the LVDTs placed symmetrically were similar.

The failure configuration of panel FL-3B is shown in Figure 31. The longitudinal bars ruptured at the failure crack (fissure 1).

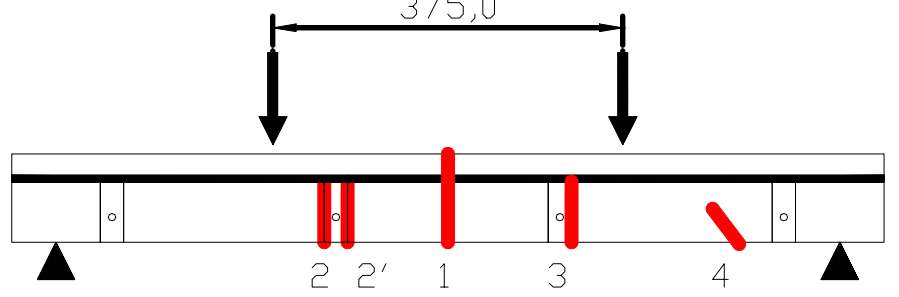

Figure 29 - Crack pattern in FL-3B.

\section{FL-3B}
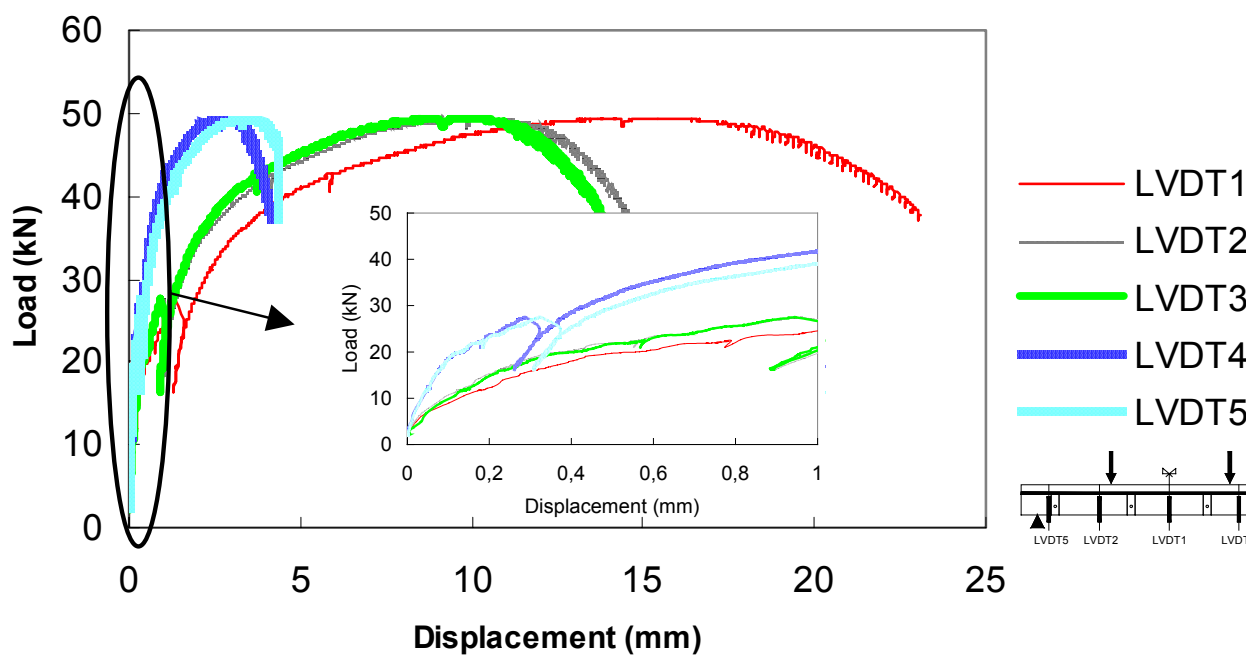

Figure 30 - Force-displacements relationship for all LVDTs.

In this panel the strain gauges were placed according to the model 5 (see Figure 9). As expected, the strains in S.G.5 were reduced because it was fixed to a transversal bar, see Figures 34 and 35. The strain evolution indicates that crack propagation has coming from rear to front face of the panel. The strain decay on strain gauges S.G.2 and S.G.3, at a load of about $40 \mathrm{kN}$, was due to the slip of the corresponding longitudinal bars, in the moment when fissures 2 and 2' occurred. 

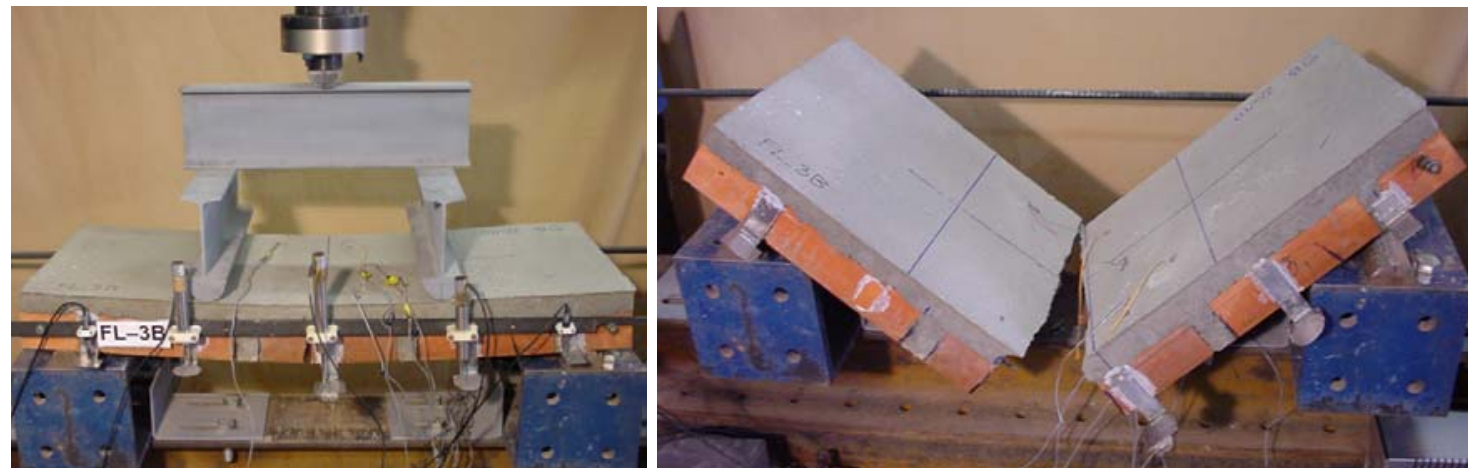

Figure 31 - Aspect of the panel FL-3B after have been tested.

\section{FL-3B}

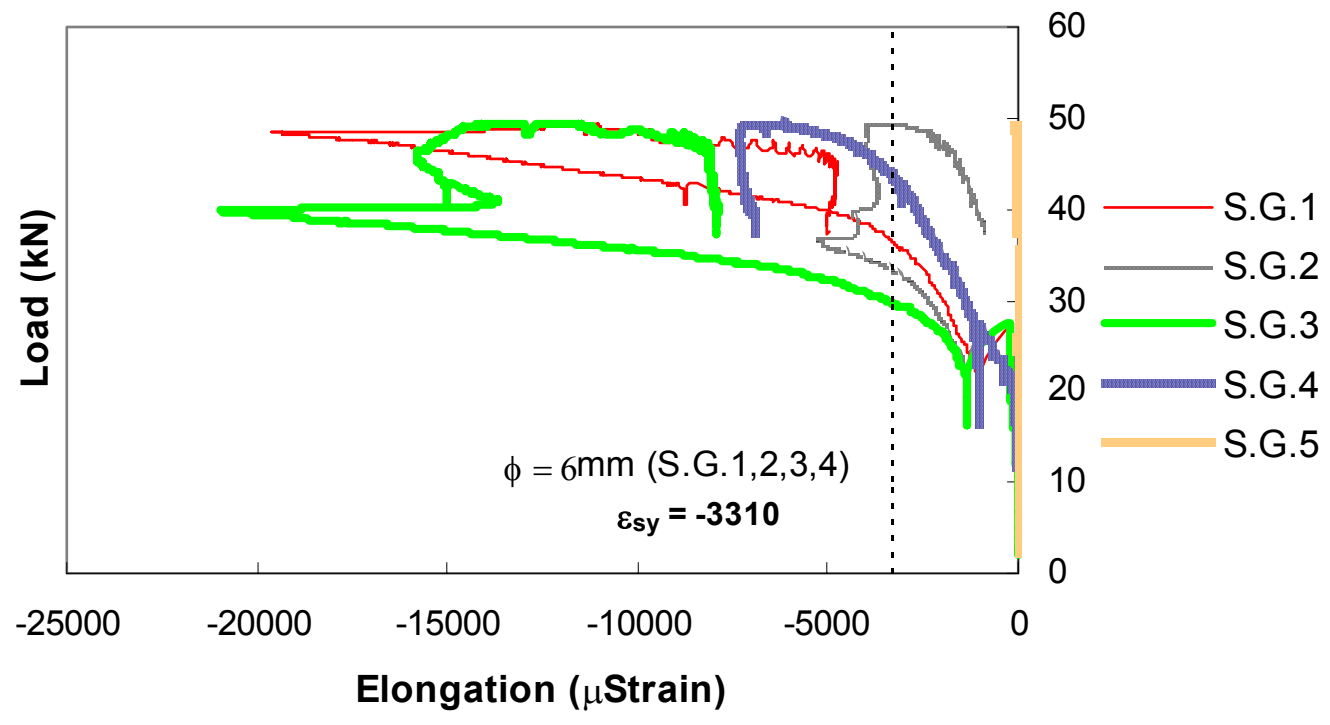

Figure 32 - Force-strain relationship for all strain gauges. 
FL-3B

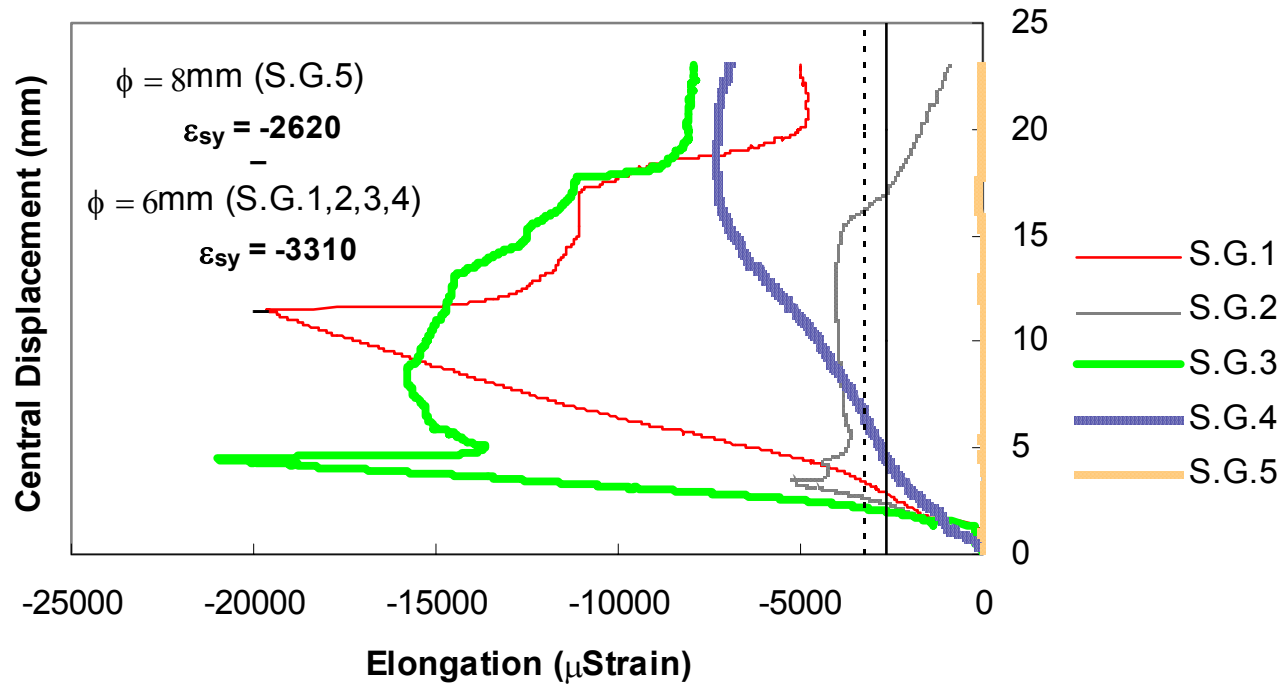

Figure 33 - Relationship between the deflection at panel mid span and the strains at strain gauges.

\subsubsection{FL-4B}

Figure 34 represents the final crack pattern of panel FL-4B. Fissure 1 was the first one to occur, crossing the brick unit near the panel mid span, at a load level of $14 \mathrm{kN}$. At a load of $24 \mathrm{kN}$ fissures 2 and 2' occurred simultaneously, followed by fissure 3 at a load of $41 \mathrm{kN}$. A significant decrease of stiffness at the moments corresponding to crack initiation of fissure 1 and fissures 2 and 2' can be detected from the forcedeflection relationship, see Figure 35. Fissure 3 was the failure crack and its crack opening increased significantly at a load level of $54 \mathrm{kN}$. At a load of about $56 \mathrm{kN}$ the crack opening of fissures 3 and $2^{\prime}$ has also increased significantly, and the panel has ruptured.

Figure 35 represents the relationship between the force and the deflections registered in all LVDTs. The panel deformability was almost symmetrical, due to the regular crack pattern. At failure, panel FL-4B remained with the aspect shown in Figure 36. 


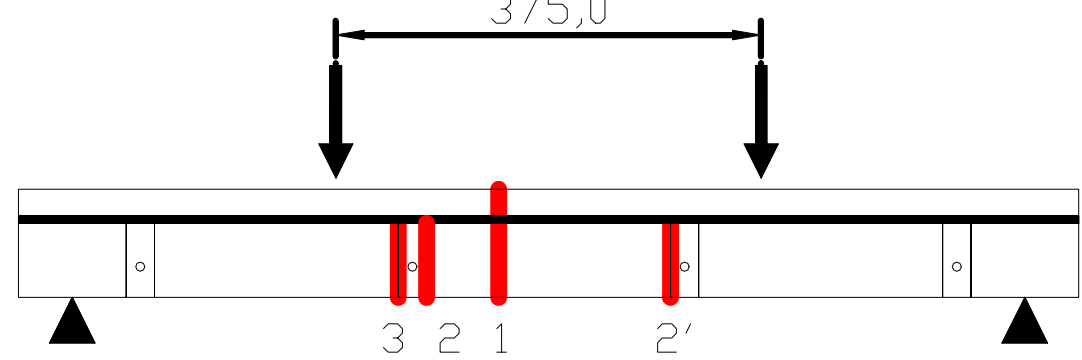

Figure 34 - Crack pattern in FL-4B.

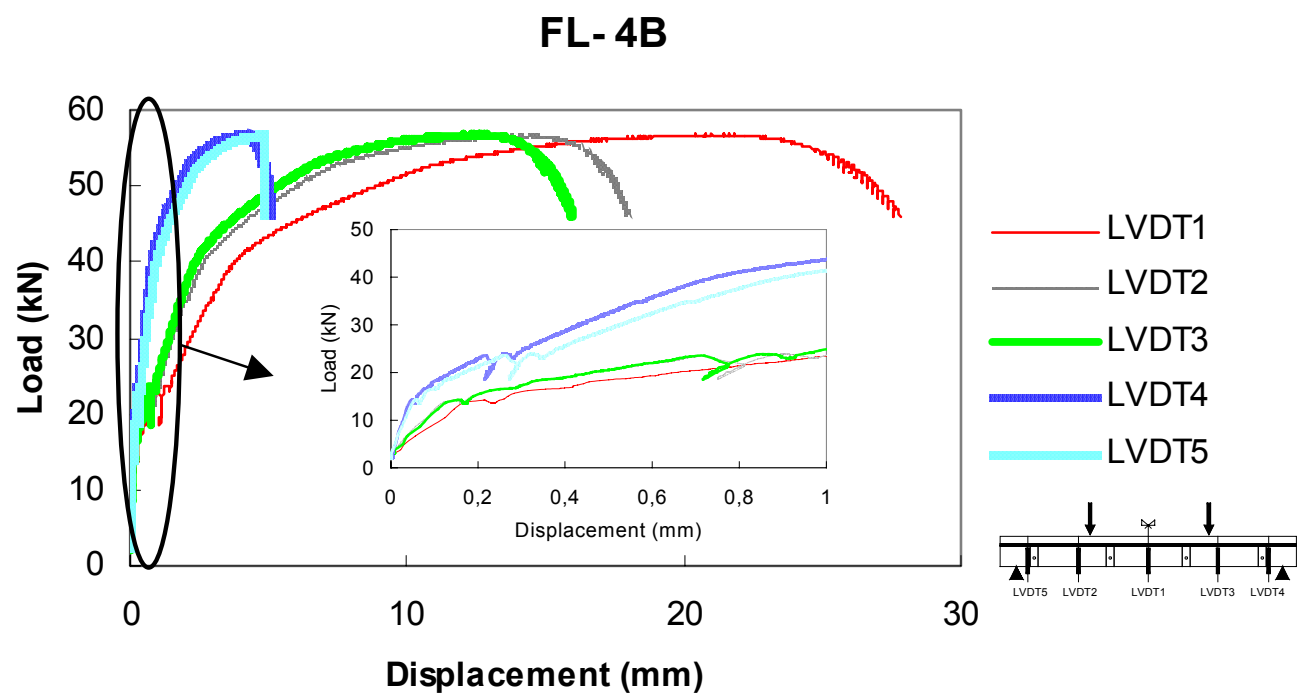

Figure 35 - Force-displacements relationship for all LVDTs.
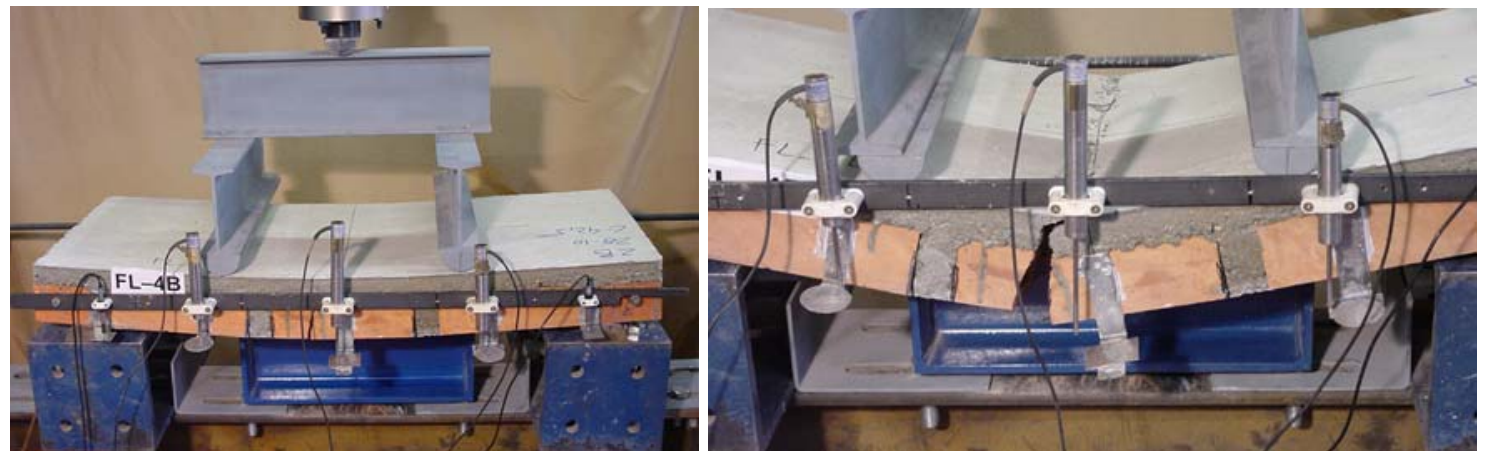

Figure 36 - Aspect of the panel FL-4B after have been tested.

\subsection{Series FLI-A}

\subsubsection{FLI-1A}

Panels of series FLI-A were similar to the panels of series FL-A, but were tested with the concrete layer turned downward. The first fissure (number 1, see Figure 37) 
occurred at the central concrete/brick interface. After concrete layer have been cracked, the force deflection rigidity decreased up to the moment when wire mesh has yielded, which occurred at a load of about $20 \mathrm{kN}$. Near $27 \mathrm{kN}$ the wire mesh have ruptured, having induced an abrupt load decay. At $30 \mathrm{kN}$ the crack opening of fissure 2 increased significantly and break crushing ahead of crack 3 was observed.

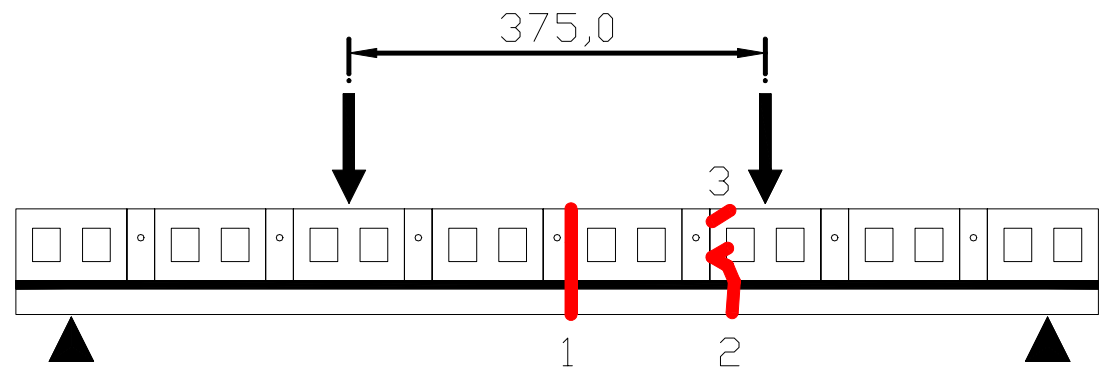

Figure 37 - Crack pattern in FLI-1A.

The relationships between the force and the displacements registered in the LVDTs are represented in Figure 38. LVDT 3 measured larger displacements than the transducer placed symmetrically to it (LVDT2) because LVDT3 was closer to the failure crack (fissure 2). Due to similar reasons, LVDT4 registered larger displacements than LVDT5. At failure, at panel front face, fissure 2 attained a crack opening of $15 \mathrm{~mm}$ and $10 \mathrm{~mm}$ at panel bottom surface and at concrete layer/brick interface, respectively. Figure 39 shows the failure mode of the panel FLI-1A.

\section{FLI-1A}
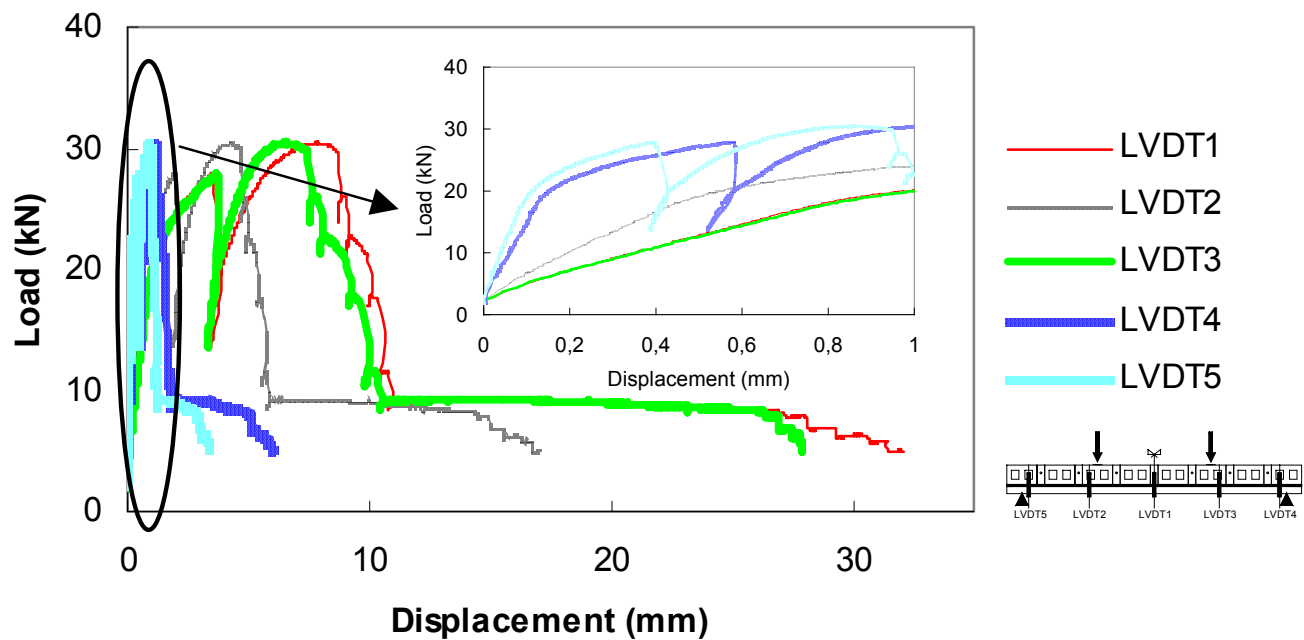

Figure 38 - Force-displacements relationship for all LVDTs. 

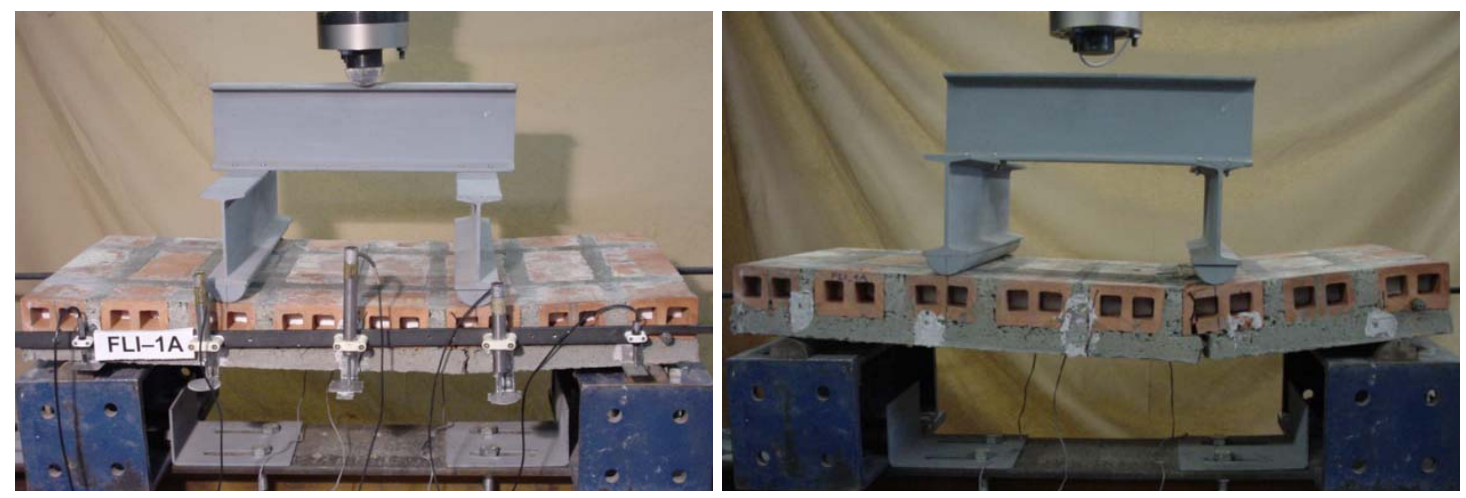

Figure 39 - Aspect of the panel FLI-1A after have been tested.

The strain gauges were applied according to the model 2 scheme represented in Figure 8. The force-strain relationship is depicted in Figures 42 and 43.

As strain gauge S.G.3 was closer to the failure crack it registered the largest strains. When structural softening was occurring, S.G.3 registered a slip, followed by an increase of strain due to a significant increment of deflection at a load of about $10 \mathrm{kN}$. During the structural softening phase, S.G.1 and S.G.2 retained the strains measured at the beginning of this phase.

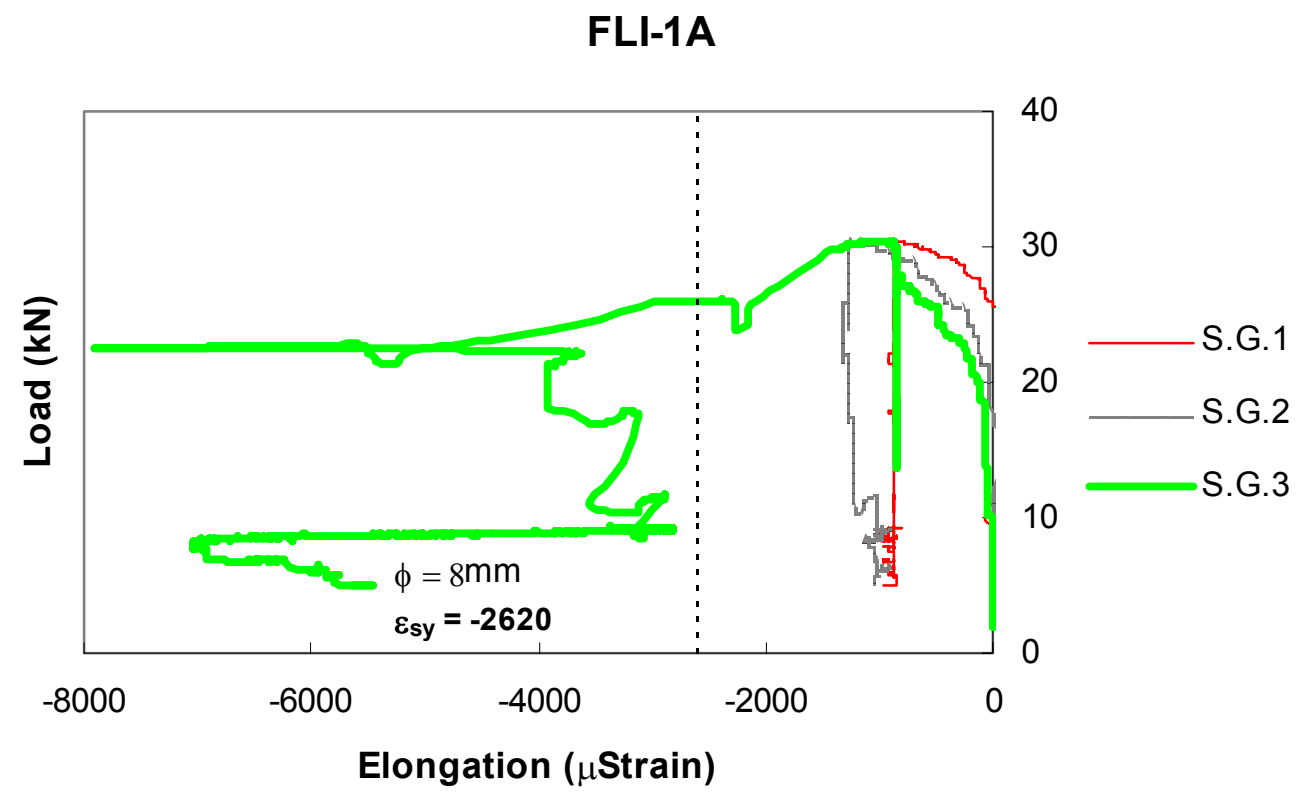

Figure 40 - Force-strain relationship for all strain gauges. 


\section{FLI-1A}

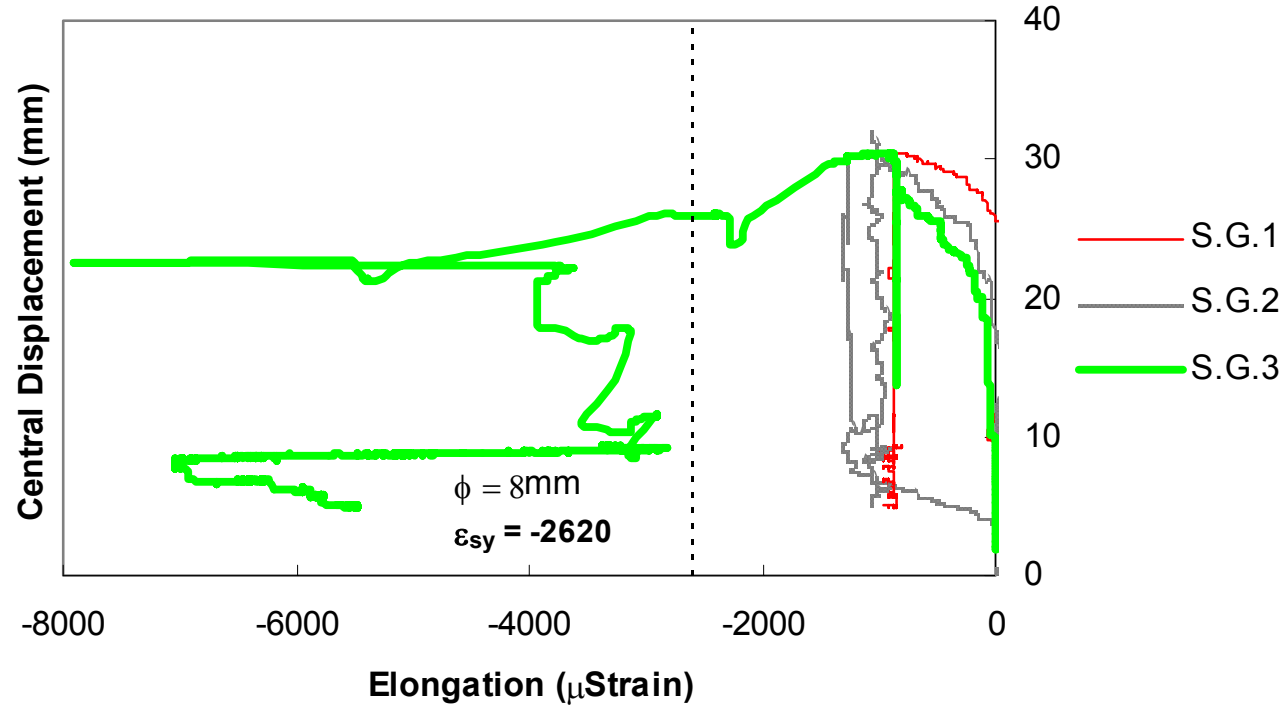

Figure 41 - Relationship between the deflection at panel mid span and the strains at strain gauges.

\subsubsection{FLI-2A}

At a load of $27 \mathrm{kN}$ fissure 1 occurred with an abrupt load decay, see Figure 44 and Figure 44. The panel has almost recovered its previous load bearing capacity, and at $25 \mathrm{kN}$ two new fissures became visible (fissures 2 and 3). The welded wire mesh started to rupture at a load of $27 \mathrm{kN}$ and, after the first rupture, other successive ruptures of the mesh were occurred. This process can be seen in graphic of Figure 43.

Fissure 2 has crossed the brick and, at failure, the horizontal top wall of this brick was crushed, see Figure 44. At panel bottom surface and at concrete layer/brick interface the crack width of fissure 2 was $15 \mathrm{~mm}$ and $10 \mathrm{~mm}$, respectively.

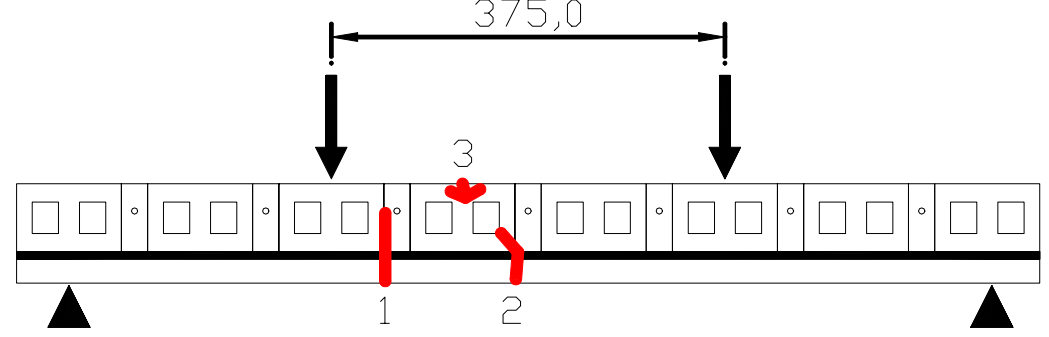

Figure 42 - Crack pattern in FLI-2A. 
Due to crack failure position, LVDTs 3 and 4 registered displacements larger than the corresponding LVDTs positioned symmetrically (LVDTs 2 and 5), see Figure 43 and Figure 43.

\section{FLI-2A}
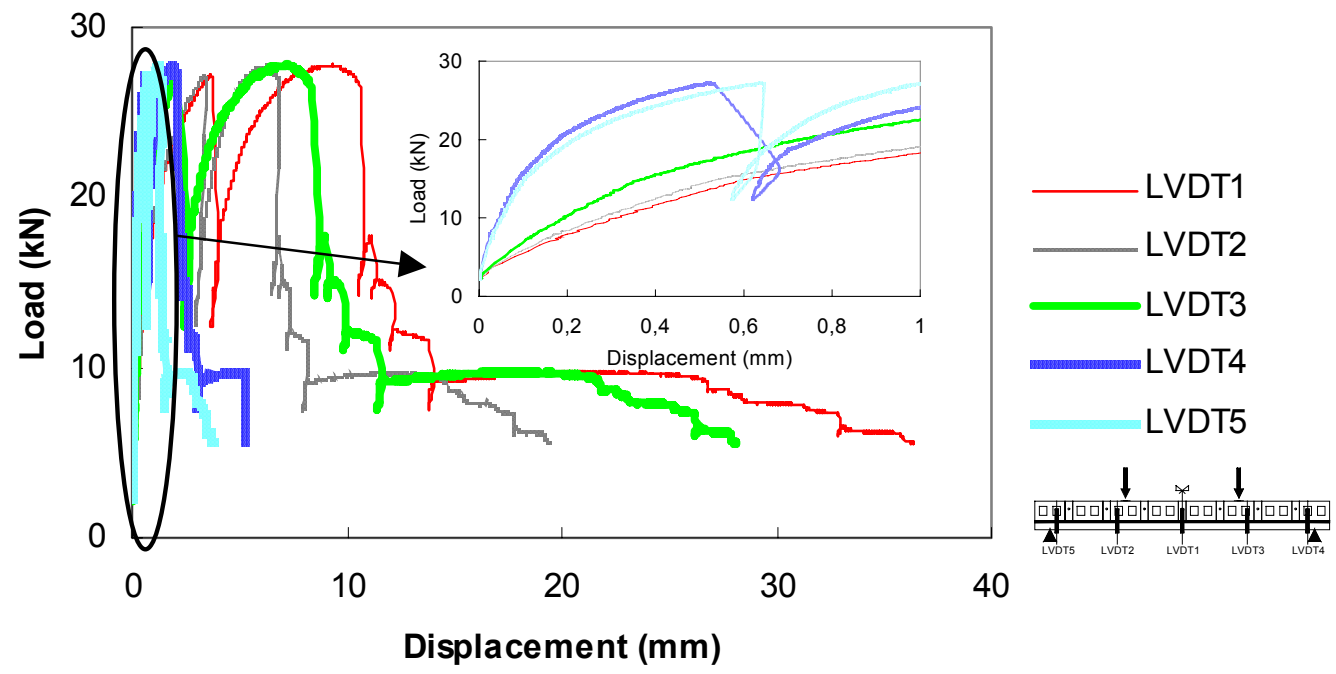

Figure 43 - Force-displacements relationship for all LVDTs.
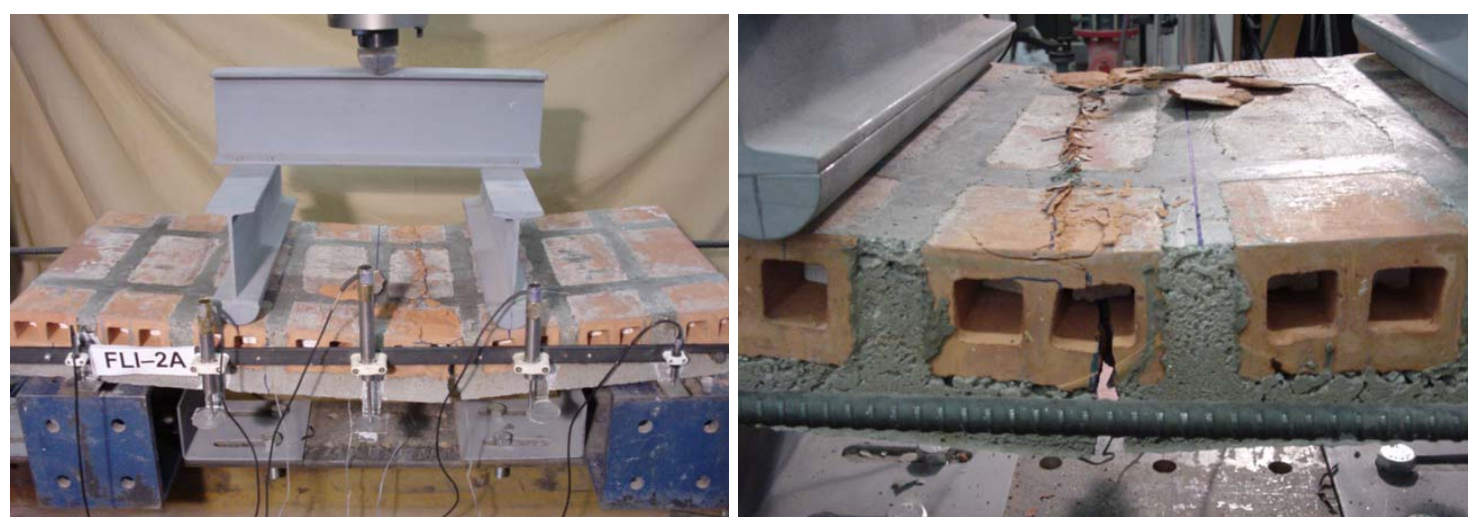

Figure 44 - Aspect of the panel FLI-2A after have been tested.

The strain gauges were placed according to model 1 of Figure 8 . As strain gauge 3 was fixed in a transversal bar, very low strain values were registered, see Figure 45. Despite strain gauges 2 and 4 (S.G.2 and S.G.4) have been positioned in the same alignment, the values registered by S.G. 4 were larger. Graphic of Figure 45 shows that the steel bar where S.G.4 was fixed started to yield at an elongation near $2.62 \times 10^{-3}$, which is a close value to the yield strain registered in the uniaxial tensile tests, see Annex 1. 


\section{FLI-2A}

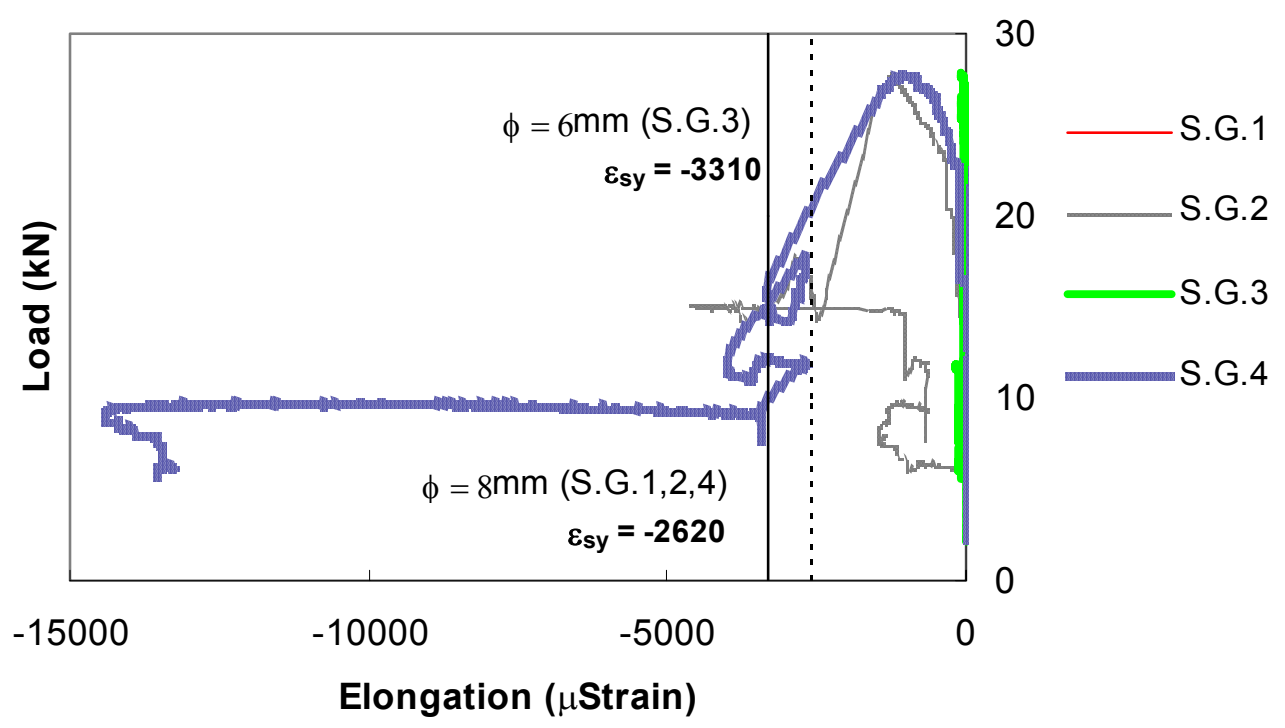

Figure 45 - Force-strain relationship for all strain gauges.

\section{FLI-2A}

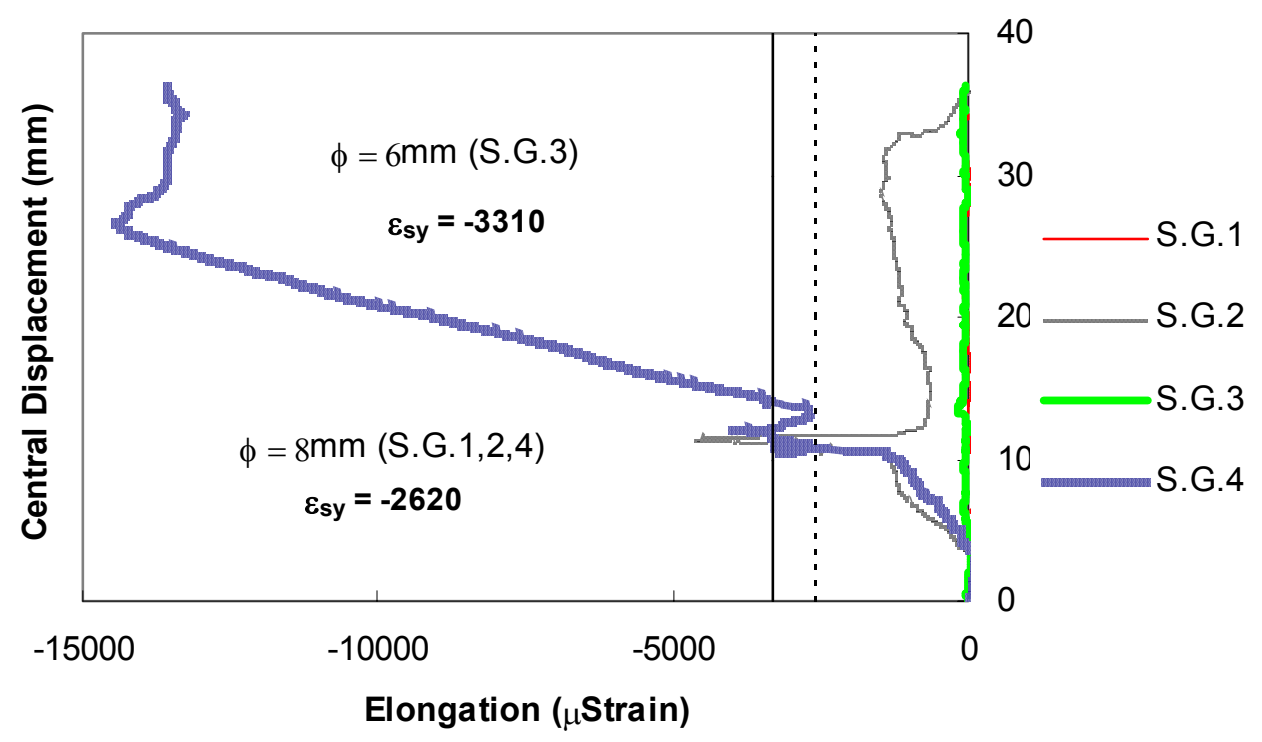

Figure 46 - Relationship between the deflection at panel mid span and the strains at strain gauges.

\subsubsection{FLI-3A}

In this panel only one crack occurred, at a load of $20 \mathrm{kN}$, see Figure 47. At a load of about $26 \mathrm{kN}$ wires of the mesh crossing the crack have ruptured. At panel rear 
face the crack opening was larger than at panel front face. During the phase corresponding to the post-peak force-deflection branch some wires of the mesh were ruptured, followed by load decay up to a minimum value of $4 \mathrm{kN}$. At the end of the test, the crack opening of fissure 1 at panel bottom surface was $15 \mathrm{~mm}$ and $20 \mathrm{~mm}$ at front and back side of the panel.

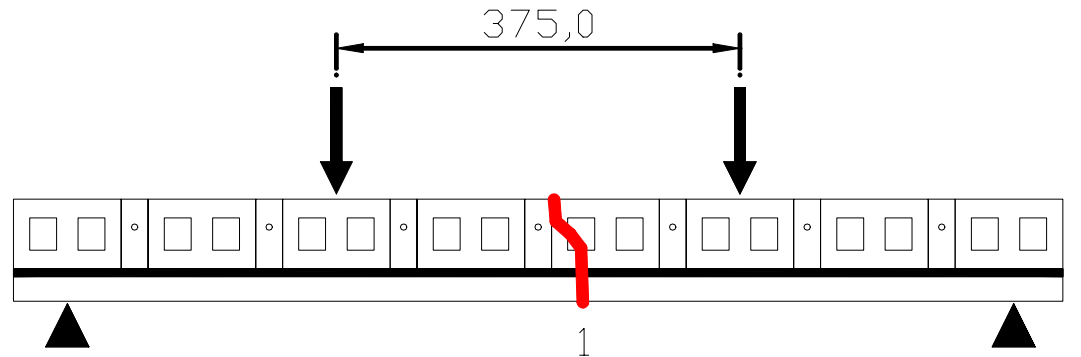

Figure 47 - Crack pattern in FLI-3A.

Due to the fact that only one fissure has occurred and it was positioned near the panel center, similar displacements were registered by LVDTs equidistant from the panel center, see Figure 48.

\section{FLI-3A}

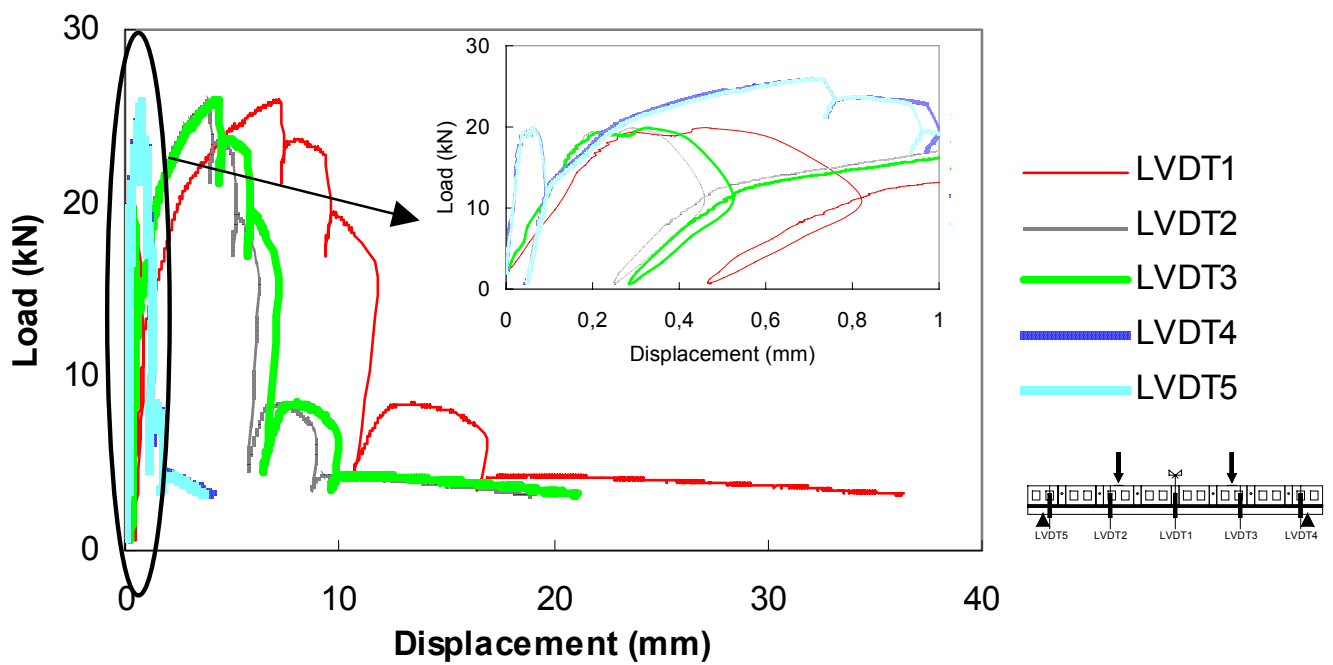

Figure 48 - Force-displacements relationship for all LVDTs.

The failure configuration of panel FLI-3A is shown in Figure 49. 

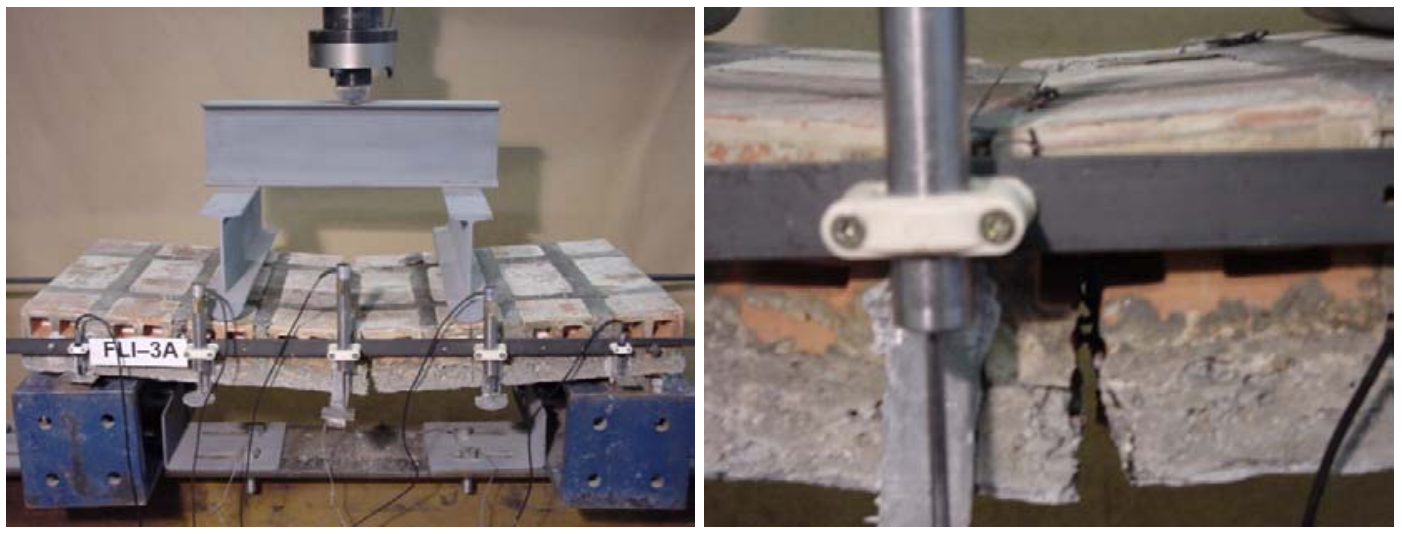

Figure 49 - Aspect of the panel FLI-3A after have been tested.

\subsubsection{FLI-4A}

Figure 50 represents the crack pattern developed in panel FLI-4A. A total of five fissures occurred. The occurrence of a fissure induced load decay, as it can be seen in the graphic force-deflection relationship of Figure 51. Fissure 1 was the first one to occur, at a load of $21 \mathrm{kN}$. For a load a little above $21 \mathrm{kN}$ occurred fissure 2 followed by rupture of some wires of the mesh. Fissures 3, 3' and 3" appeared almost simultaneously at a load around $29 \mathrm{kN}$. In between $20 \mathrm{kN}$ and $29 \mathrm{kN}$, fissure 2 opened significantly. At panel rupture, the superior part of the bricks crossed by fissure 2 was crushed. This fissure attained $15 \mathrm{~mm}$ and $10 \mathrm{~mm}$ of crack opening at panel bottom surface and at concrete layer/brick interface, respectively. These crack opening values were observed in front and rear sides of the panel.

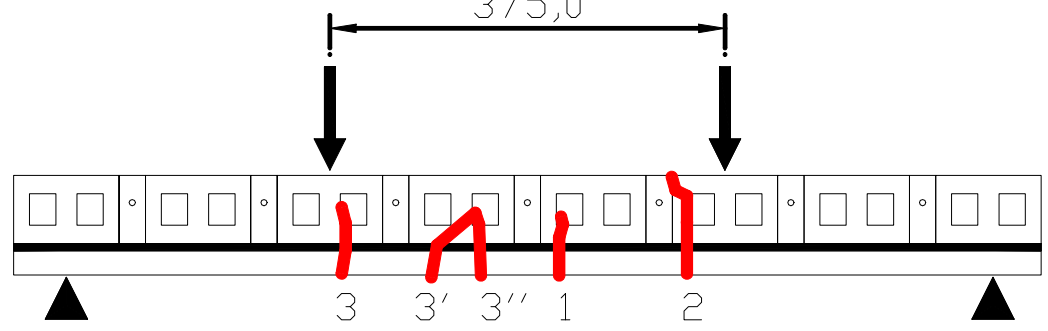

Figure 50 - Crack pattern in FLI-4A.

As LVDT 3 was positioned closer to the failure crack (fissure 2) than its symmetrical transducer (LVDT 2), it registered larger displacements. Similar reasons justify LVDT 4 has measured larger displacements than LVDT 5. 


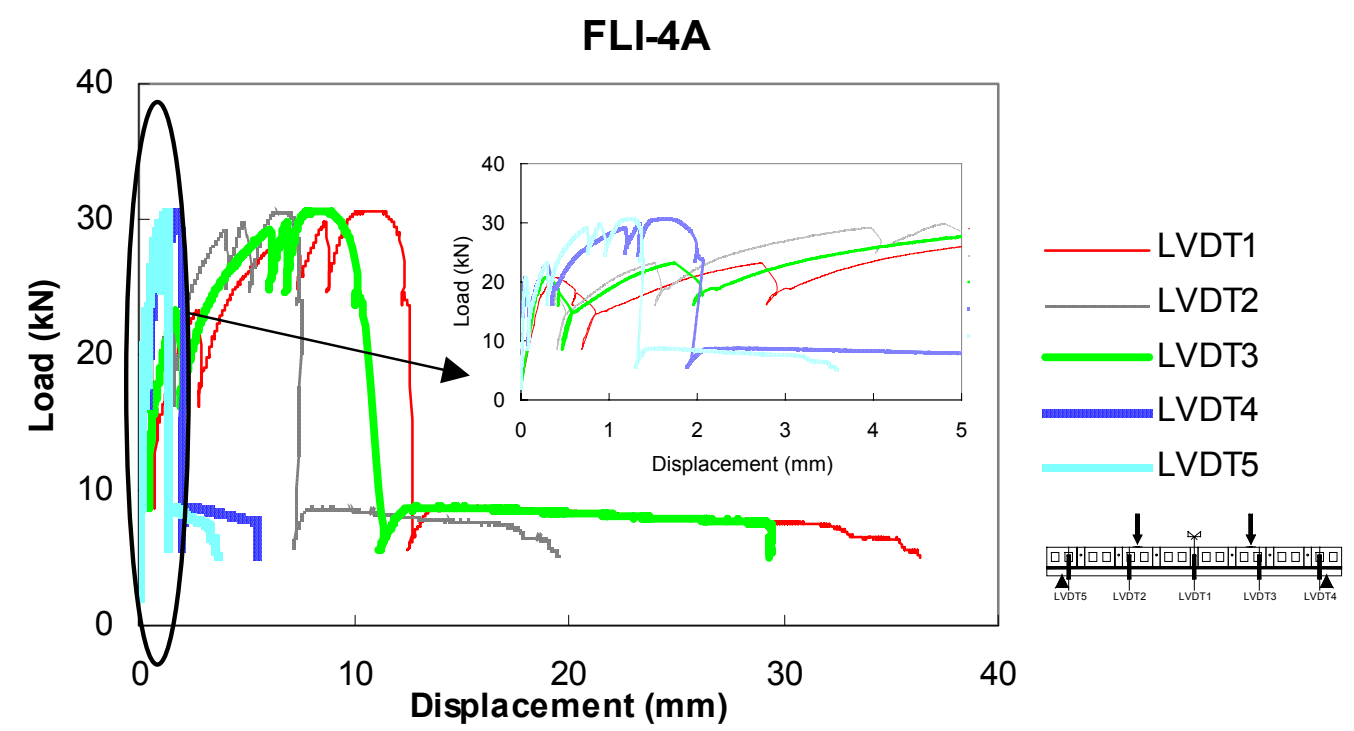

Figure 51 - Force-displacements relationship for all LVDTs.

The failure configuration of panel FLI-4A is shown in Figure 52.
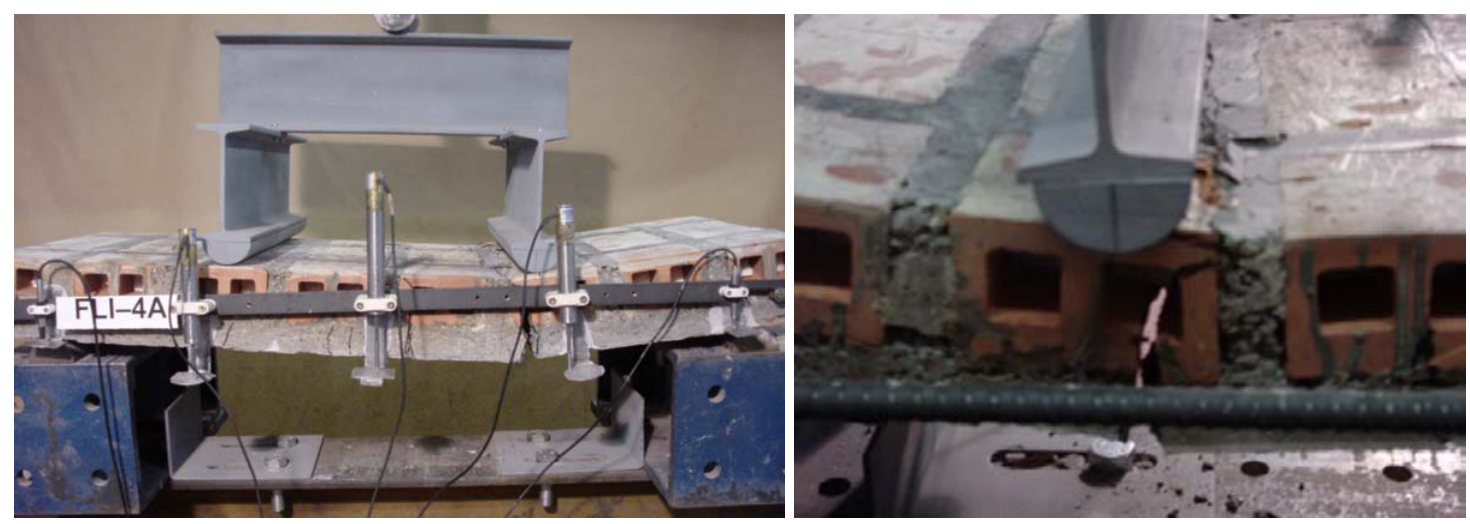

Figure 52 - Aspect of the panel FLI-4A after have been tested.

\subsection{Series FLI-B}

\subsubsection{FLI-1B}

The main difference between series FLI-B and series FL-B (section 4.2) is that, when tested, panel of series FLI-B was positioned in such a way that concrete layer was submitted to tensile stresses. At a load of $30 \mathrm{kN}$ occurred successive ruptures of the welded wire mesh, as well as, a diagonal crack in the brick, near the panel upper face. The final crack pattern of panel FLI-B is represented in Figure 53. First crack (fissure 1) occurred at a load of about $22 \mathrm{kN}$, while fissures 2 and 3 occurred almost 
simultaneously for a load about $26 \mathrm{kN}$, see Figure 54 . At $30 \mathrm{kN}$, due to high compression stresses in the cracked brick, an inclined crack (fissure 2) was formed above the crack mouth of fissure 1. For the same load level some wires of the mesh were ruptured, which induced the load drops observed in Figure 54. At panel failure the volume of brick above fissure 2 was crushed, see Figure 55. Due to the position of the cracks, the LVDTs at right side of the panel (from front view) registered larger displacements than the corresponding ones at left side.

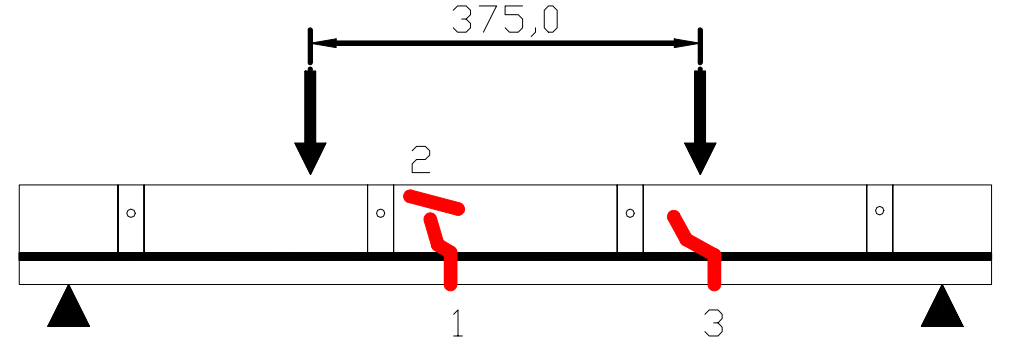

Figure 53 - Crack pattern in FLI-1B.

\section{FLI-1B}

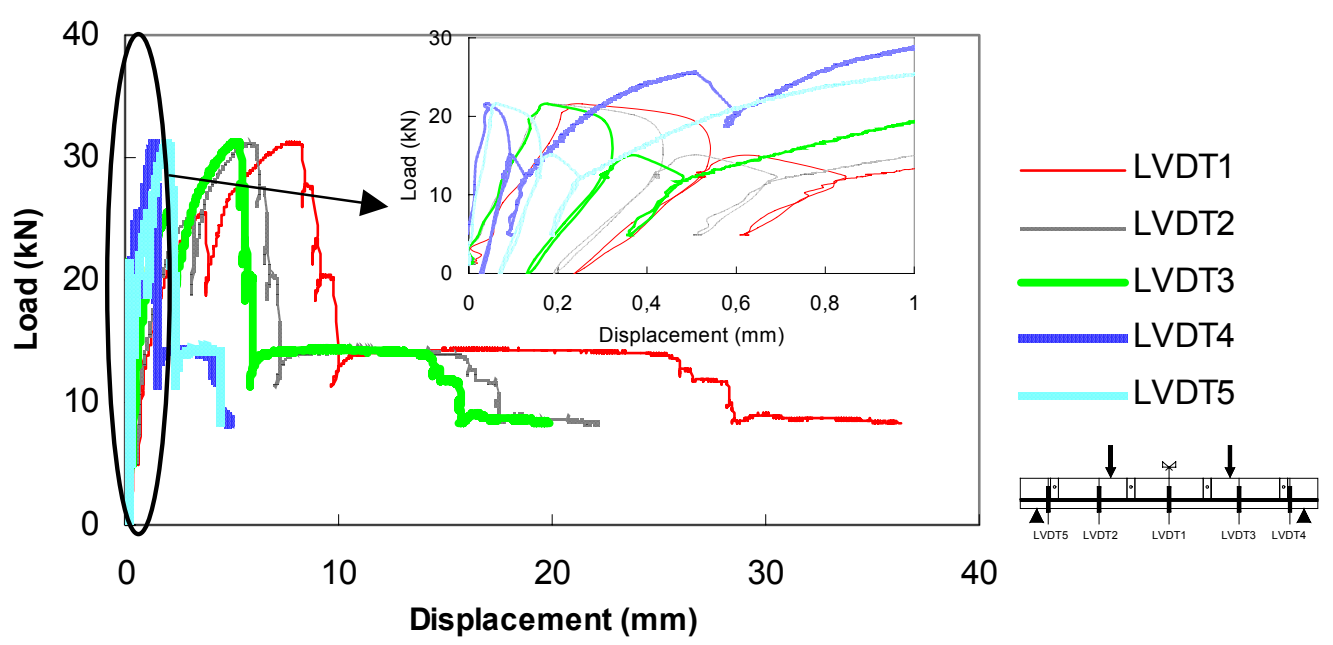

Figure 54 - Force-displacements relationship for all LVDTs. 

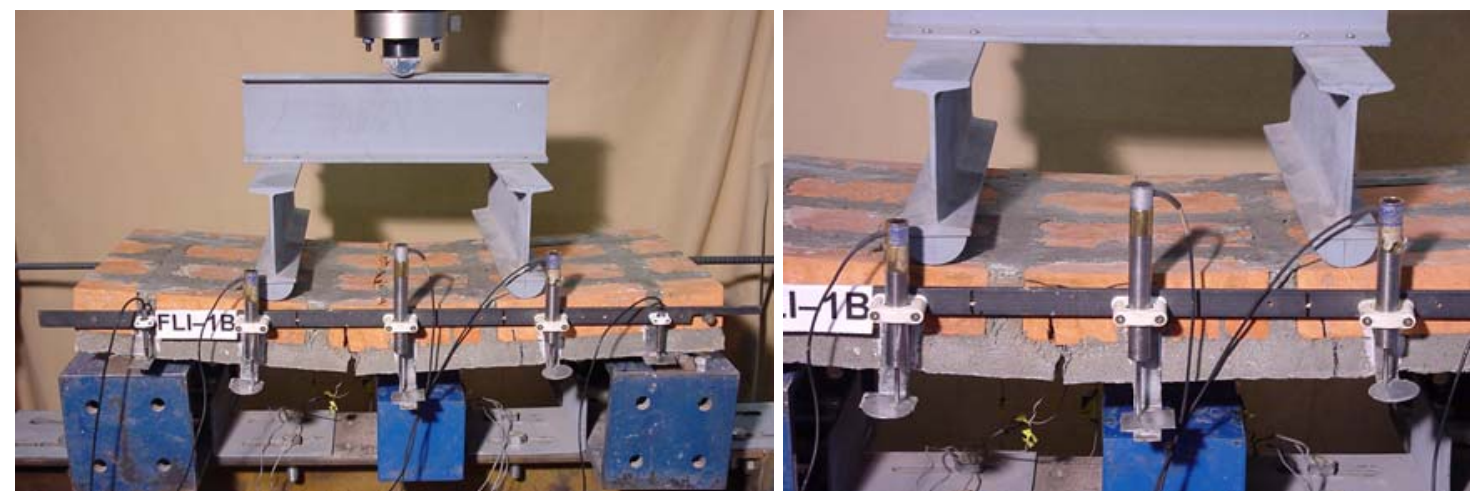

Figure 55 - Aspect of the panel FLI-1B after have been tested.

Figures 58 and 59 represent the evolution of the strains measured in the strain gauges positioned according to model 1 of Figure 9. The strain gauges S.G.1, S.G.2 and S.G.3, placed at panel mid span, registered yielding of the corresponding bars for a load level of about $30 \mathrm{kN}$. In spite of S.G.5 have been near the fissure 3, the corresponding bar has not yielded at this section because, when the panel entered in the structural softening phase, the crack opening of fissure 3 remained almost constant, while failure crack was opening.

\section{FLI-1B}

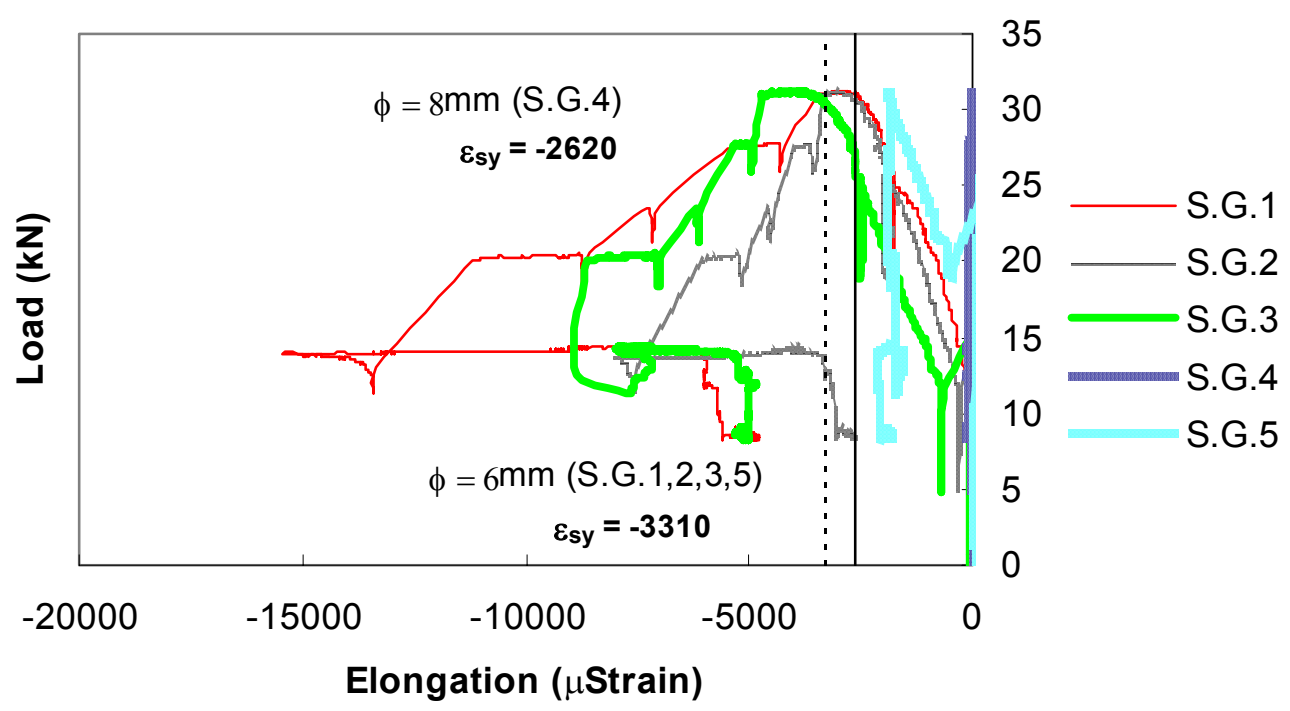

Figure 56 - Force-strain relationship for all strain gauges. 


\section{FLI-1B}

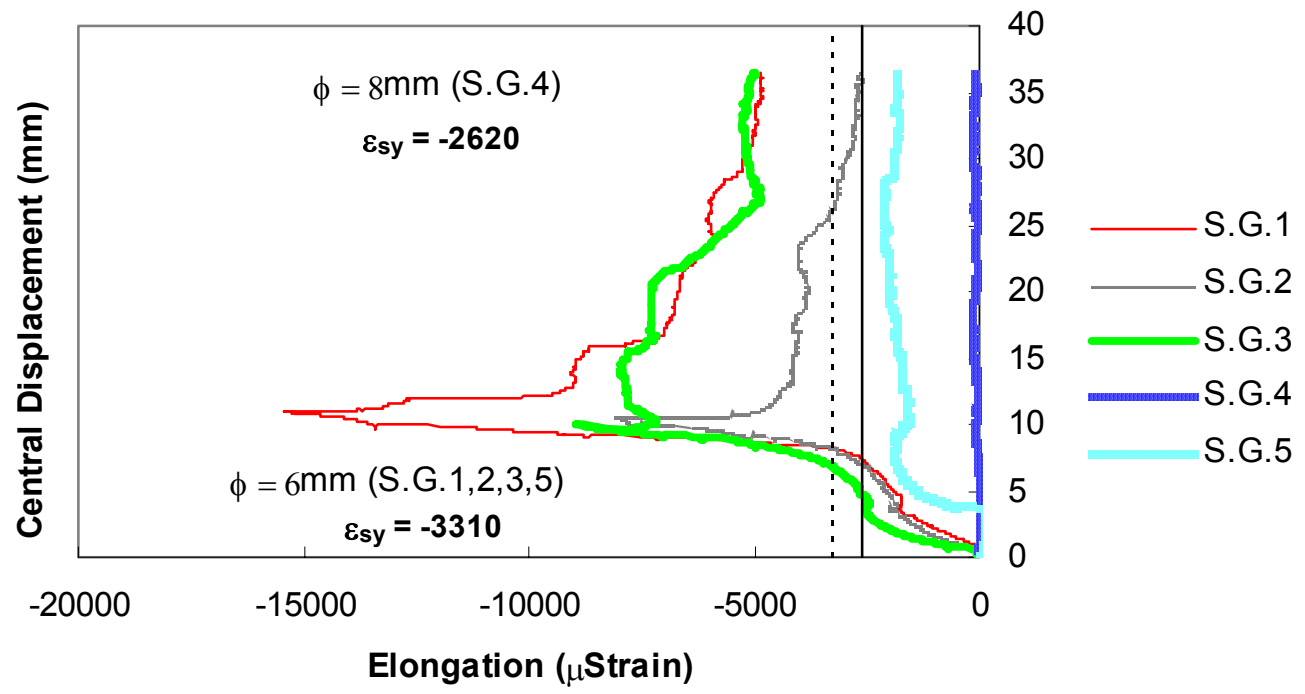

Figure 57 - Relationship between the deflection at panel mid span and the strains at strain gauges.

\subsubsection{FLI-2B}

Figure 60 represents the final crack pattern observed at the end of the test of panel FLI-2B. The first fissure (number 1) occurred at a load level of about $28 \mathrm{kN}$, followed by a load decay. At a load of $26 \mathrm{kN}$ appeared the fissure 2, in the symmetrical position of fissure 1 , followed by a second drop on the panel load bearing capacity. At a load level of $30 \mathrm{kN}$ arose a fissure at panel mid span followed by crushing of the concrete joint just at right of the left line load, see Figure 60.

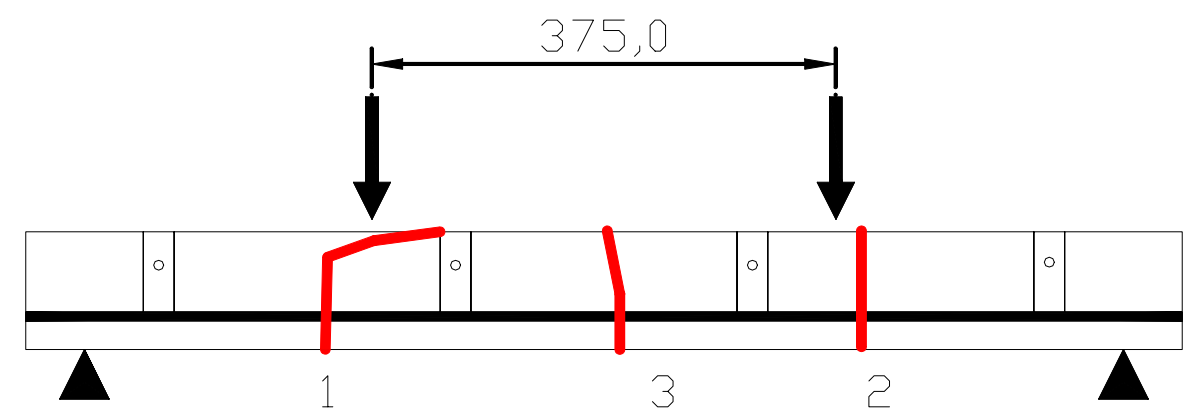

Figure 58 - Fissures configuration. 
At a load level of $32 \mathrm{kN}$, the crack opening of fissure 1 increased significantly and wires of the mesh have ruptured, having the panel lost its capacity to support loads above $5 \mathrm{kN}$. Above $10 \mathrm{~mm}$ of deflection the values registered by LVDT 2 are not real because the plate support of this LVDT has dropped, see Figure 60. The panel section where LVDT 5 was positioned deflected more than $5 \mathrm{~mm}$. As the measuring length of LVDT 5 was $5 \mathrm{~mm}$, the deflections above $5 \mathrm{~mm}$ were not registered.

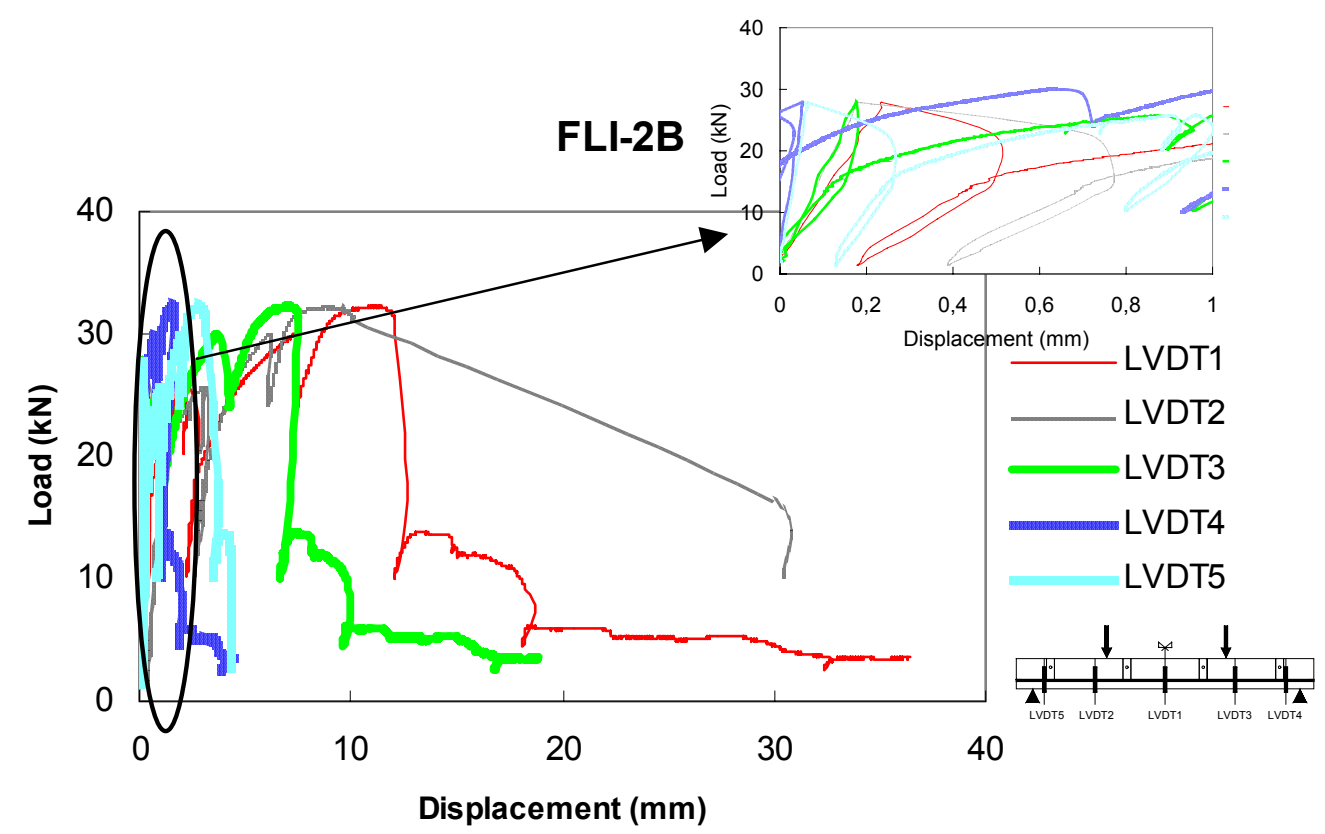

Figure 59 - Force-displacements relationship for all LVDTs.

During the fracture process, fissures 1 and 3 were mandatory. However, at a peak load fissure 1 became the main failure crack and fissure 3 entered into closing process, inducing a decrease in the strain of the bar where S.G.1 was glued. The strain evolution registered by the strain gauges placed at panel mid span (near fissure 3), S.G.1, S.G.2 and S.G.3, indicates that the crack opening profile of fissure 3 was not homogeneous at panel width. Larger crack opening occurred at panel front side.

Strain gauge 1, see model 2 in Figure 9, revealed that yielding of steel bar initiated at a load of $32 \mathrm{kN}$, see Figure 61. 

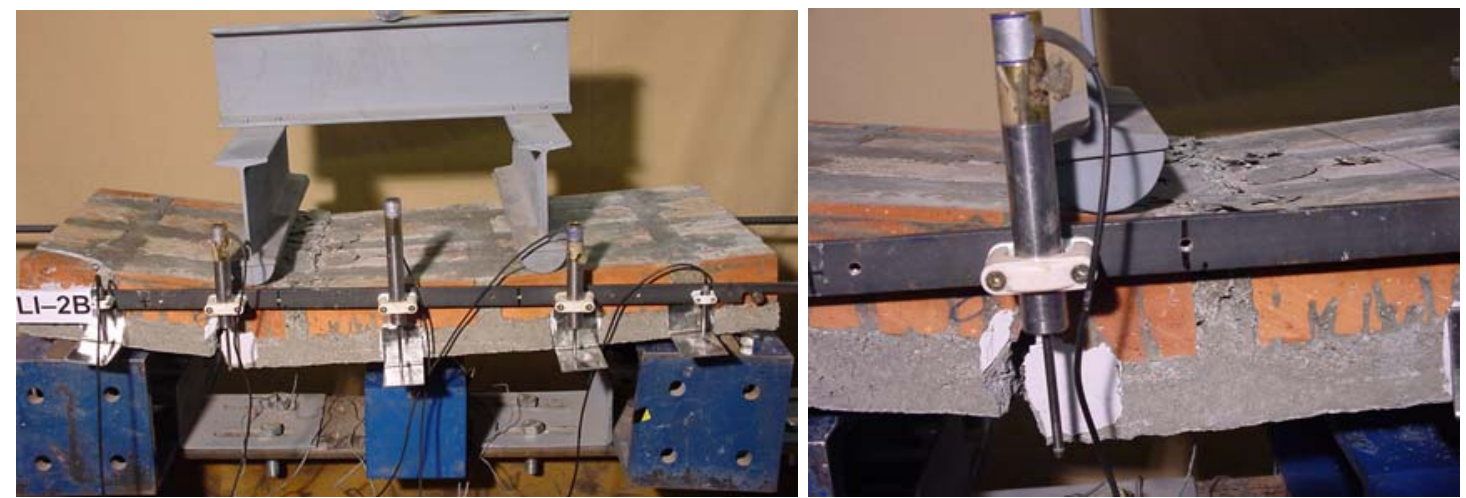

Figure 60 - Aspect of the panel FLI-2B after have been tested.

\section{FLI-2B}

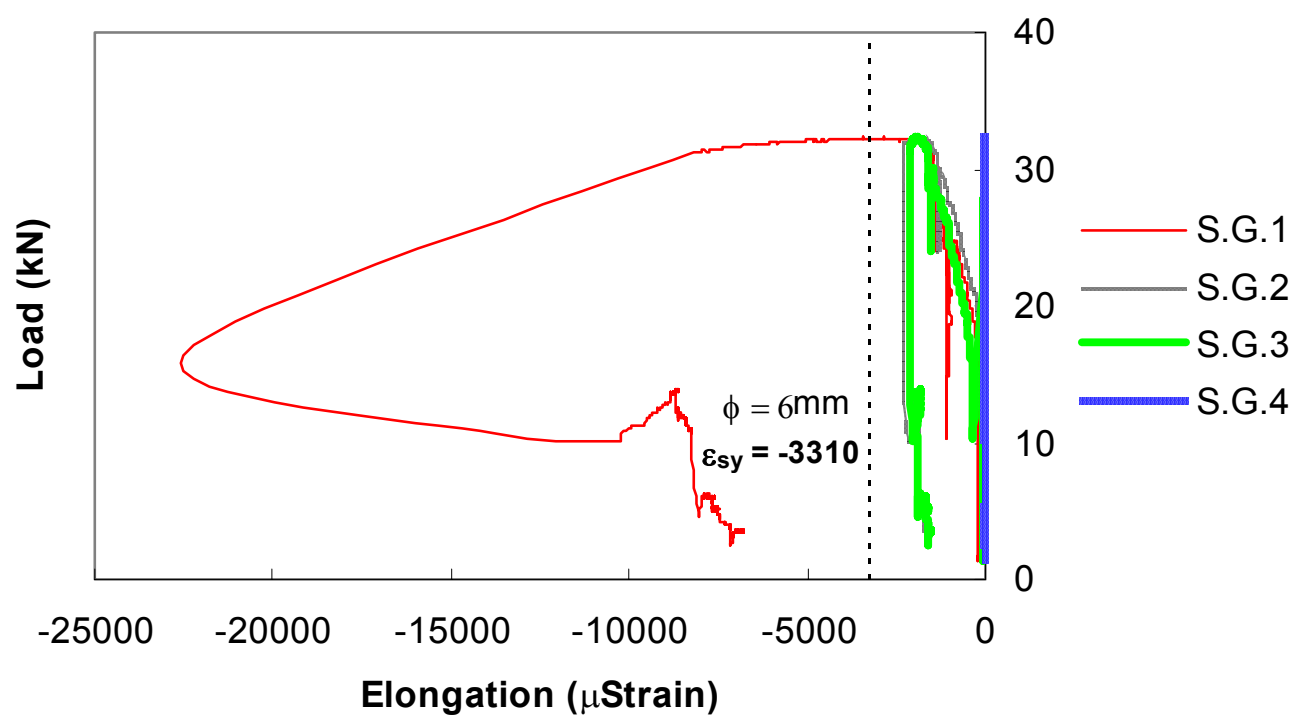

Figure 61 - Force-strain relationship for all strain gauges. 


\section{FLI-2B}

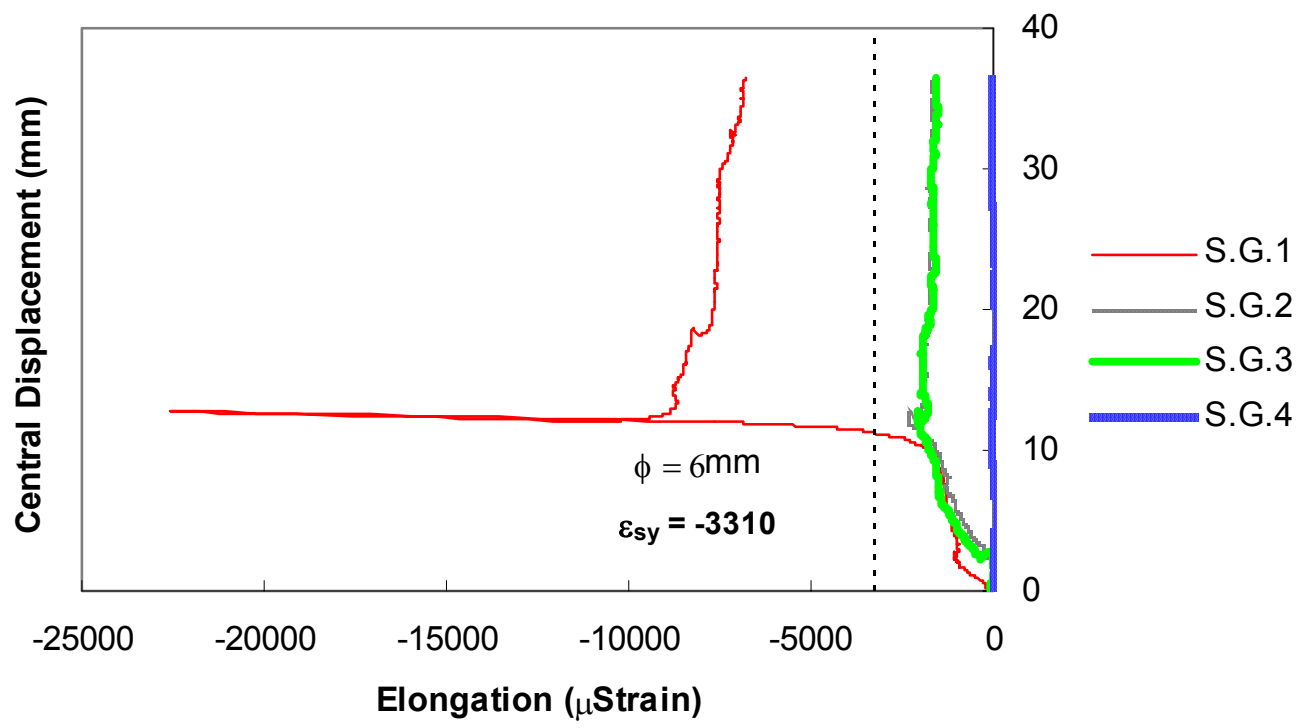

Figure 62 - Relationship between the deflection at panel mid span and the strains at strain gauges.

\subsubsection{FLI-3B}

Final crack pattern is represented in Figure 63. First crack (fissure 1) occurred at panel mid span for a load level of about $20 \mathrm{kN}$, followed by a drop on the panel load bearing capacity. Second fissure appeared at a load of $25 \mathrm{kN}$, just at left of the right line load. The crack opening procedure of fissure 2 was slower than of fissure 1. At a load level of $28 \mathrm{kN}$, ahead of fissure 1, an horizontal fissure was formed (fissure 3) due to the high compression horizontal stresses. During the crack opening process of the failure crack (fissure 1), wires of the mesh crossing this crack have ruptured, leading to the drops on the leading, that can be observed on the structural softening branch, see Figure 64.

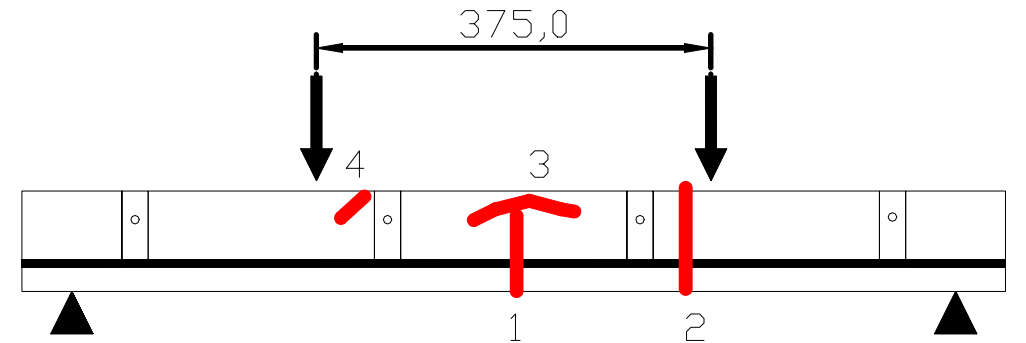

Figure 63 - Crack pattern in FLI-3B. 
Crushing in the bricks was visible at a load of $13 \mathrm{kN}$. At the end of the test the panel failure configuration is shown in Figure 65.

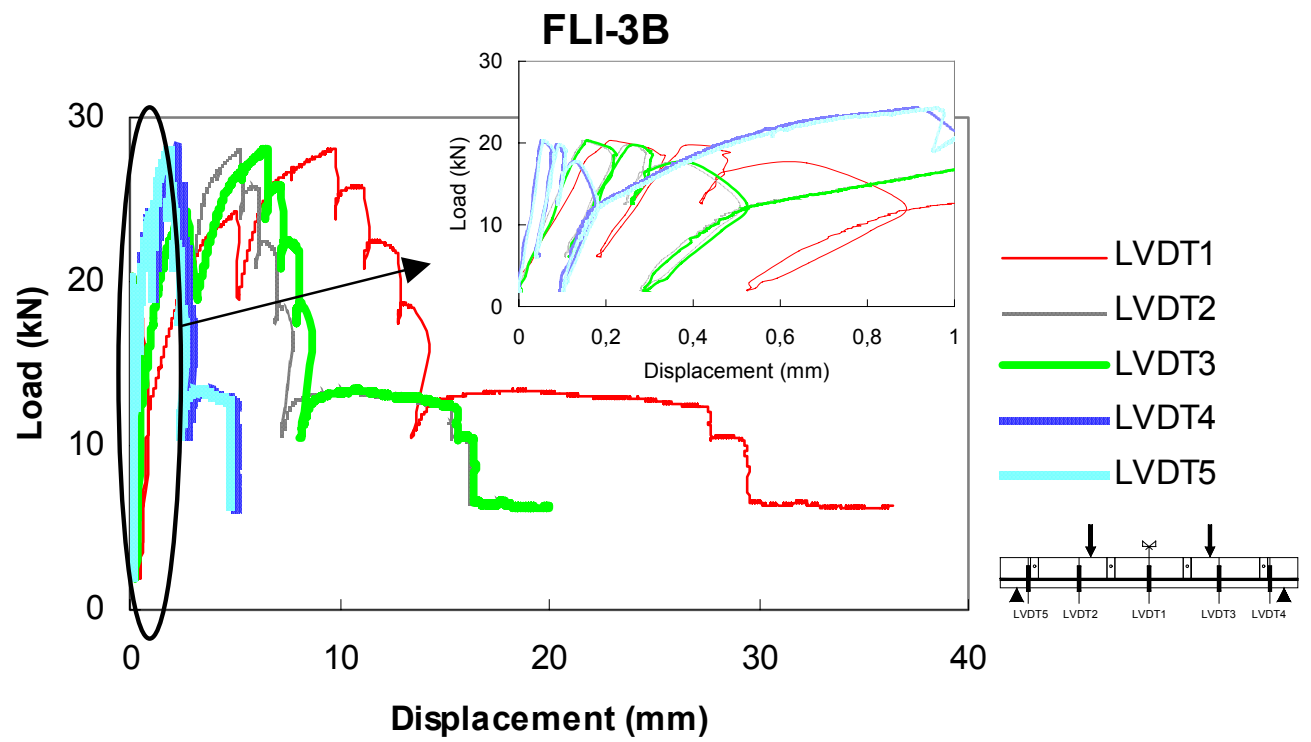

Figure 64 - Force-displacements relationship for all LVDTs.
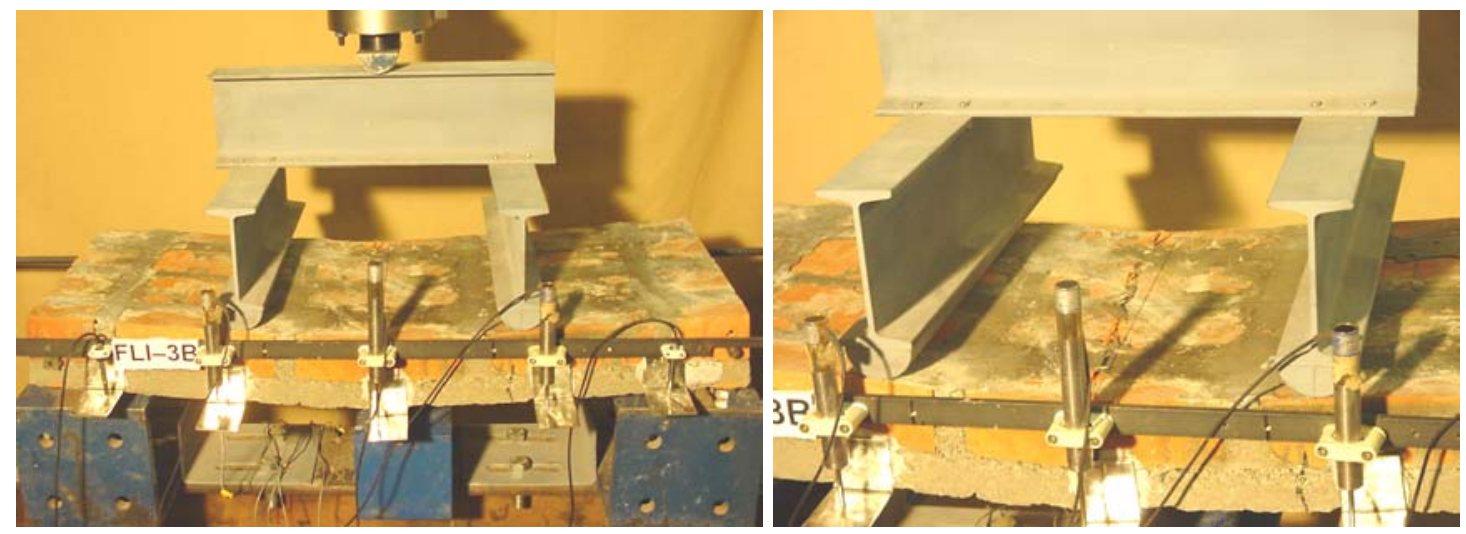

Figure 65 - Aspect of the panel FLI-3B after have been tested.

Panel FLI-3B was monitored with the strain gauges arrangement of model 3 of Figure 9. According to Figures 66 and 67, the bars began yielding just before panel has entered in the structural softening. The bars corresponding to S.G.4 and S.G.2 have first yielded, followed by bar of S.G.3, revealing that the crack opening of the failure crack was larger at panel extremities than at its center. 


\section{FLI-3B}

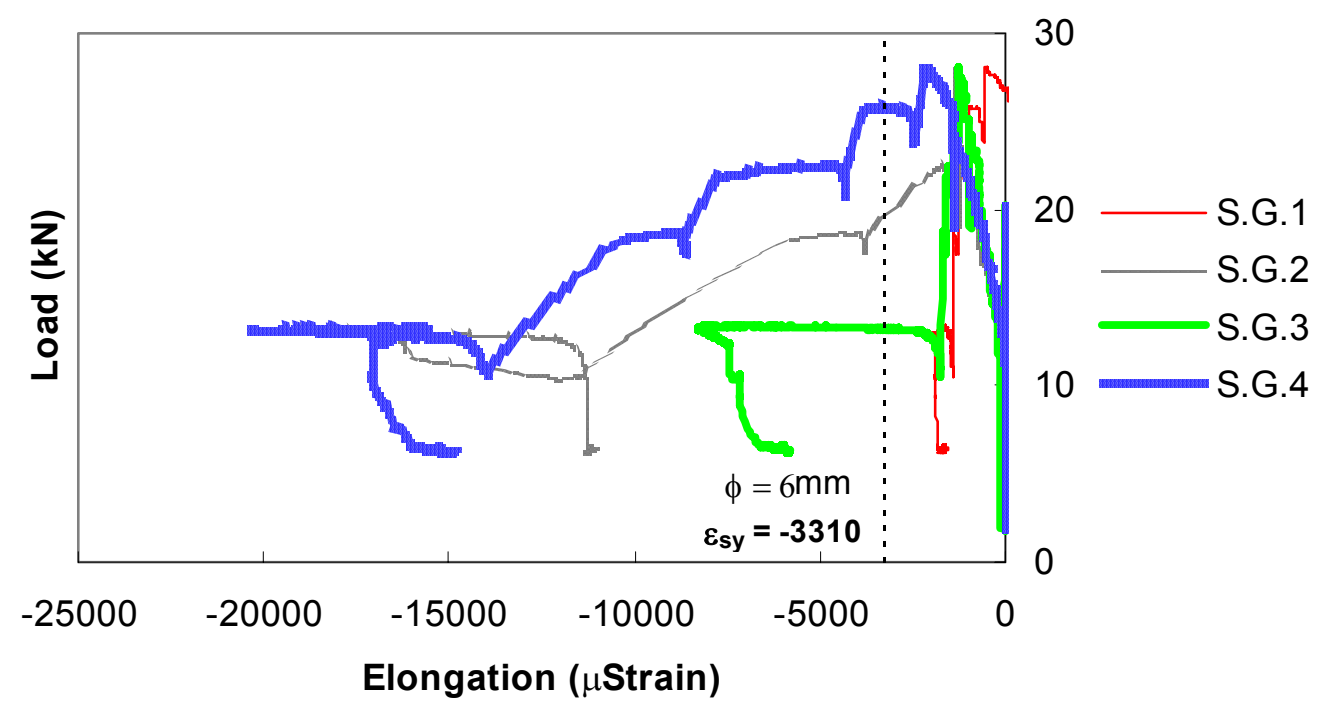

Figure 66 - Force-strain relationship for all strain gauges.

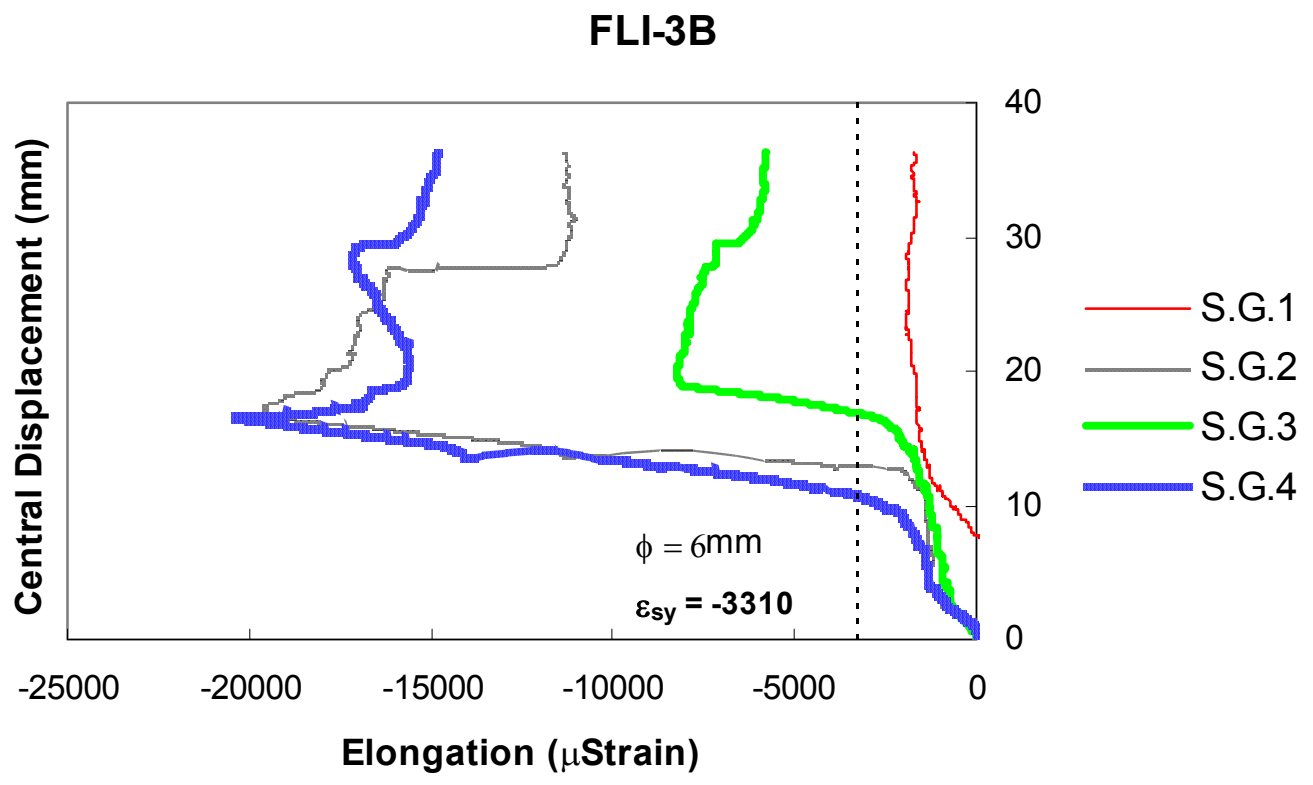

Figure 67 - Relationship between the deflection at panel mid span and the strains at strain gauges.

\subsubsection{FLI-4B}

The behavior of this panel was quite similar of the previous one. At a load of about $20 \mathrm{kN}$ fissure 1 was observed just at left of left line load, see Figures 68 and 69. 
For a load slightly higher than $20 \mathrm{kN}$ fissure 2 was formed. At a load level of $24 \mathrm{kN}$ occurred fissure 3 and finally horizontal fissure 4 was arisen at a load of about $30 \mathrm{kN}$. At this load level, some wires of the mesh were ruptured at the crack surface of fissure 3 , and the panel entered in structural softening, having the load bearing capacity decreased to a load level of $12 \mathrm{kN}$. For this load level and during the deflection evolution, the brick volume in the alignment of fissure 3 and above fissure 4, was crushed, see Figure 70.

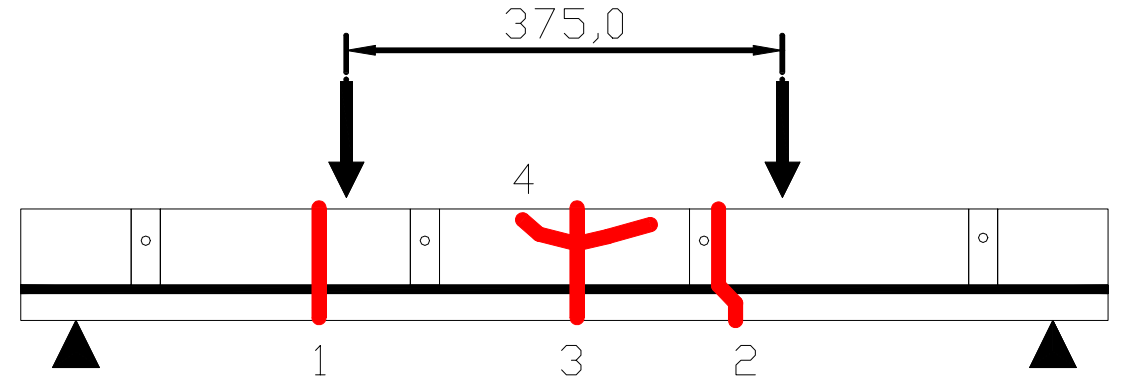

Figure 68 - Crack pattern in FLI-4B.

At the end of panel test, fissure 3 had a crack opening of $10 \mathrm{~mm}$ and $5 \mathrm{~mm}$ at panel bottom surface and at concrete layer/brick interface, respectively.

\section{FLI-4B}
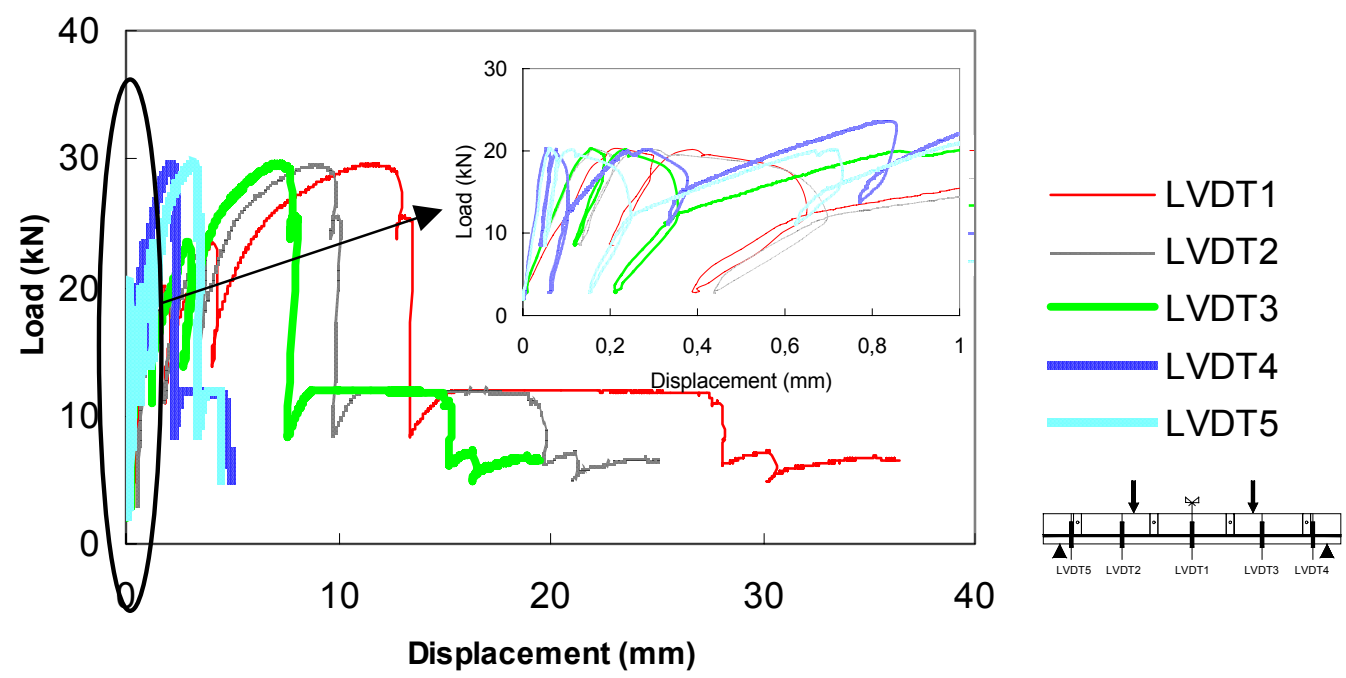

Figure 69 - Force-displacements relationship for all LVDTs. 

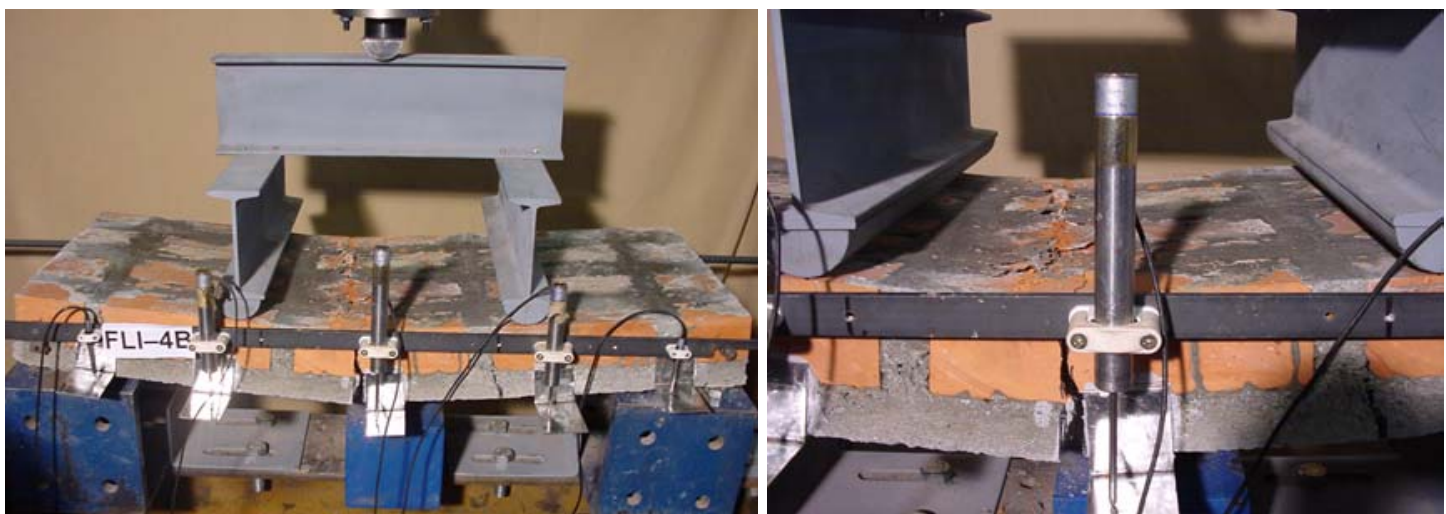

Figure 70 - Aspect of the panel FLI-4B after have been tested.

\subsection{Series FLC-A and $-B$}

\subsubsection{FLC-1A}

Fissures 1, 1', 1" and 1"' appeared simultaneously at a load of about $55 \mathrm{kN}$, and all of them started at joint/brick interface, see Figure 72 . The maximum load bearing capacity of the panel was $74 \mathrm{kN}$, that was attained when fissures 2 and 2' were formed. After that, the panel entered in structural softening. In spite of the reduced value of the shear span ratio $(\mathrm{a} / \mathrm{d} \approx 175 / 75 \approx 2.3)$ no shear cracks were visible.

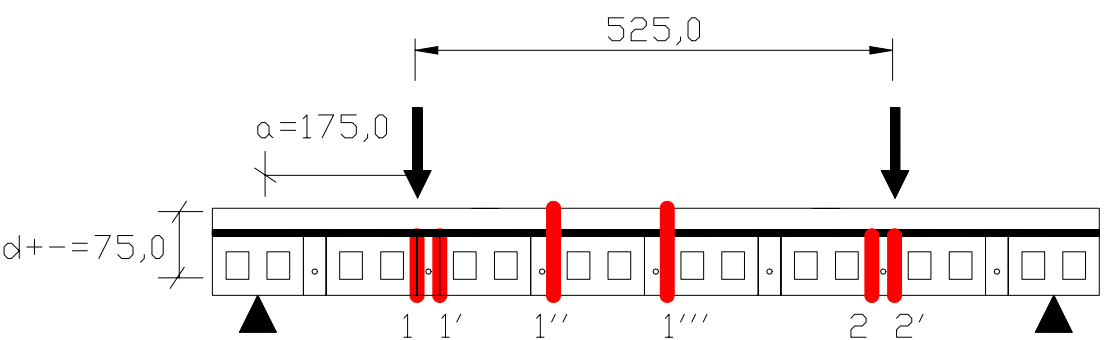

Figure 71 - Crack pattern in FLC-1A.

This panel showed a very ductile behavior. The test was interrupted when LVDT placed at panel mid span measured a deflection larger than $35 \mathrm{~mm}$. As crack pattern was practically symmetric, the displacements registered by LVDTs positioned symmetrically were similar, see Figure 72 . The panel failure configuration at the end of the test is shown in Figure 73. The largest crack opening was measured in fissure 2', having $8 \mathrm{~mm}$ and $4 \mathrm{~mm}$ at panel bottom surface and at brick-concrete concrete layer 
interface, respectively. For this deformation, fissure 2 had a crack opening of $7 \mathrm{~mm}$ and $1 \mathrm{~mm}$ at the aforementioned levels.

\section{FLC-1A}

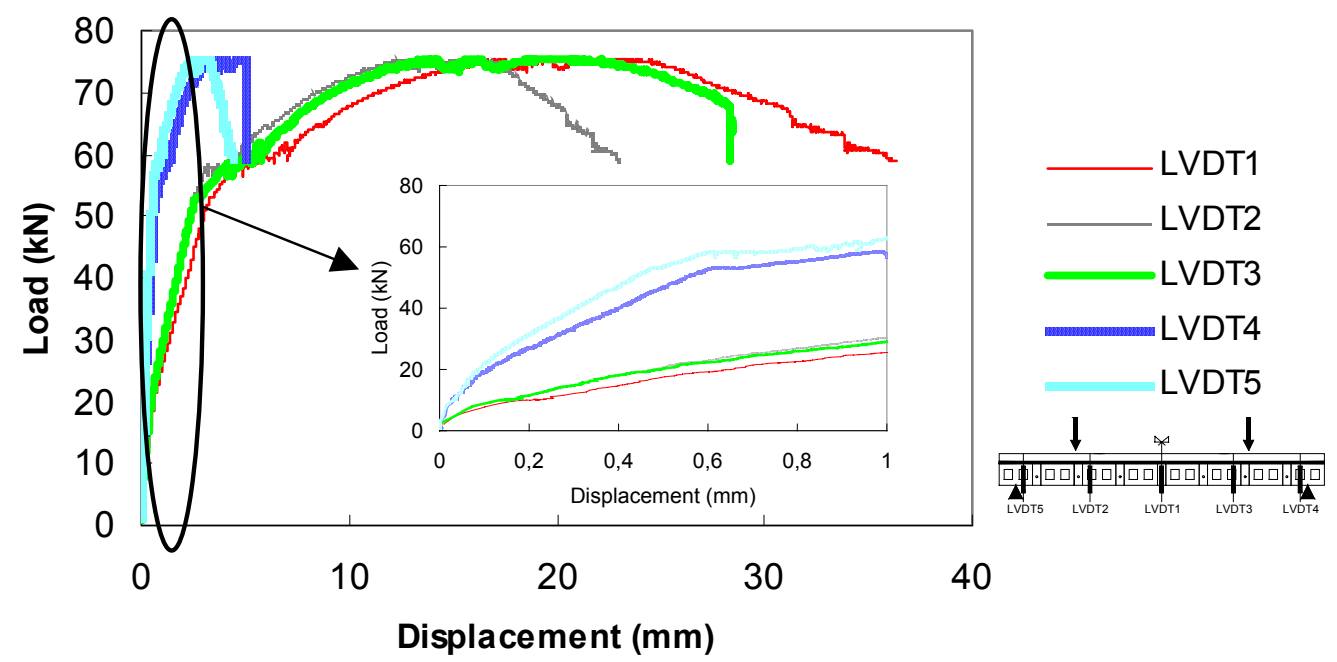

Figure 72 - Force-displacements relationship for all LVDTs.
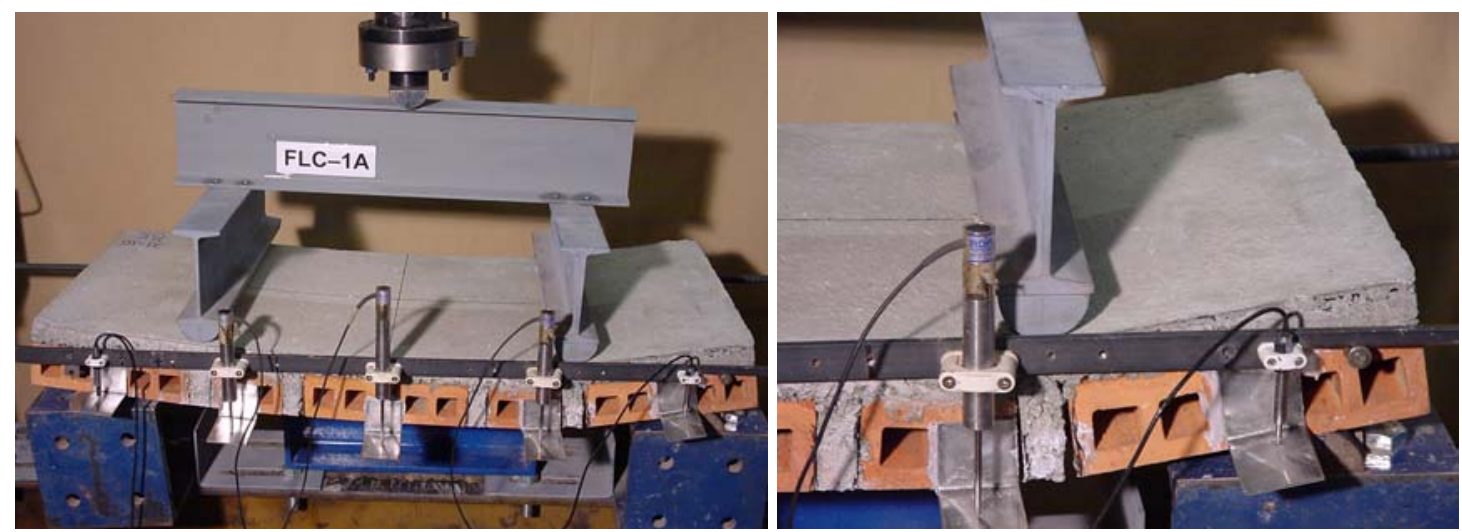

Figure 73 - Aspect of the panel FLI-4B after have been tested.

\subsubsection{FLC-2A}

This panel showed a behavior very similar to the one of the panel FLC-1A, as Figures 74 and 77 reveal. The final crack pattern of panel FLC-2A is represented in Figure 74. Up to a load level of $55 \mathrm{kN}$ no fissure was visible. At a load of about $60 \mathrm{kN}$ fissures 1 and 1' were formed simultaneously and at $70 \mathrm{kN}$ occurred fissures 2,2 ', 2" and 2"'. Fissures 3 and 3 ' arose at a load of $72 \mathrm{kN}$. Between the first and last crack formation, the panel developed large deflection with a very ductile behavior. When the 
test was interrupted, the maximum deflection was $36 \mathrm{~mm}$ and the panel sustained a load of $65 \mathrm{kN}$. The photos included in Figure 76 show that, at the end of the test, fissure 1 was the most widen. At panel front face this fissure had a crack opening of $10 \mathrm{~mm}$ and $3 \mathrm{~mm}$ at panel bottom surface and at brick/concrete layer interface, while at panel rear face values of $3 \mathrm{~mm}$ and $1 \mathrm{~mm}$ were measured.

As Figure 75 shows, the LVDTs placed in the "pure bending zone" have registered similar deflections values. Since crack pattern was quasi-symmetrical, the panel deformability was almost symmetrical.

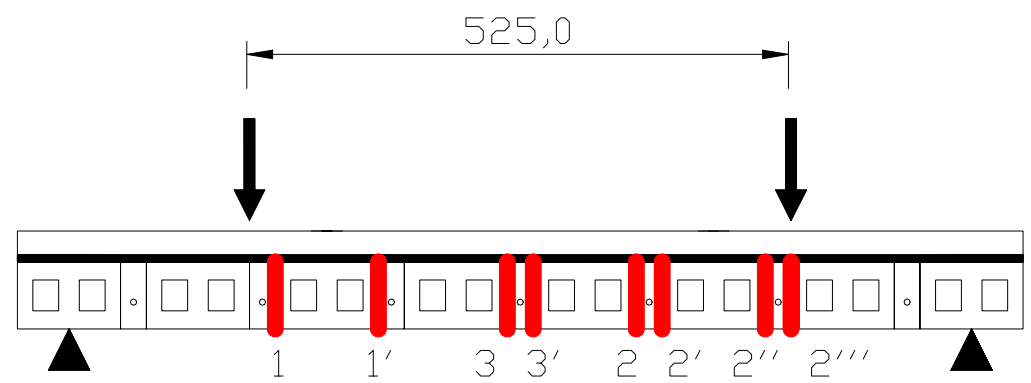

Figure 74 - Crack pattern in FLC-2A.

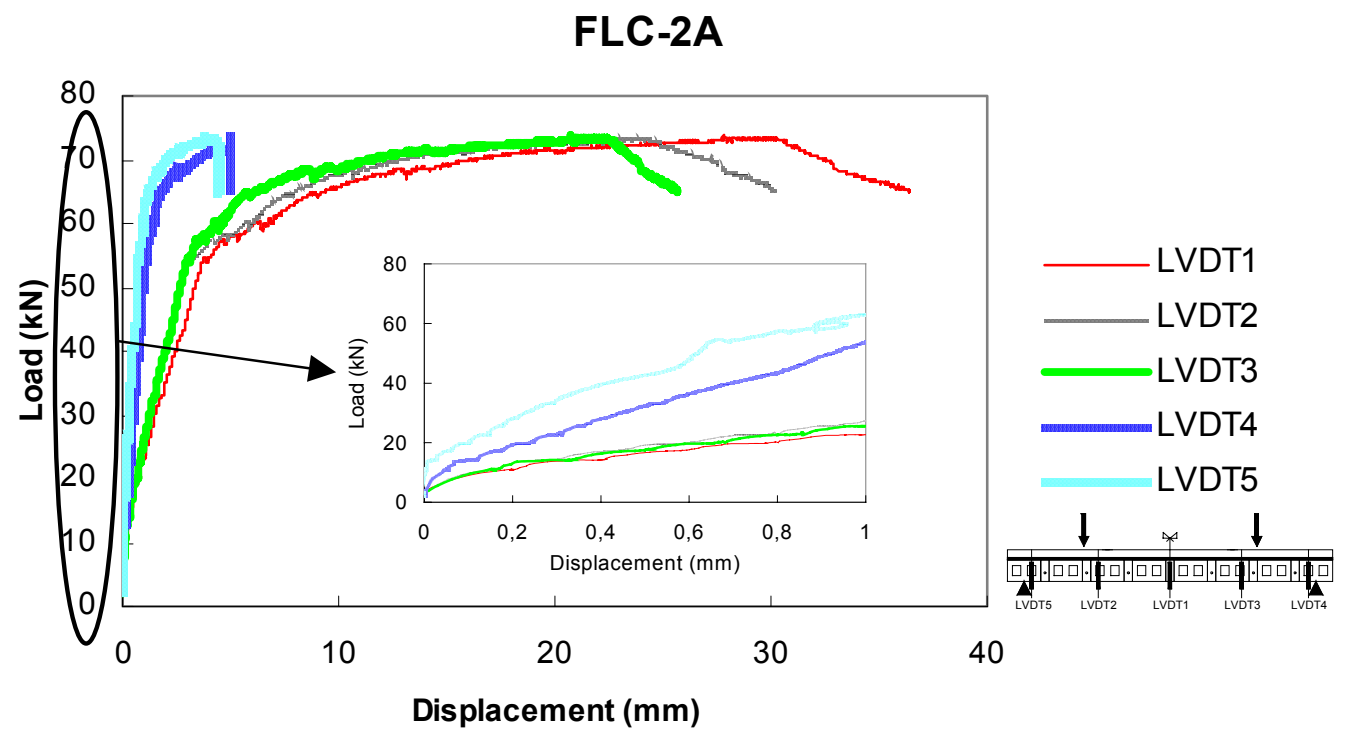

Figure 75 - Force-displacements relationship for all LVDTs. 

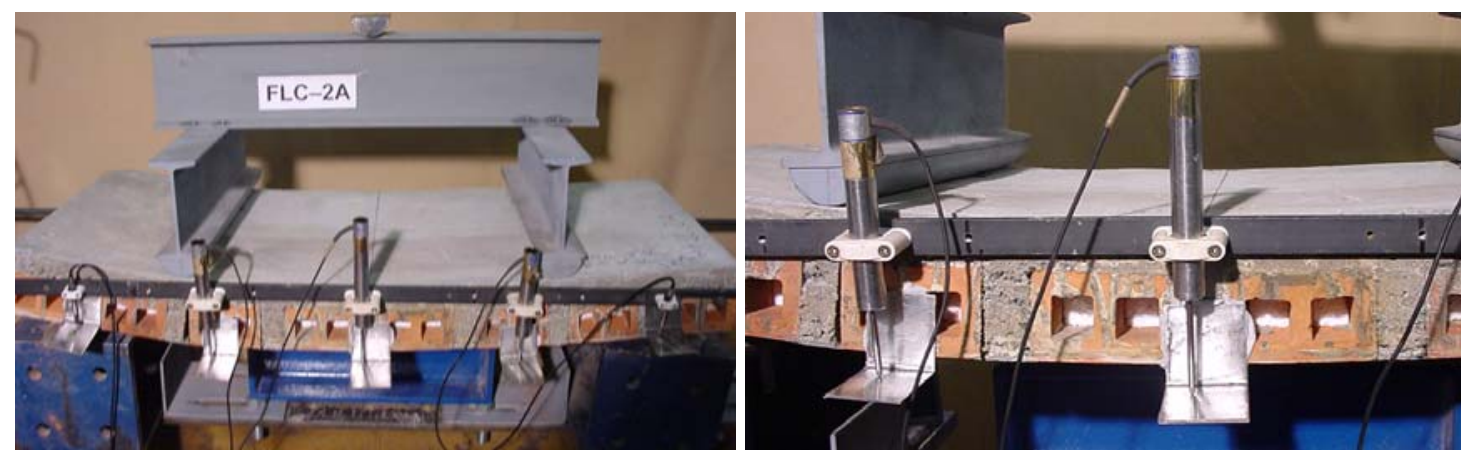

Figure 76 - Aspect of the panel FLC-2A after have been tested.

\subsubsection{FLC-1B}

Fissure 1 was the first one to occur, and was formed at a load level of about $25 \mathrm{kN}$ crossing the brick, at the panel left shear span. Fissure 2 occurred at a load of about $40 \mathrm{kN}$ and appeared in the same brick, but in between line loads. The remaining fissures were formed at a load level of $47 \mathrm{kN}$. Before have attained the concrete layer, fissure 1 changed from vertical to inclined direction $\left(\alpha \approx 38^{\circ}\right)$, see Figure 77 .

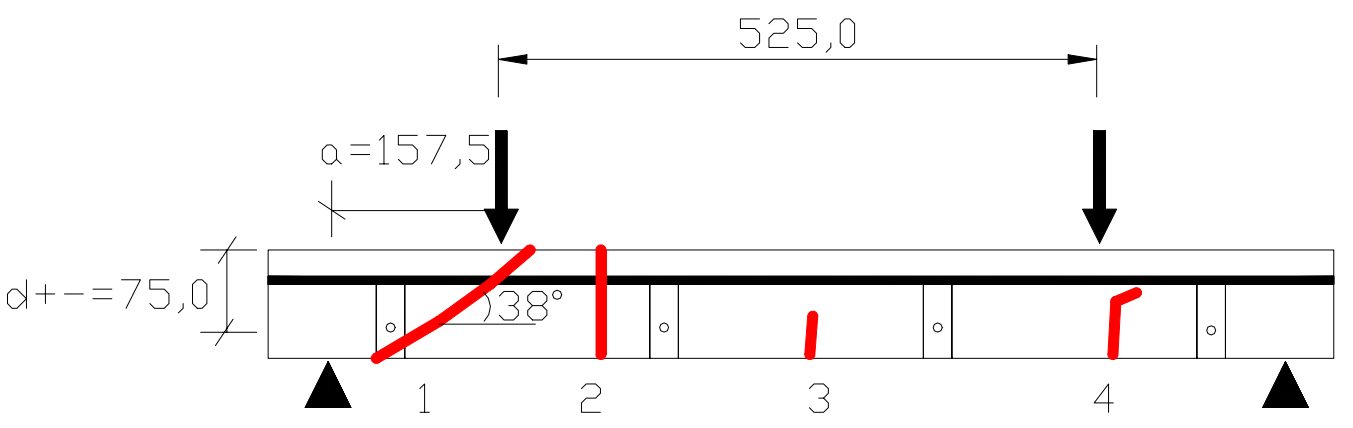

Figure 77 - Crack pattern in FLC-1B.

The panel was failed by shear, see Figure 79 , in a very brittle way. As failure shear crack was developed at panel left shear span, the LVDTs positioned at panel left side have registered larger displacements than the corresponding ones at panel right side, see Figure 78. 


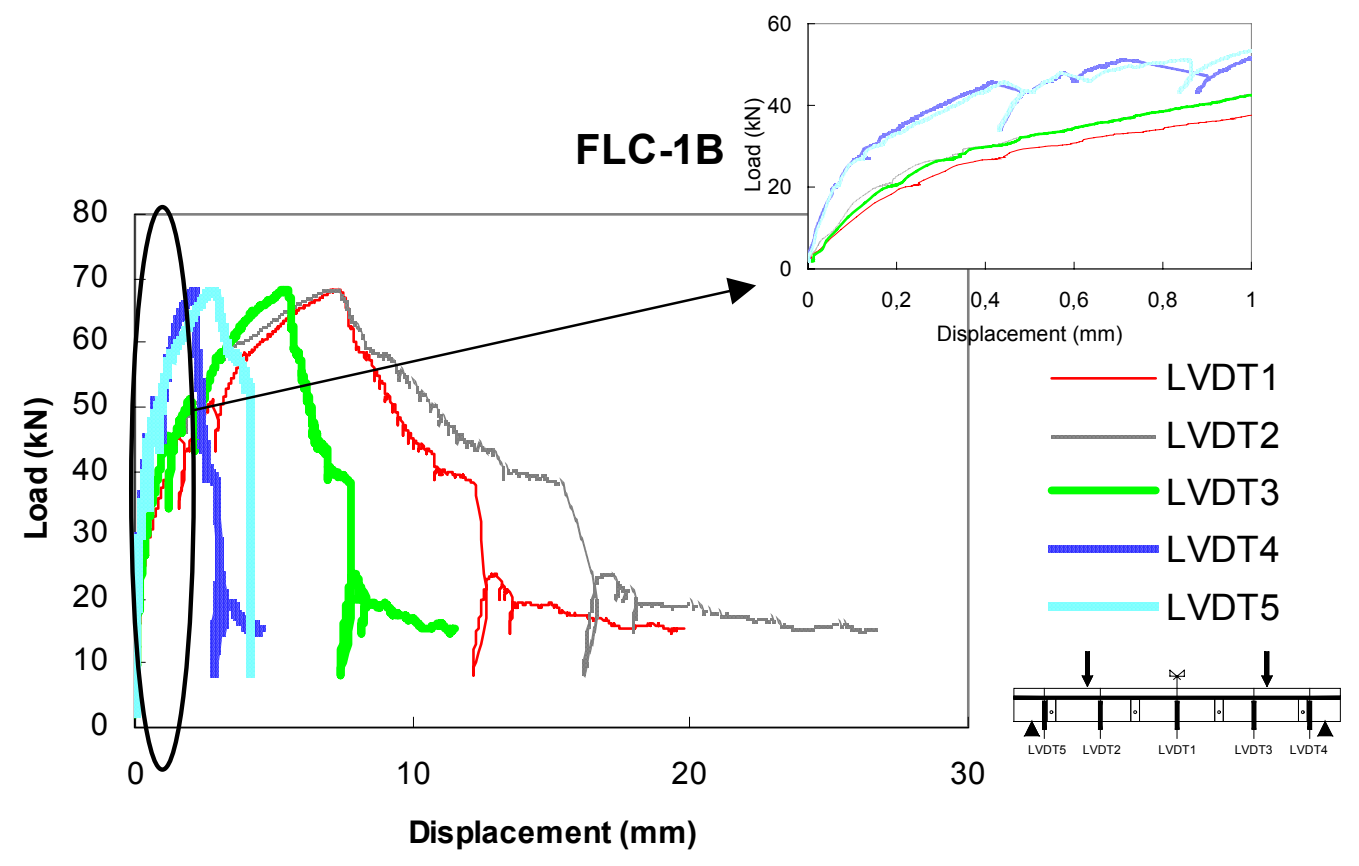

Figure 78 - Force-displacements relationship for all LVDTs.

Due to excessive rotation of the part of the panel at left of the failure crack, the LVDT 5 exceeded its measuring length when registering a deflection of about $4.2 \mathrm{~mm}$ and, consequently, the measuring process of this LVDT was interrupted.
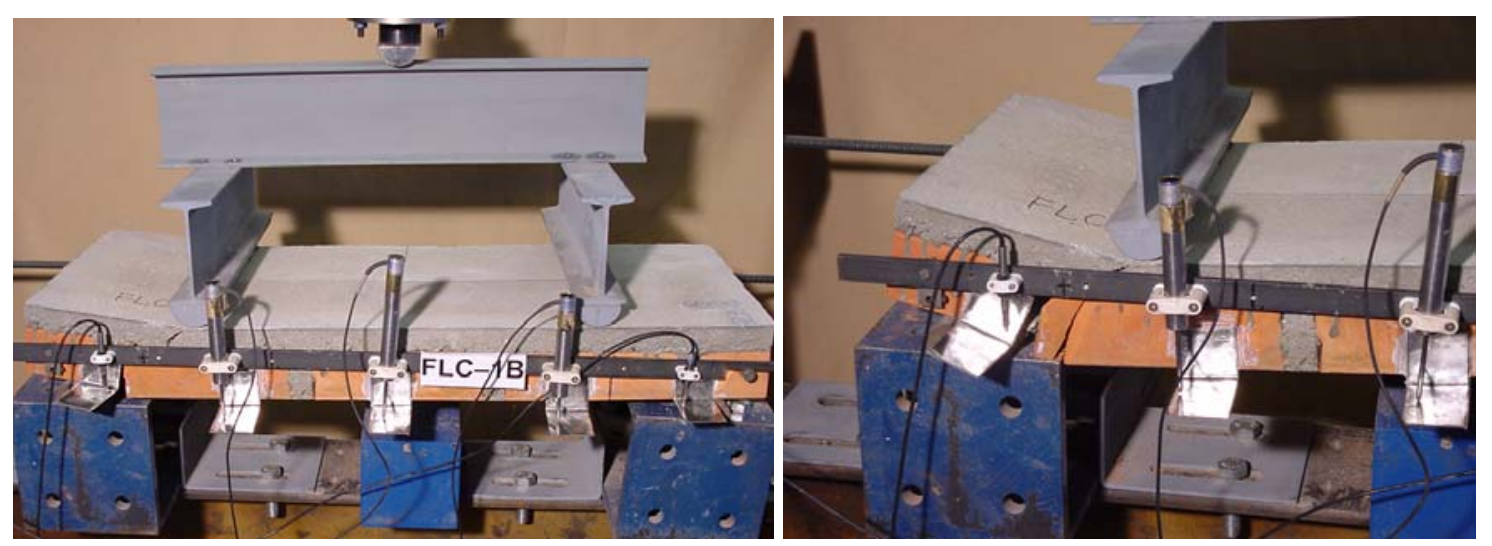

Figure 79 - Aspect of the panel FLC-1B after have been tested.

\subsubsection{FLC-2B}

In spite of being part of the same series this panel has failed by bending, while the previous one has failed by shear. At a load of $25 \mathrm{kN}$ fissures 1 and 2 were formed at concrete joint/brick interface. At a load of $48 \mathrm{kN}$ fissure 3 appeared under the left line load and fissure 3' in the concrete joint/brick interface. Fissure 4 occurred at a load of 
$68 \mathrm{kN}$. The crack opening process of fissures 1 and 3' has increased significantly at a load of about $82 \mathrm{kN}$. After the deflection corresponding to maximum load the panel entered in structural softening and at a load of about $70 \mathrm{kN}$ fissure 1 has widen significantly and the longitudinal reinforcement has ruptured in this section, see Figure 82. Figure 81 reveals that the panel deformability was quasi-symmetrical.

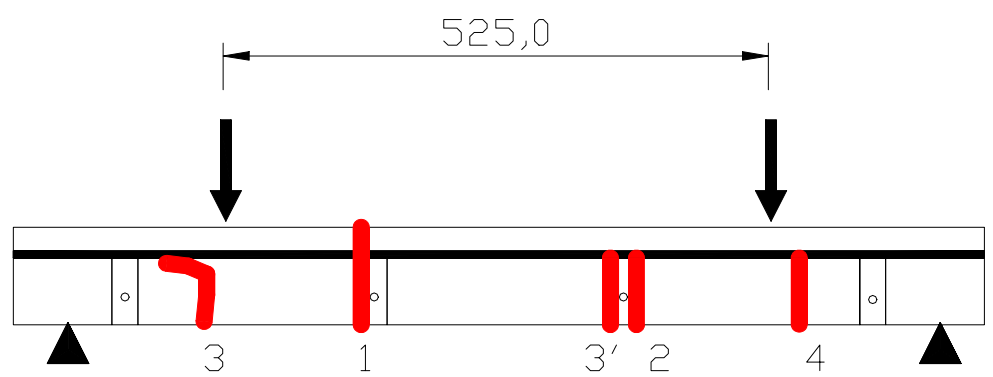

Figure 80 - Crack pattern in FLC-2B.

\section{FLC-2B}

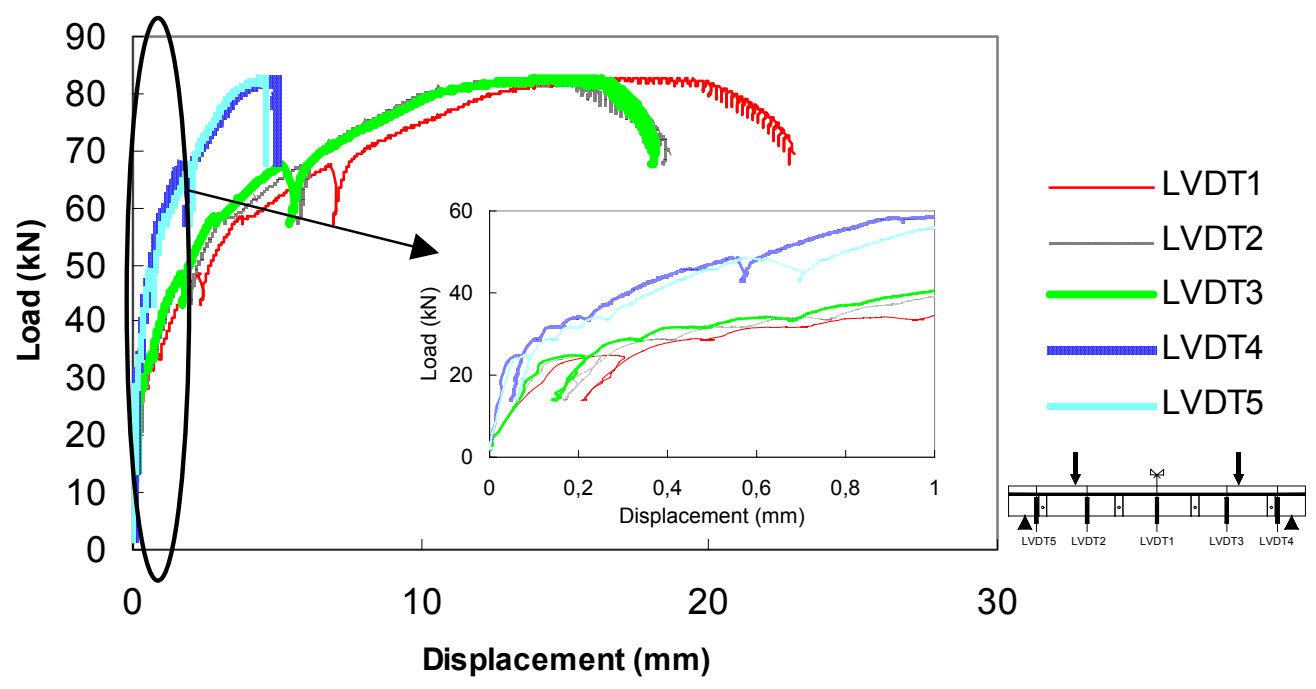

Figure 81 - Force-displacements relationship for all LVDTs. 

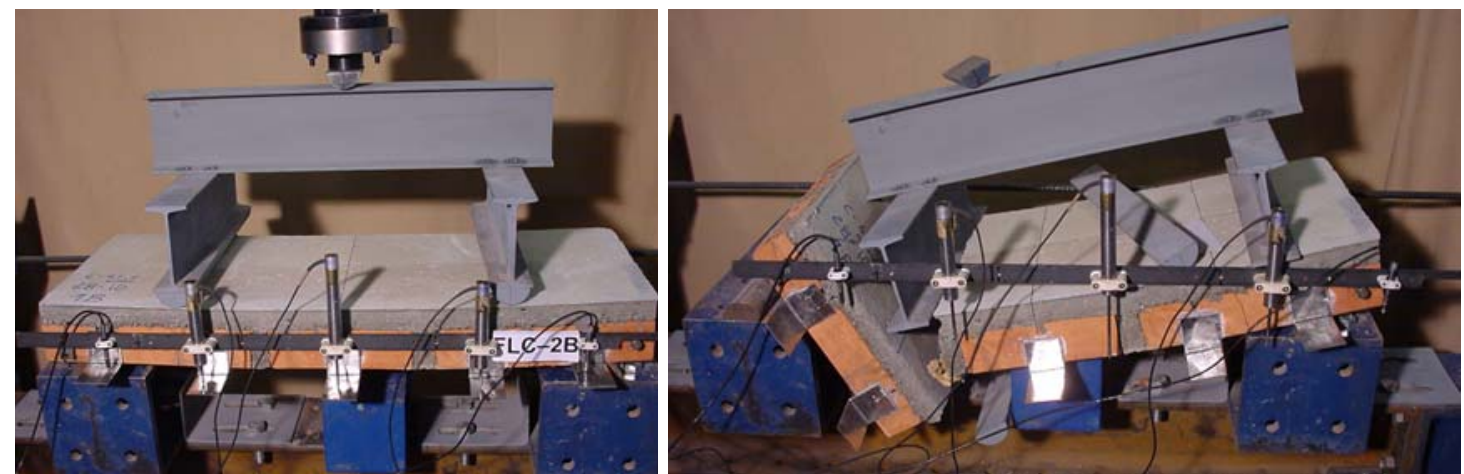

Figure 82 - Aspect of the panel FLC-2B after have been tested.

\section{Analysis of Results}

Figure 83 includes the relationship between the average force and the mid span deflection of series FLA, FLI-A, FLB and FLI-B. As series FLB had three concrete ribs (the joints) in the longitudinal direction, while FLA had only two, FLB showed higher initial stiffness. Besides higher stiffness, series FLB had also larger load bearing capacity than series FLA. The cross sectional area of the longitudinal reinforcement of series FLB was lower than the one of series FLA $\left(A_{s}=84.8 \mathrm{~mm}^{2}\right.$ in FLB and $\mathrm{A}_{\mathrm{s}}=100.5 \mathrm{~mm}^{2}$ in series FLA), but the tensile yield stress and strength of the bars reinforcing series FLB $(\phi 6)$ were larger than the values obtained on the specimen's bars reinforcing series FLA $(\phi 8)$, see Annex 1.

Comparing the deformability response of the series up to a deflection of about $1 \mathrm{~mm}$ (see inset of Figure 83), it is visible that panels FL- entered firstly in non-linear behavior than series FLI-. This was due to the fact that in series FLI- the loss of linearity was due to cracking of the bottom concrete layer, while in series FL the cracking process has always mobilized the brick-concrete joint interface, which is a poor link in the panel system. Therefore, the higher initial stiffness of series FLI- was due to the tensile resistance provided by the concrete layer. After this layer have been cracked, the stiffness decreased significantly and crack propagation was followed by rupture of wires of the mesh. Due to wire mesh rupture, series FLI- showed lower ductility than series FL-.

As it was expected, FLI-A and FLI-B series had similar maximum load bearing capacity and deformability behavior, since the amount and position of the tensile reinforcement were equal in both series. However, the force corresponding to crack 
initiation was larger in series FLI-B, as this panel had three concrete ribs while series FLI-A had only two.

Series with the concrete layer turned upward (FLA and FLB) had higher maximum load than their counterpart's series with the concrete layer turned downward (FLI-A and FLI-B). This was due to the high tensile longitudinal reinforcement ratio and internal arm of series FLA and FLB (in series FLI the wire mesh was positioned at brick-concrete layer interface). The tension stiffening effect might have also contributed for this distinct behavior (Barros 1995). Due to the amount and position of the tensile longitudinal reinforcement, the tension stiffening effect in series FLI might have been marginal, while in series FLA and FLB it should be not neglected.

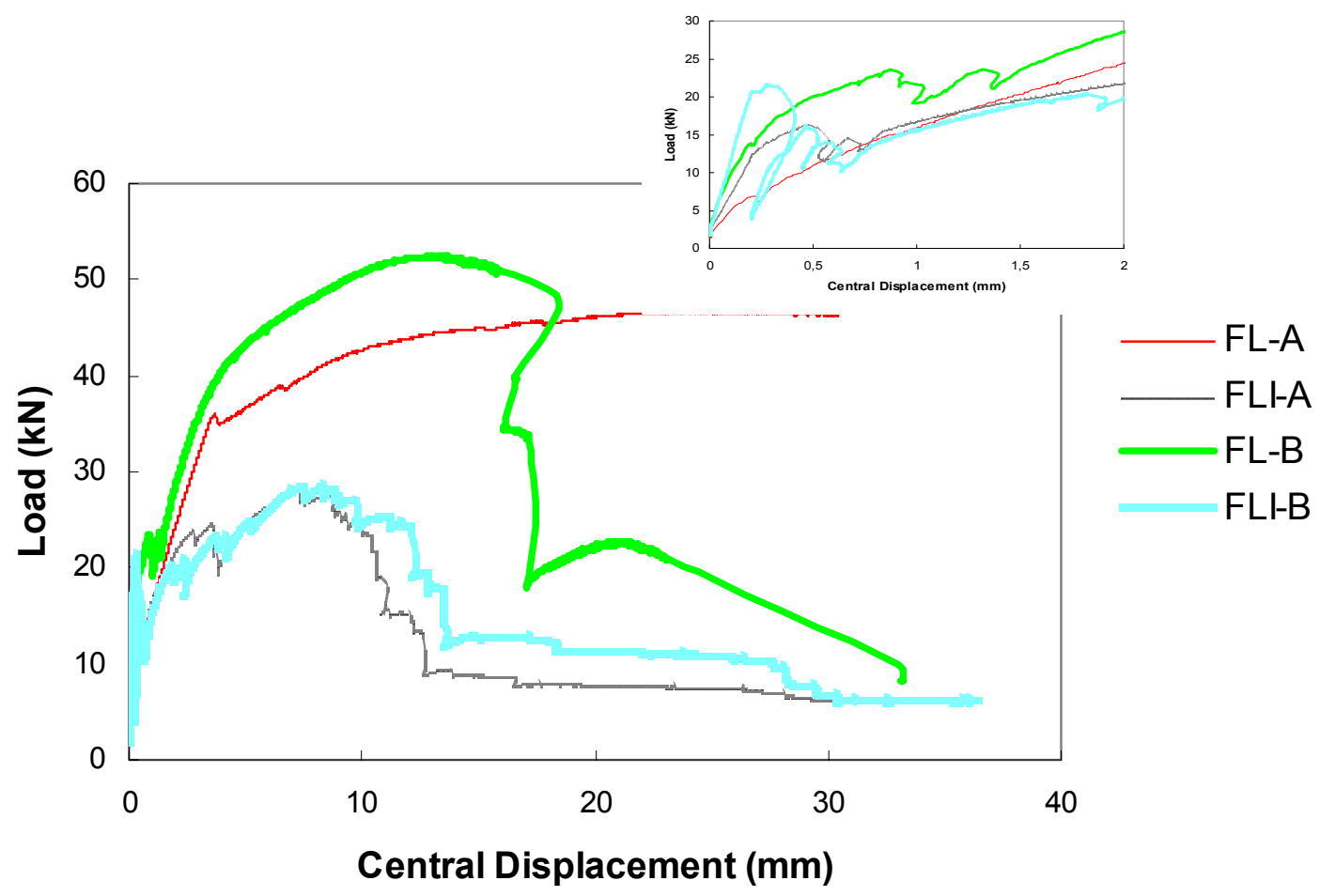

Figure 83 - Relationship between the average force of the mid span deflection of series FL- and FLI-.

Figure 84 represents the force-mid span relationship of series FL-A. The panels of this series showed very similar deformability behavior, but panel FL-4A attained a higher ultimate load. After a very short linear branch corresponding to uncracked state, a quasi-linear force-deflection relationship was observed for the cracked state, up to the beginning of the yielding of the tensile reinforcement. Due to the formation of several cracks (four to six) stress redistribution was occurred, leading to a maximum load ( $\left.\mathrm{F}_{\max }\right)$ 
greater than the load corresponding to the steel yielding initiation $\left(\mathrm{F}_{\mathrm{sy}}\right)$. The hardening type response observed in the uniaxial tensile tests with $\phi 6$ bar specimens has also contributed for this behavior (see annex 1). The larger load bearing capacity of panel FL-4A might be related to the fact that a higher number of cracks was occurred in this panel, and more cracks were actives (in crack opening process) beyond the deflection corresponding to $\mathrm{F}_{\mathrm{sy}}$.

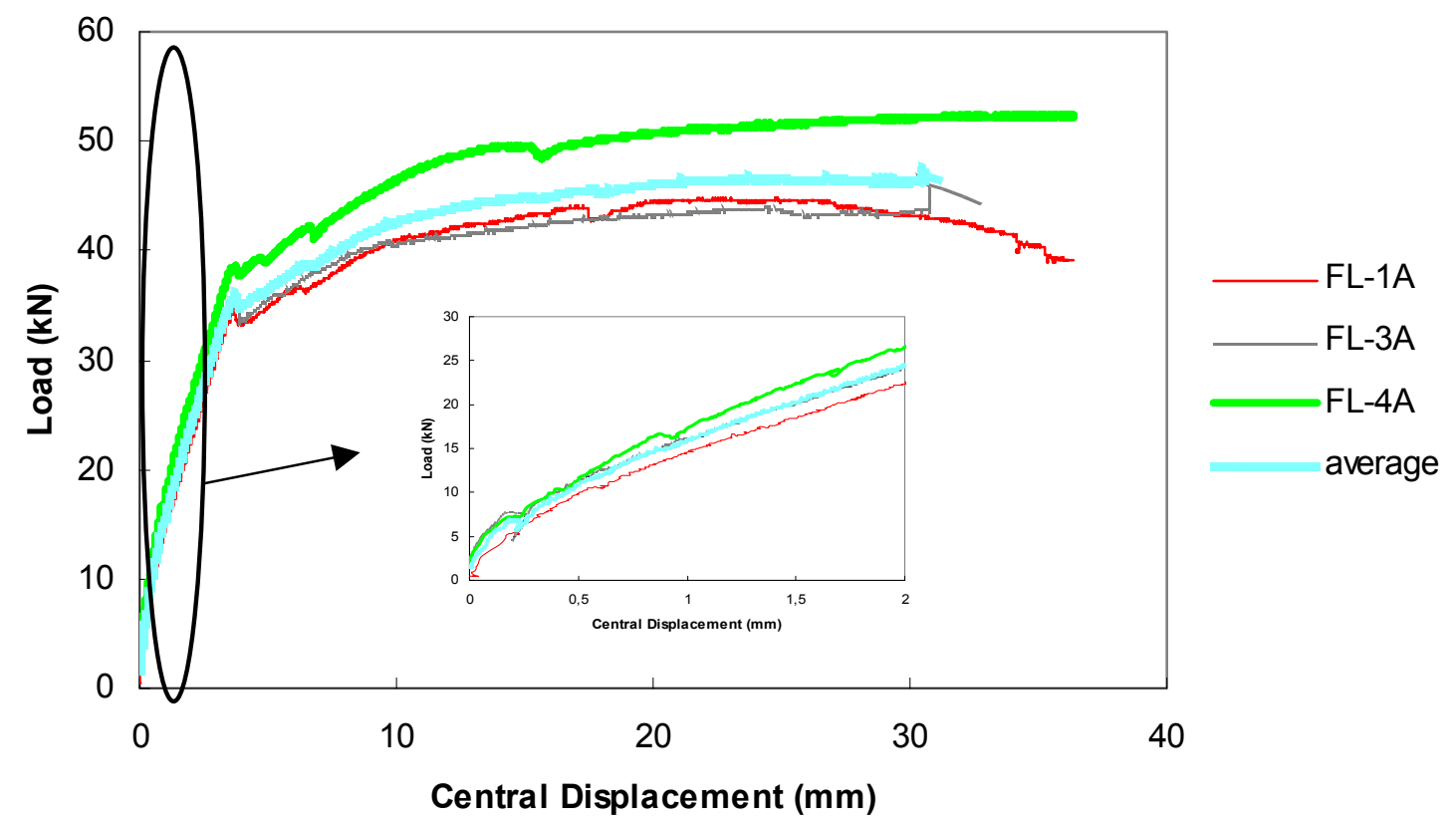

Figure 84 - Force-mid span deflection of series FL-A.

The relationship between the force and the panel mid span deflection of series FLI-A is depicted in Figure 85. In general, the behavior of the panels of this series is similar. However, up to a deflection of about $0.5 \mathrm{~mm}$ the stiffness of the panels FLI-1A and FLI-2A was lower than the stiffness observed in panels FLI-3A and FLI-4A, which might be related to the tensile strength of the concrete layer and to the position of the wire mesh. The wire mesh in panels FLI-3A and FLI-4A might have been at the middle surface of the concrete layer, giving a higher contribution for the tension stiffening effect. In panels FLI-1A and FLI-2A the wire mesh might have been positioned at brick-concrete layer interface. 


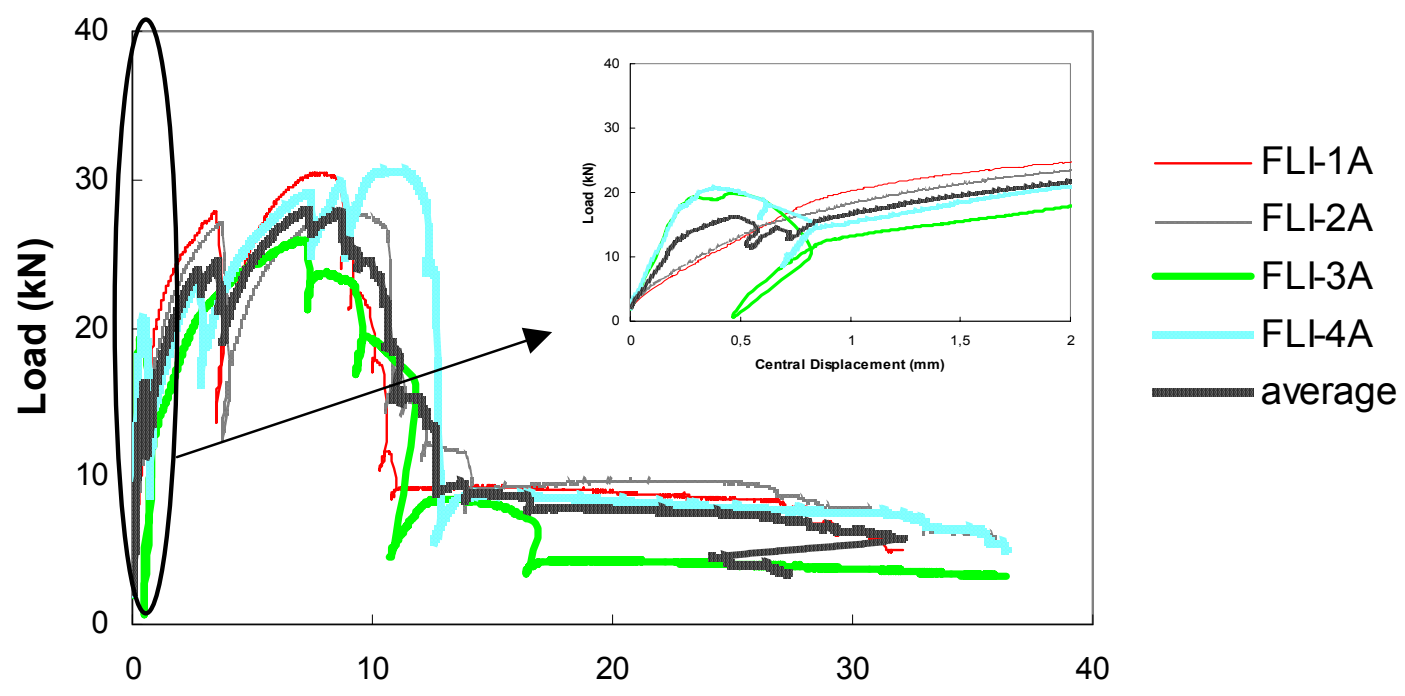

Central Displacement (mm)

Figure 85 - Force-mid span deflection of series FLI-A.

Figure 86 includes the force-mid span deflection relationship of series FL-B.

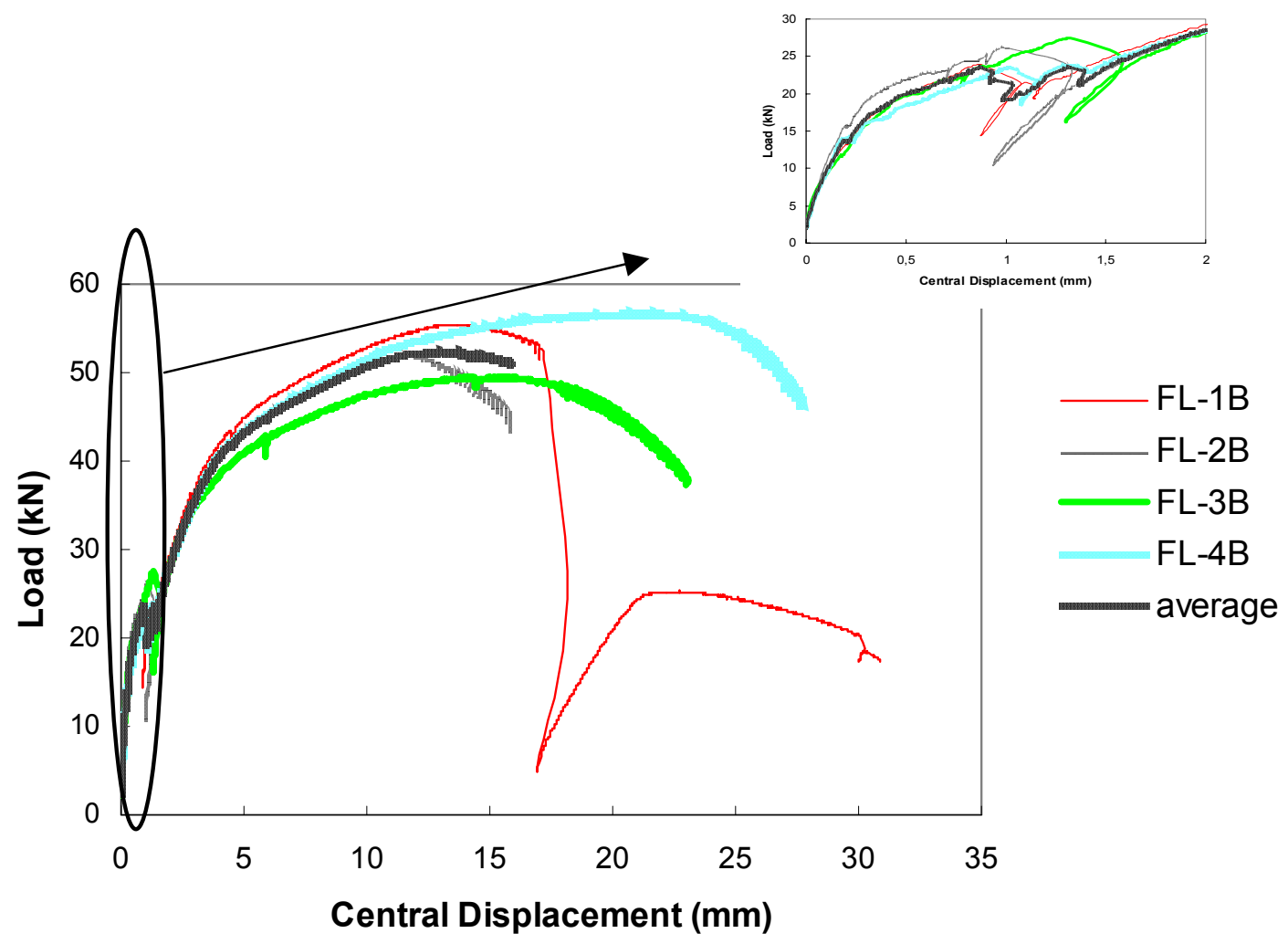

Figure 86 - Force-mid span deflection of series FLI-B. 
The panels of this series had very similar deformational behavior up to a deflection of about $3 \mathrm{~mm}$, when a considerable loss of stiffness occurred, due to yield initiation of the longitudinal reinforcement. After this deflection the stiffness and the load bearing capacity of panel FL-3B was less than of the remaining panels, maybe due to the larger number of cracks formed in this panel.

The force-mid span deflection relationship of series FLI-B is represented in Figure 87. Up to a load of about $20 \mathrm{kN}$ the panels have showed a quasi-elastic response. After the deflection corresponding to this load, a decay on the load occurred due to the formation of macro-cracks. Than, the wire mesh was activated, resulting an increment in the panel load bearing capacity up to the moment when wires of the mesh have ruptured. The structural softening occurred for a mid span deflection of about $10 \mathrm{~mm}$.

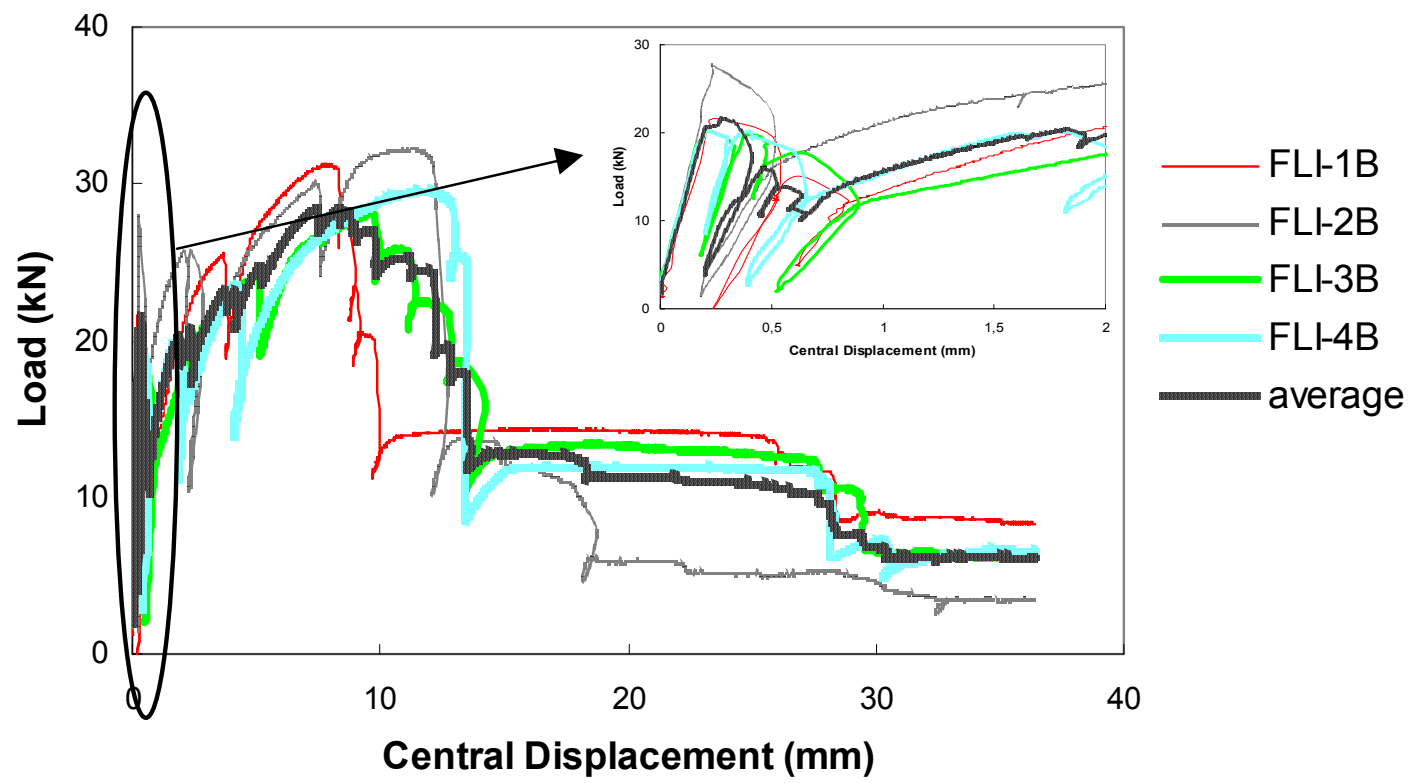

Figure 87 - Force-mid span deflection of series FLI-B.

Figure 88 represents the force-mid span deflection relationship of series FLC-A and FLC-B. The only difference between these series and the corresponding FL-A and FL-B series was the distance between the line loads, which was increased in the former series in order to, eventually, induce shear failure. The shear span of series FLC was about $175 / 75 \cong 2.3$. In concrete elements with this shear span value and without shear reinforcement, shear failure would be expected. However, only panel FLC-1B failed by 
shear, resulting in a brittle failure mode and inferior load bearing capacity. The remaining panels failed by bending, showing a very ductile behavior. As panels of series FLC-B had three longitudinal concrete ribs while series FLC-A had only two, the stiffness of series FLC-B was larger. Series FLC- had larger load bearing capacity than series FL-.

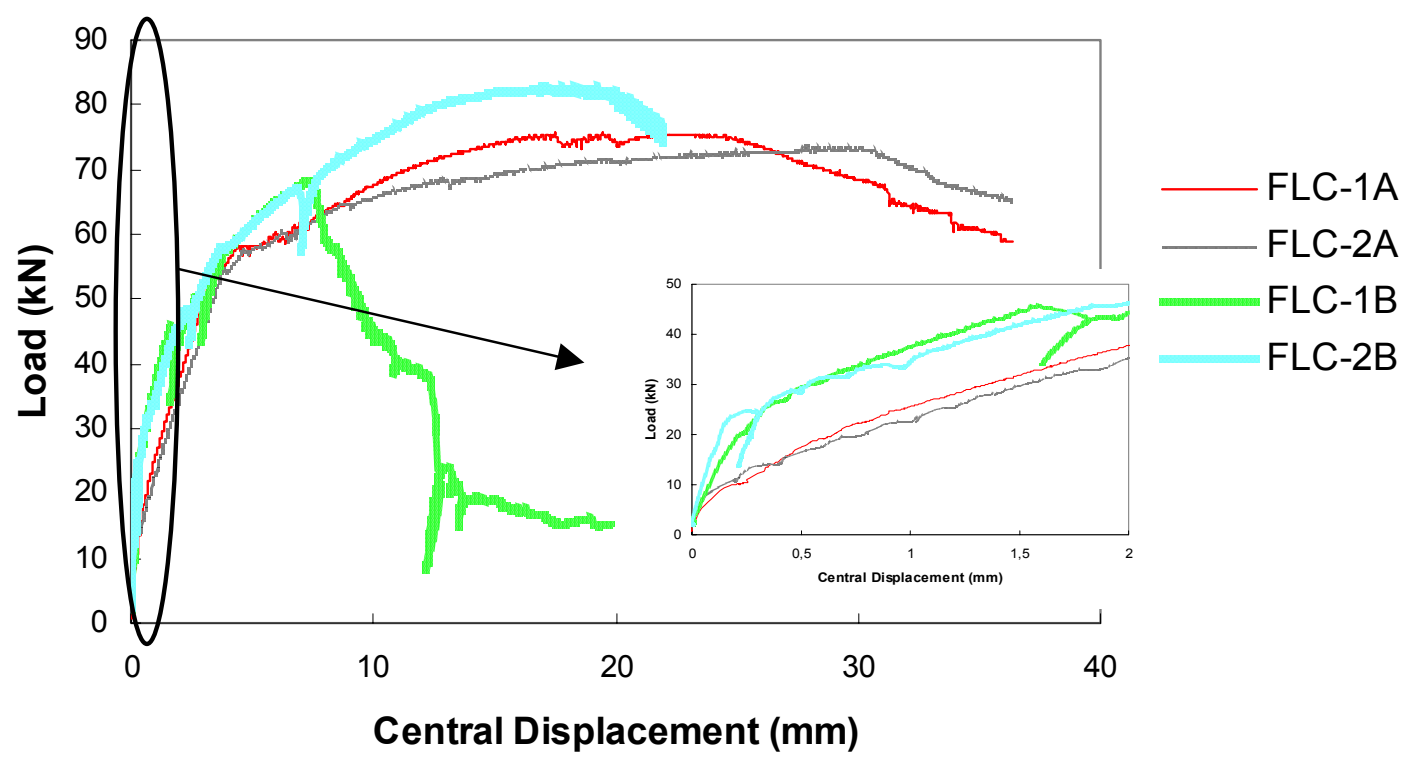

Figure 88 - Force-mid span deflection of series FLC.

The relationships between the average force and the displacement at LVDTs number 2, 3, 4 and 5 are depicted in Annex 2.

Table 5.1 includes some data registered in the panels tested, where $\mathrm{F}_{\max }$ is the maximum force and $\delta_{1, \mathrm{Fmax}}, \delta_{2, \mathrm{Fmax}}, \delta_{3, \mathrm{Fmax}}, \delta_{4, \mathrm{Fmax}}, \delta_{5, \mathrm{Fmax}}$ are the deflection at $\mathrm{F}_{\max }$ registered in LVDT1, LVDT2, LVDT3, LVDT4 and LVDT5, respectively. 
Table 5.1 - Results in the panels tested.

\begin{tabular}{|c|c|c|c|c|c|c|}
\hline Specimens & $\begin{array}{l}\mathbf{F}_{\max } \\
(\mathbf{k N})\end{array}$ & $\begin{array}{l}\delta_{1, \mathrm{Fmax}} \\
(\mathbf{m m})\end{array}$ & $\begin{array}{l}\delta_{2, \mathrm{Fmax}} \\
(\mathbf{m m})\end{array}$ & $\begin{array}{l}\delta_{3, F \max } \\
(\mathbf{m m})\end{array}$ & $\begin{array}{l}\delta_{4, F \max } \\
(\mathbf{m m})\end{array}$ & $\begin{array}{l}\delta_{5, \mathrm{Fmax}} \\
(\mathbf{m m})\end{array}$ \\
\hline FL-1A & 44.58 & 25.05 & 19.99 & 14.19 & 3.87 & 3.59 \\
\hline FL-2A & - & - & - & - & - & - \\
\hline FL-3A & 45.25 & 30.74 & 20.77 & 22.65 & 5.04 & 3.80 \\
\hline FL-4A & 52.31 & 36.40 & 9.29 & 25.38 & 4.55 & 4.67 \\
\hline Average & 47.38 & 30.73 & 16.68 & 20.74 & 4.49 & 4.02 \\
\hline FL-1B & 55.30 & 13.94 & 9.02 & 9.13 & 3.12 & 3.37 \\
\hline FL-2B & 51.91 & 11.63 & 7.62 & 7.37 & 2.48 & 2.62 \\
\hline FL-3B & 49.38 & 16.14 & 10.30 & 9.76 & 2.55 & 3.46 \\
\hline FL-4B & 56.68 & 21.86 & 14.53 & 12.74 & 4.83 & 4.56 \\
\hline Average & 53.32 & 15.89 & 10.37 & 9.75 & 3.25 & 3.50 \\
\hline FLI-1A & 30.44 & 8.31 & 4.24 & 6.93 & 0.96 & 0.93 \\
\hline FLI-2A & 27.79 & 9.76 & 6.97 & 7.09 & 2.05 & 1.18 \\
\hline FLI-3A & 28.10 & 9.77 & 5.27 & 6.54 & 2.21 & 1.81 \\
\hline FLI-4A & 30.60 & 11.20 & 6.85 & 8.55 & 1.32 & 1.30 \\
\hline Average & 29.23 & 9.76 & 5.83 & 7.28 & 1.64 & 1.31 \\
\hline FLI-1B & 31.00 & 8.30 & 6.13 & 5.40 & 1.38 & 2.04 \\
\hline FLI-2B & 32.18 & 11.25 & 9.29 & 7.32 & 1.61 & 2.94 \\
\hline FLI-3B & 28.10 & 9.77 & 5.27 & 6.54 & 2.21 & 1.81 \\
\hline FLI-4B & 29.42 & 12.20 & 9.13 & 7.55 & 2.20 & 3.15 \\
\hline Average & 30.18 & 10.38 & 7.46 & 6.70 & 1.85 & 2.49 \\
\hline FLC-1A & 75.40 & 21.50 & 12.75 & 19.87 & 4.83 & 3.20 \\
\hline FLC-2A & 73.17 & 30.65 & 24.39 & 22.46 & 4.90 & 4.22 \\
\hline FLC-1B & 67.23 & 7.43 & 7.40 & 5.57 & 2.13 & 2.88 \\
\hline FLC-2B & 82.17 & 17.65 & 14.32 & 15.85 & 4.93 & 4.59 \\
\hline Average & - & - & - & - & - & - \\
\hline
\end{tabular}

\section{Acknowledgements}

The study presented in this report makes part of the research program "Industrialised Solutions for Construction of Masonry Shell Roofs" supported by ISO-BRICK project. 
The cement was generously supplied by SECIL - Companhia Geral de Cal e Cimento, S.A, the gravel by stone-quarry "Pedreira Bezerras" and the superplasticizer by Bettor MBT Portugal Produtos Químicos para Construção S.A. Special thanks for Portuguese Science and Technology Foundation (FCT) to support the first author.

\section{Bibliography}

Barros, J.A.O., Comportamento do betão reforçado com fibras - análise experimental e simulação numérica, PhD Thesis, Civil Eng. Dept., Faculty of Engineering, University of Porto, Portugal, 1995 (in Portuguese).

CEB-FIP Model Code 1990 Comite Euro-International du Beton, Bulletin d'Information n ${ }^{\circ}$ 213/214, Ed. Thomas Telford, 1993.

EN 10 002-1 - Tensile Testing, 1990, Part 1: method of test

EN 1052-2, European Norm to Methods of test for masonry - Part 2: Determination of flexural strength, 2000.

RILEM TC 50-FMC, "Determination of fracture energy of mortar and concrete by means of three-point bend tests on notched beams", Materials and Structures, 18(106), 285-290, 1985. 


\section{ANNEX 1}




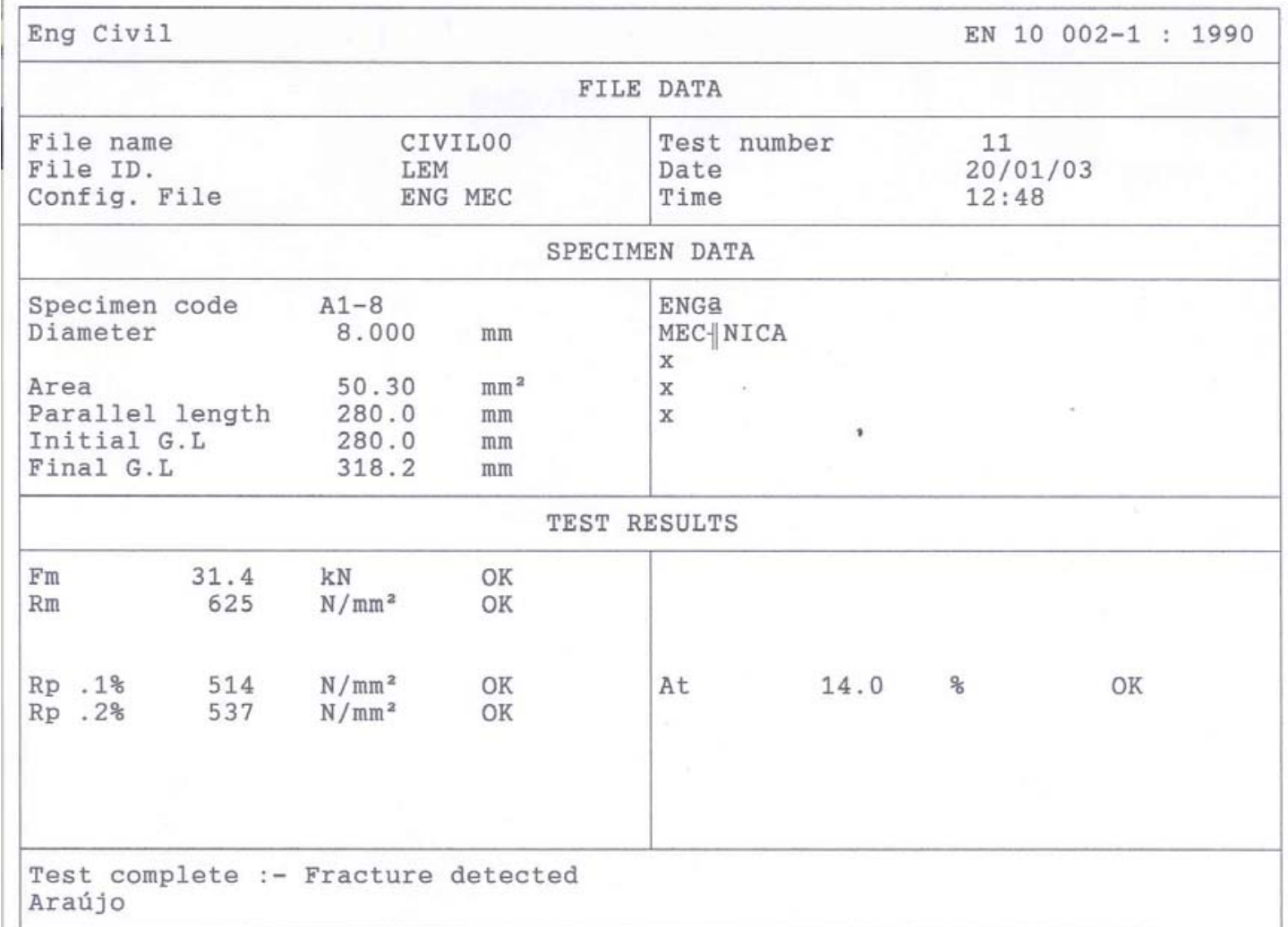

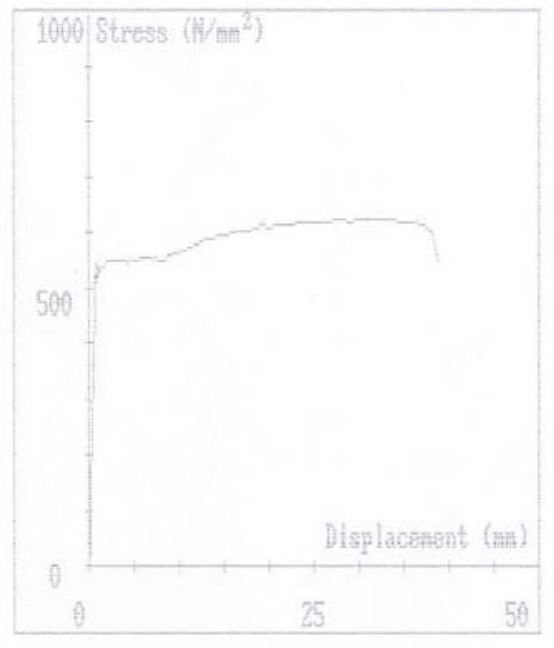

Figure 89 - Test of bar diameter $8 \mathrm{~mm}$. 


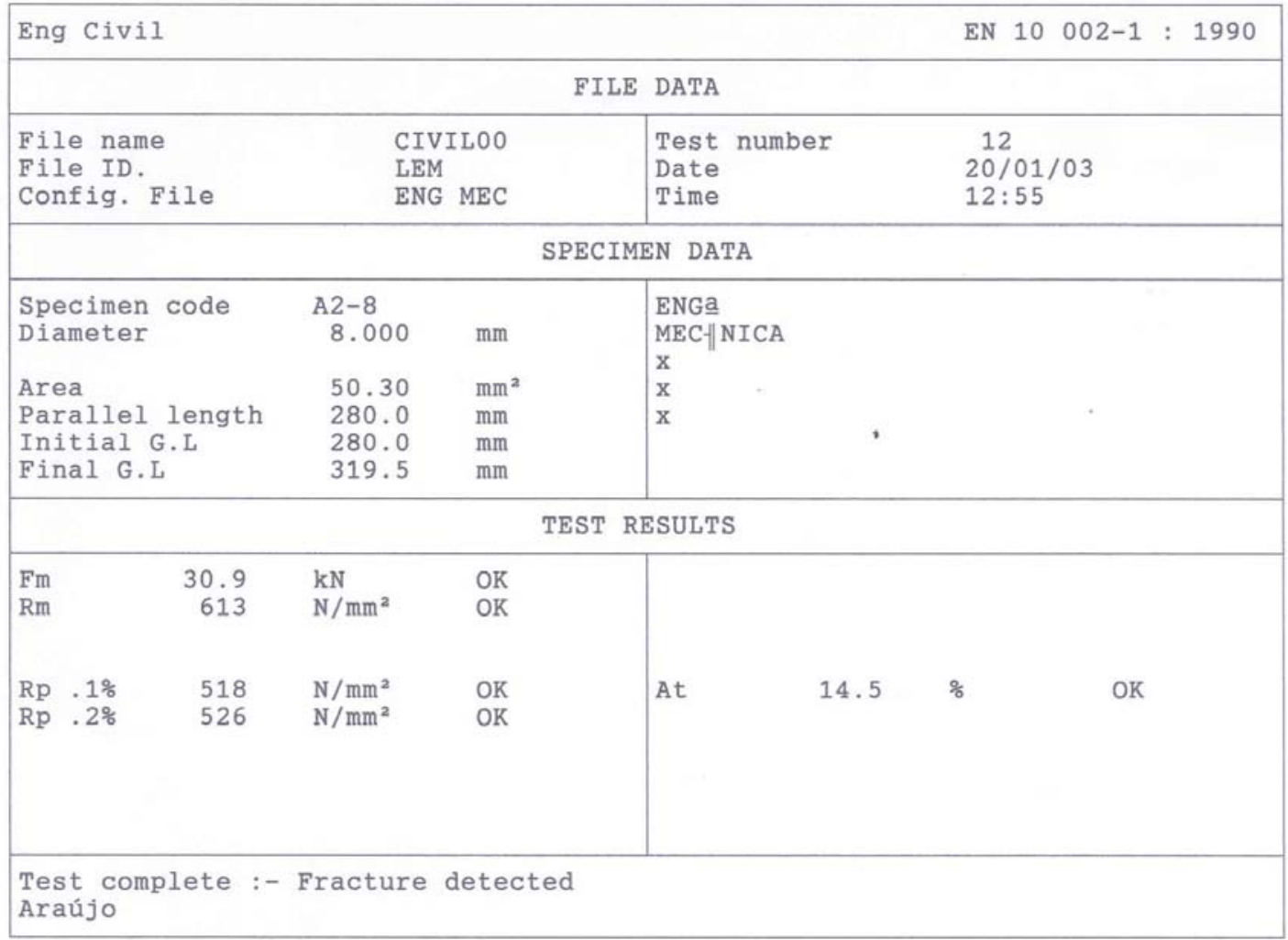

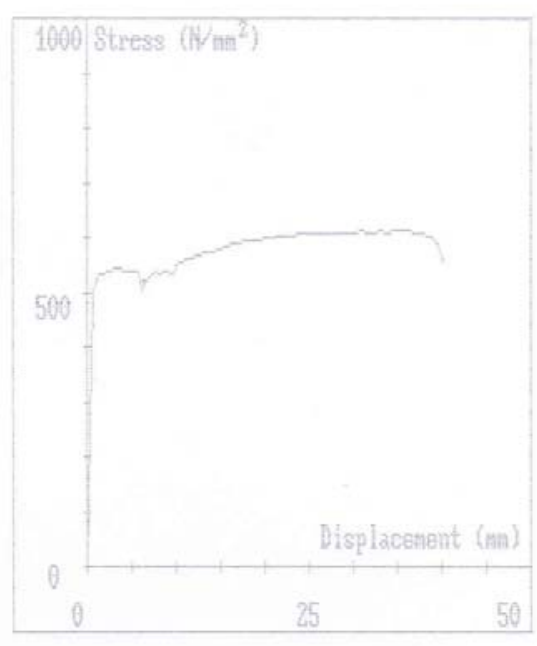

Figure 90 - Test of bar diameter $8 \mathrm{~mm}$. 


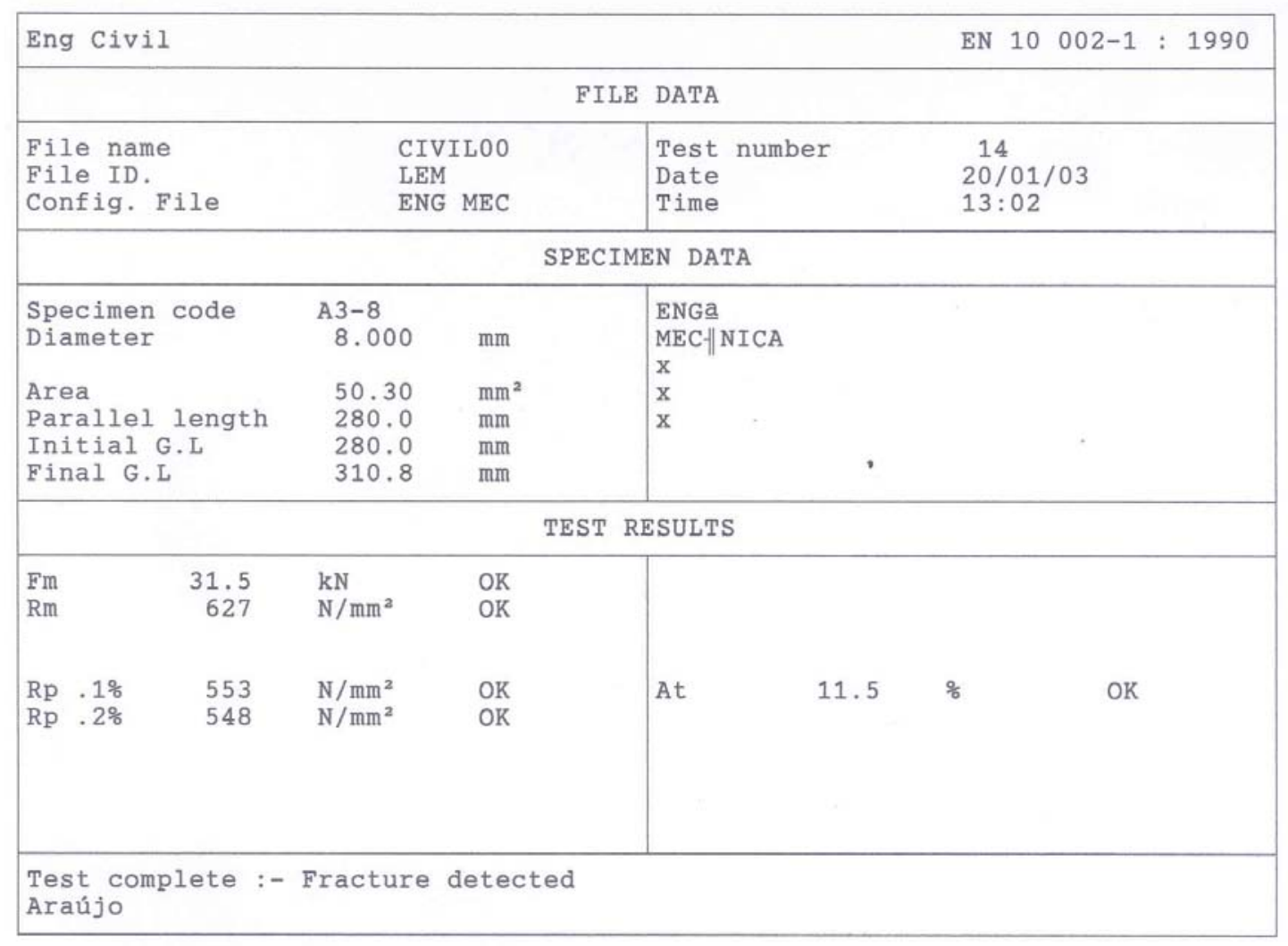

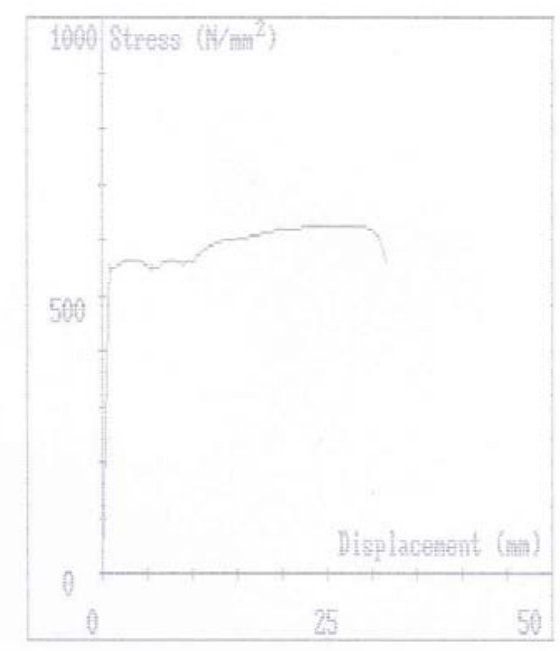

Figure 91 - Test of bar diameter $8 \mathrm{~mm}$. 


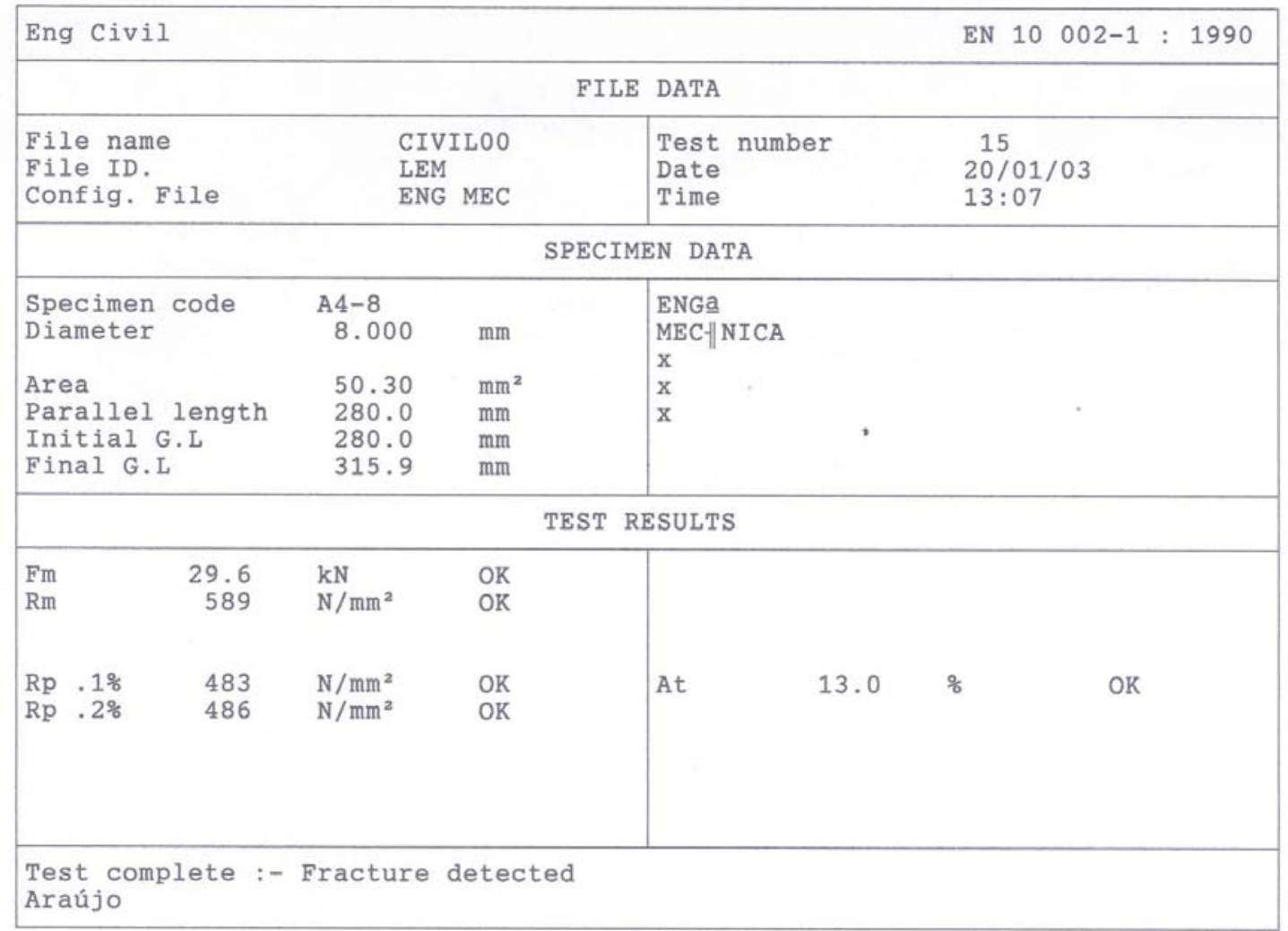

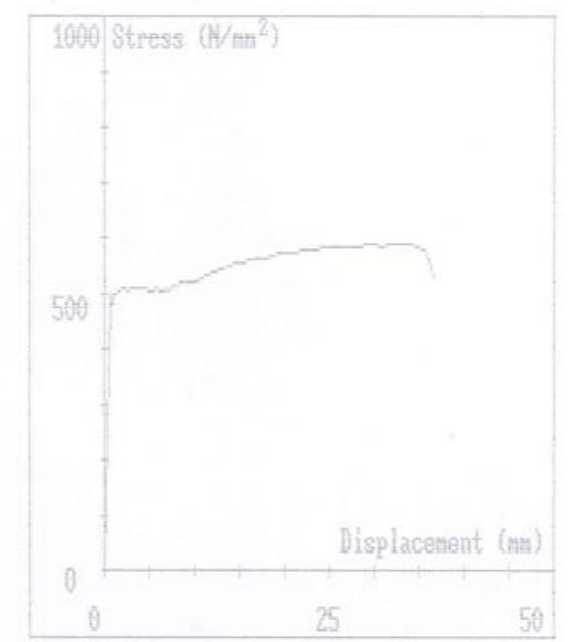

Figure 92 - Test of bar diameter $8 \mathrm{~mm}$. 


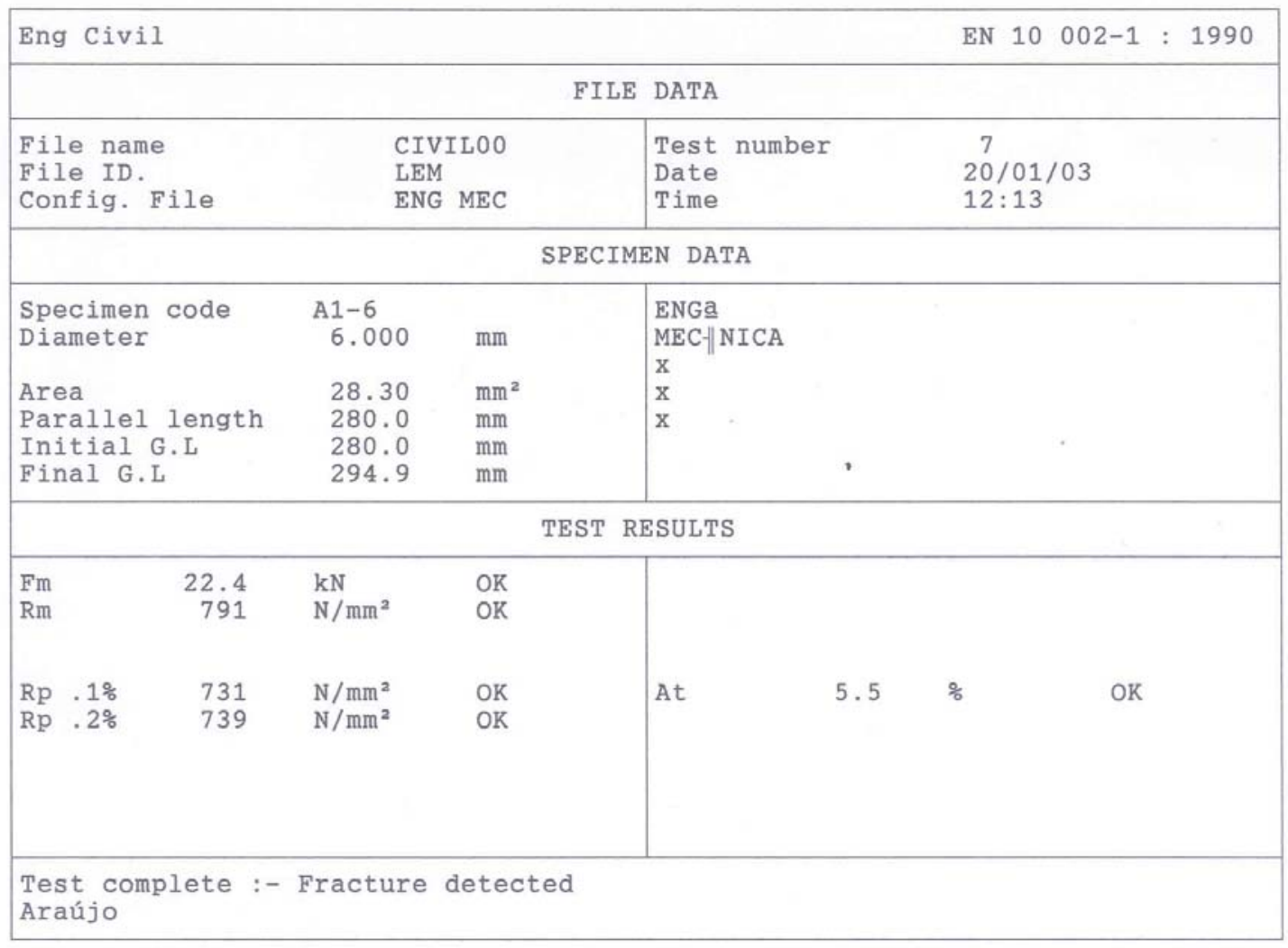

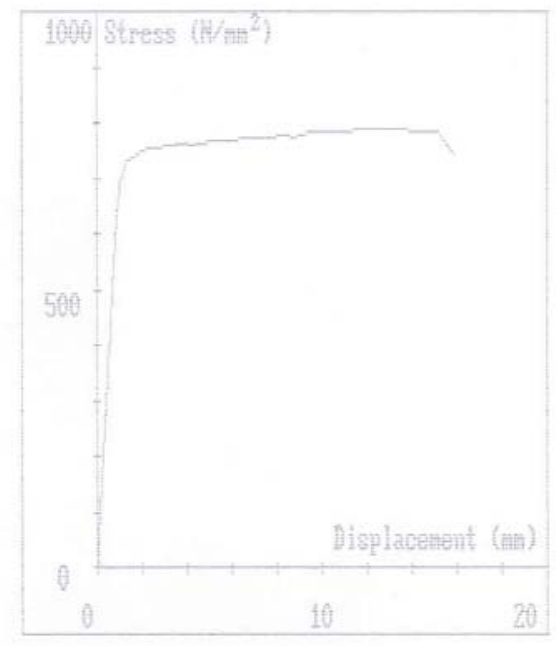

Figure 93 - Test of bar diameter $6 \mathrm{~mm}$. 


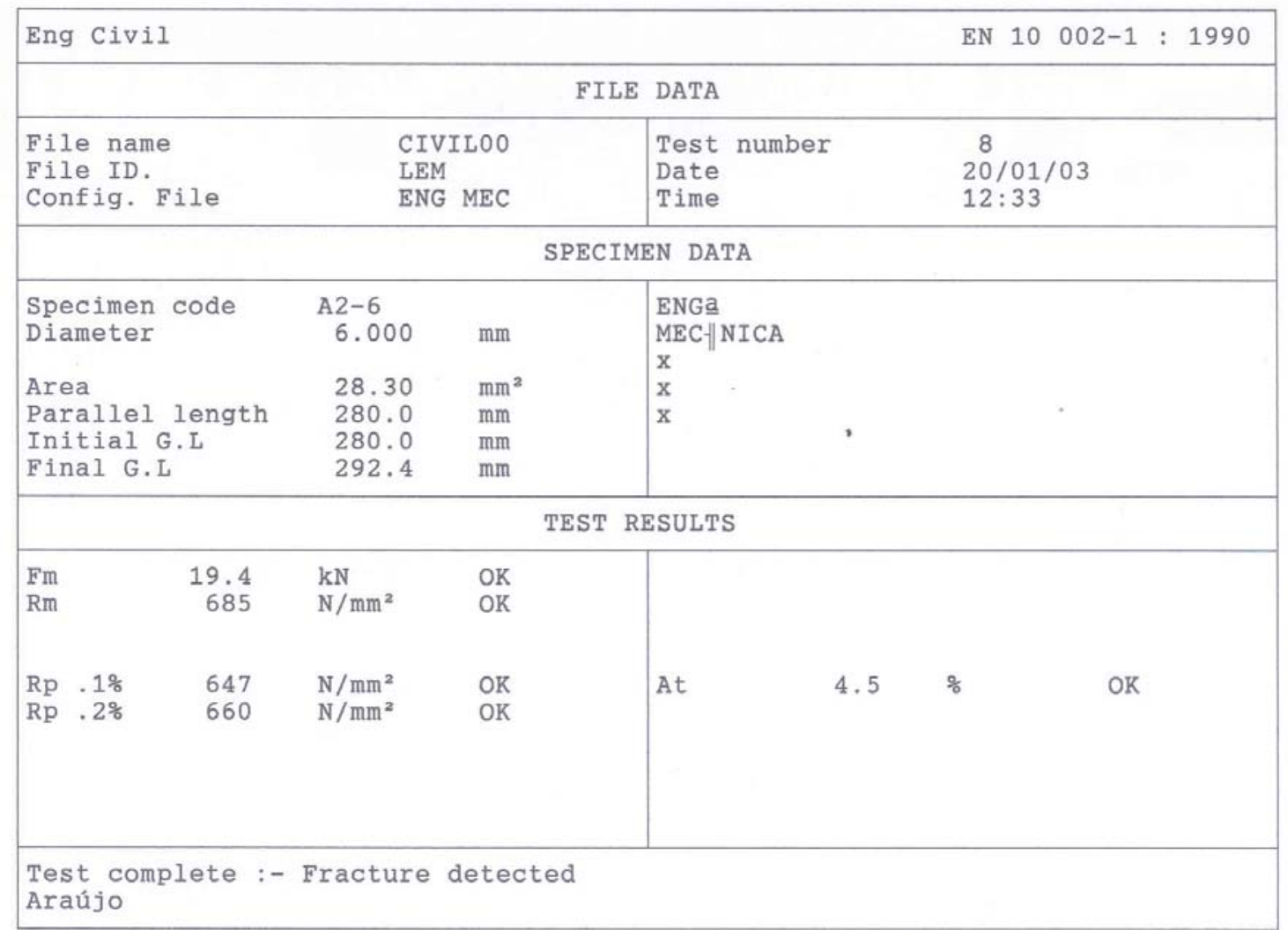

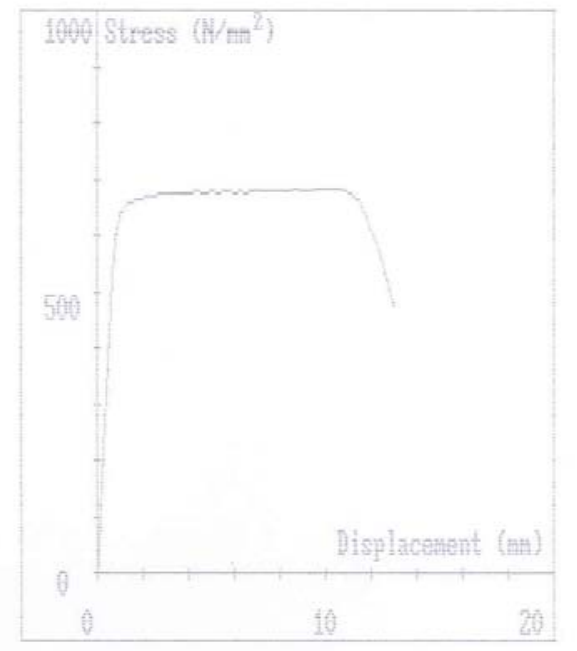

Figure 94 - Test of bar diameter $6 \mathrm{~mm}$. 


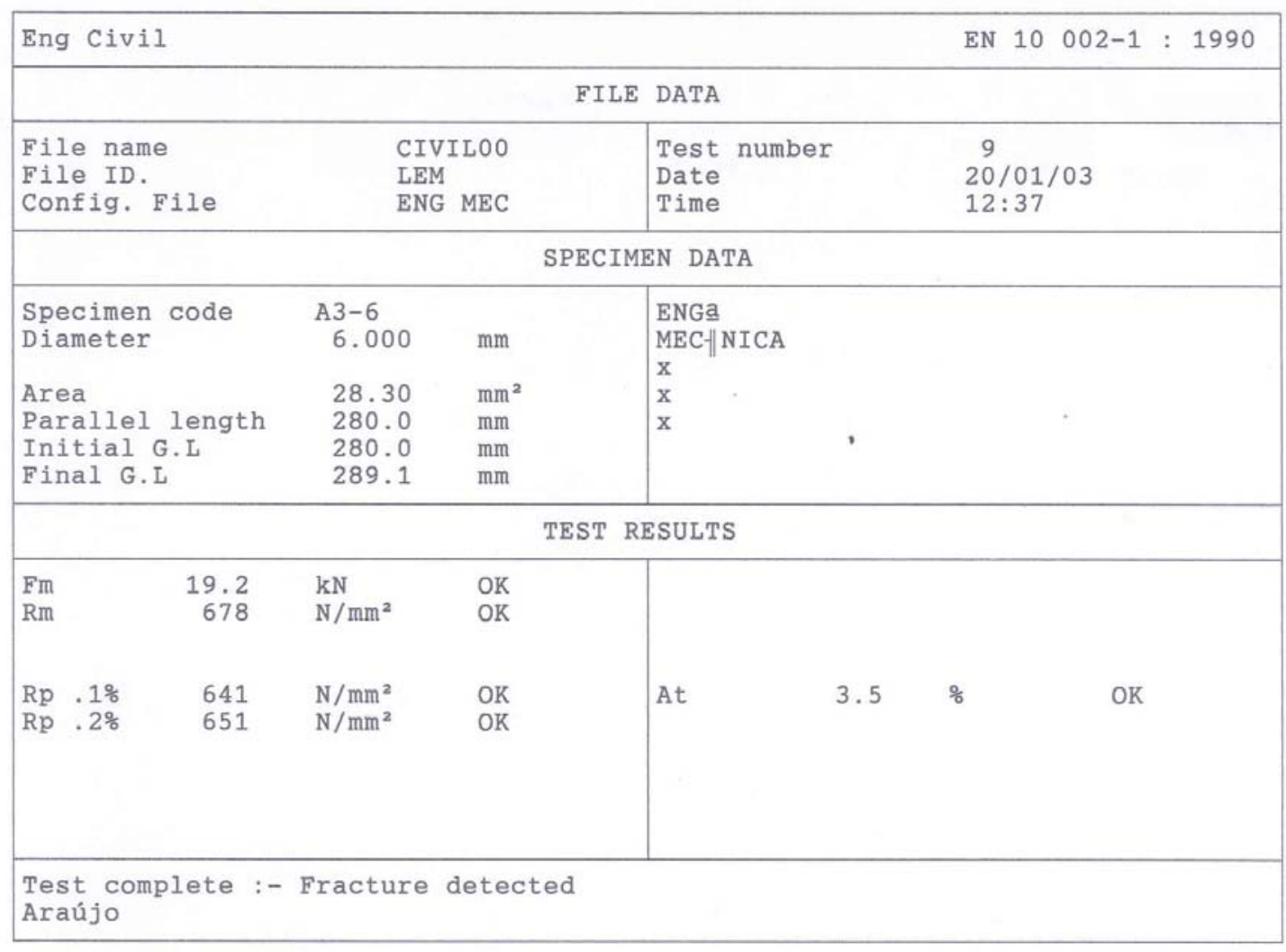

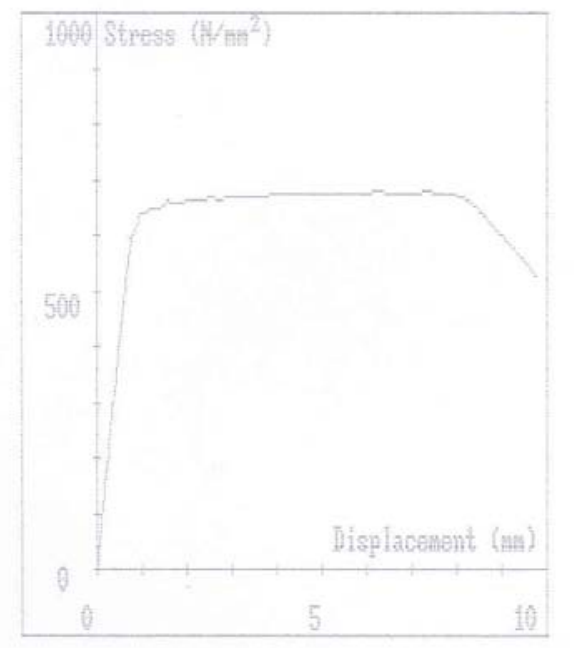

Figure 95 - Test of bar diameter $6 \mathrm{~mm}$. 


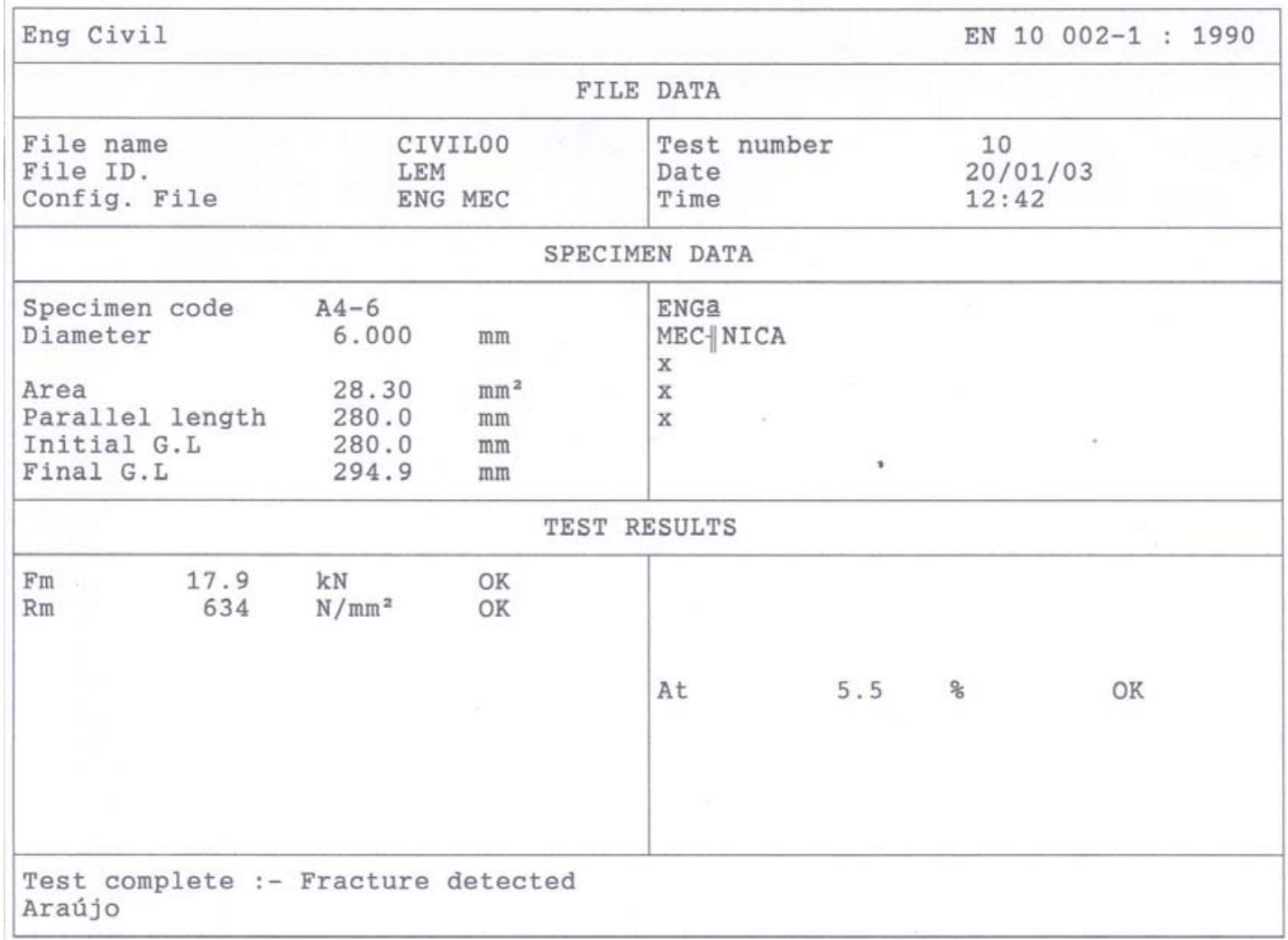

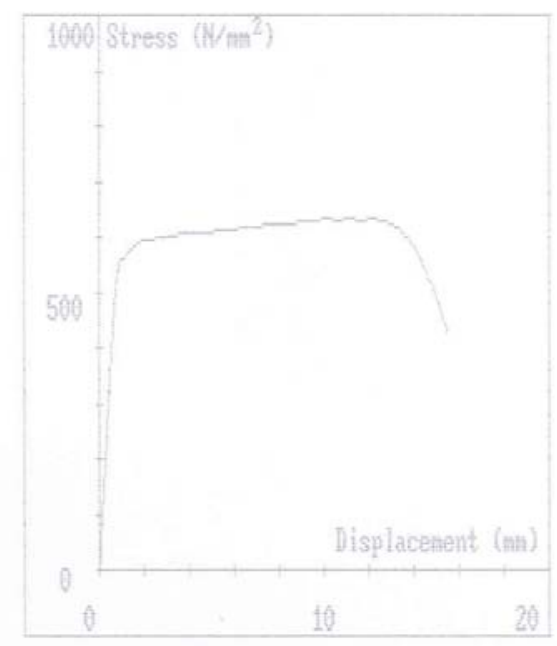

Figure 96 - Test of bar diameter $6 \mathrm{~mm}$. 


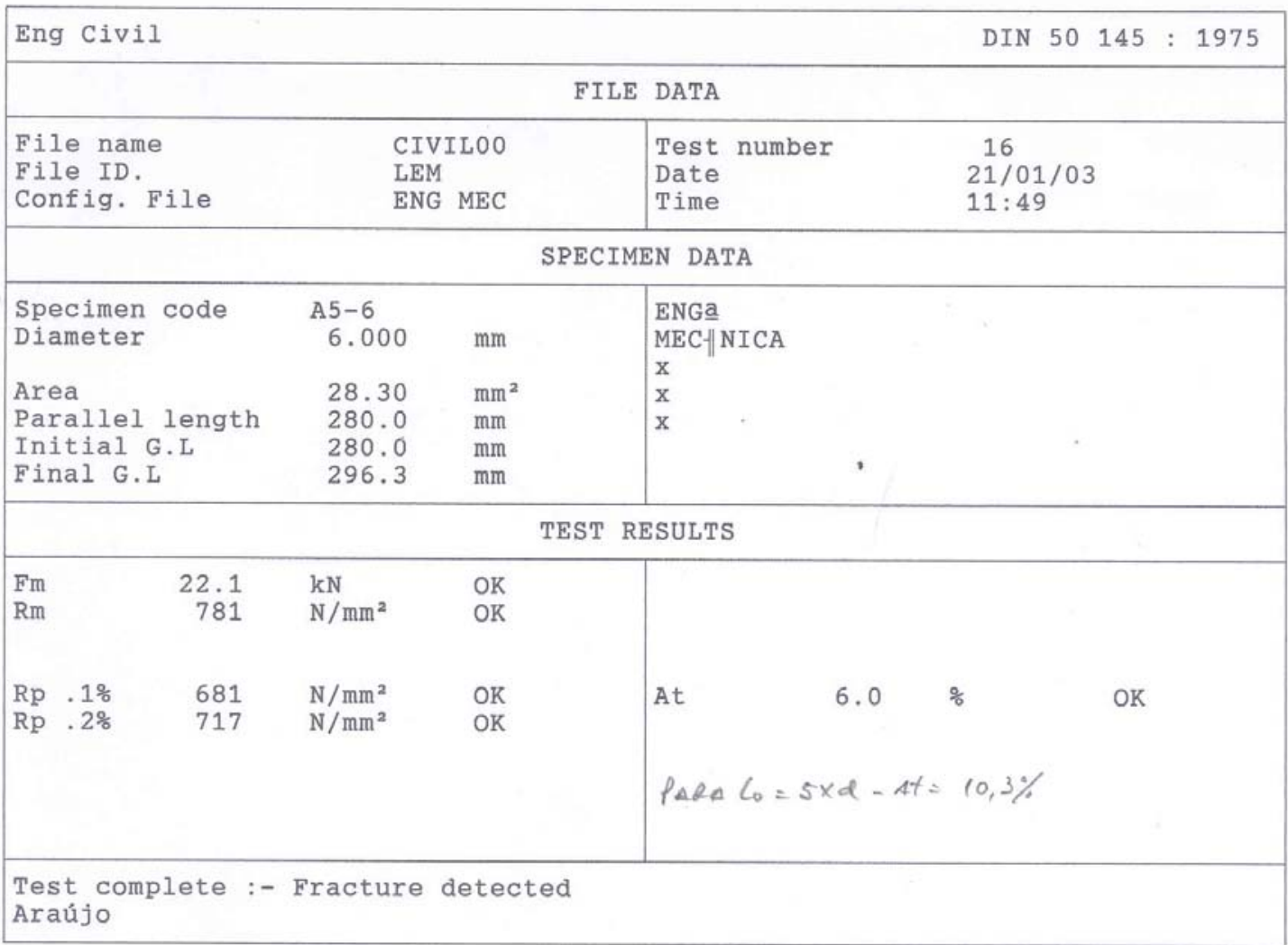

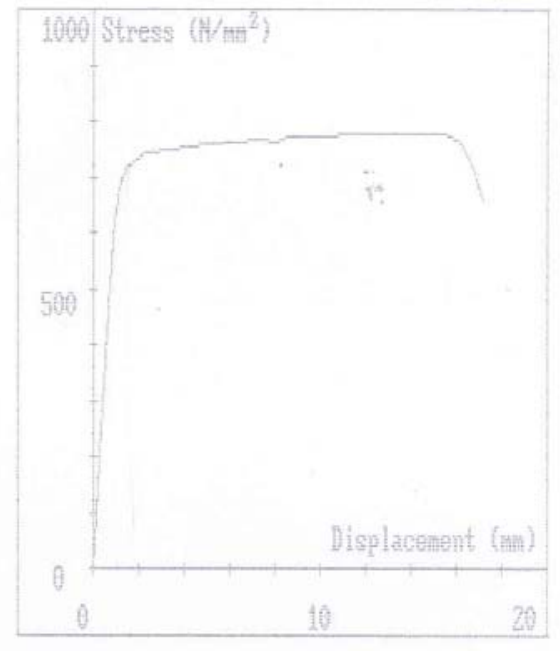

Figure 97 - Test of bar diameter $6 \mathrm{~mm}$. 


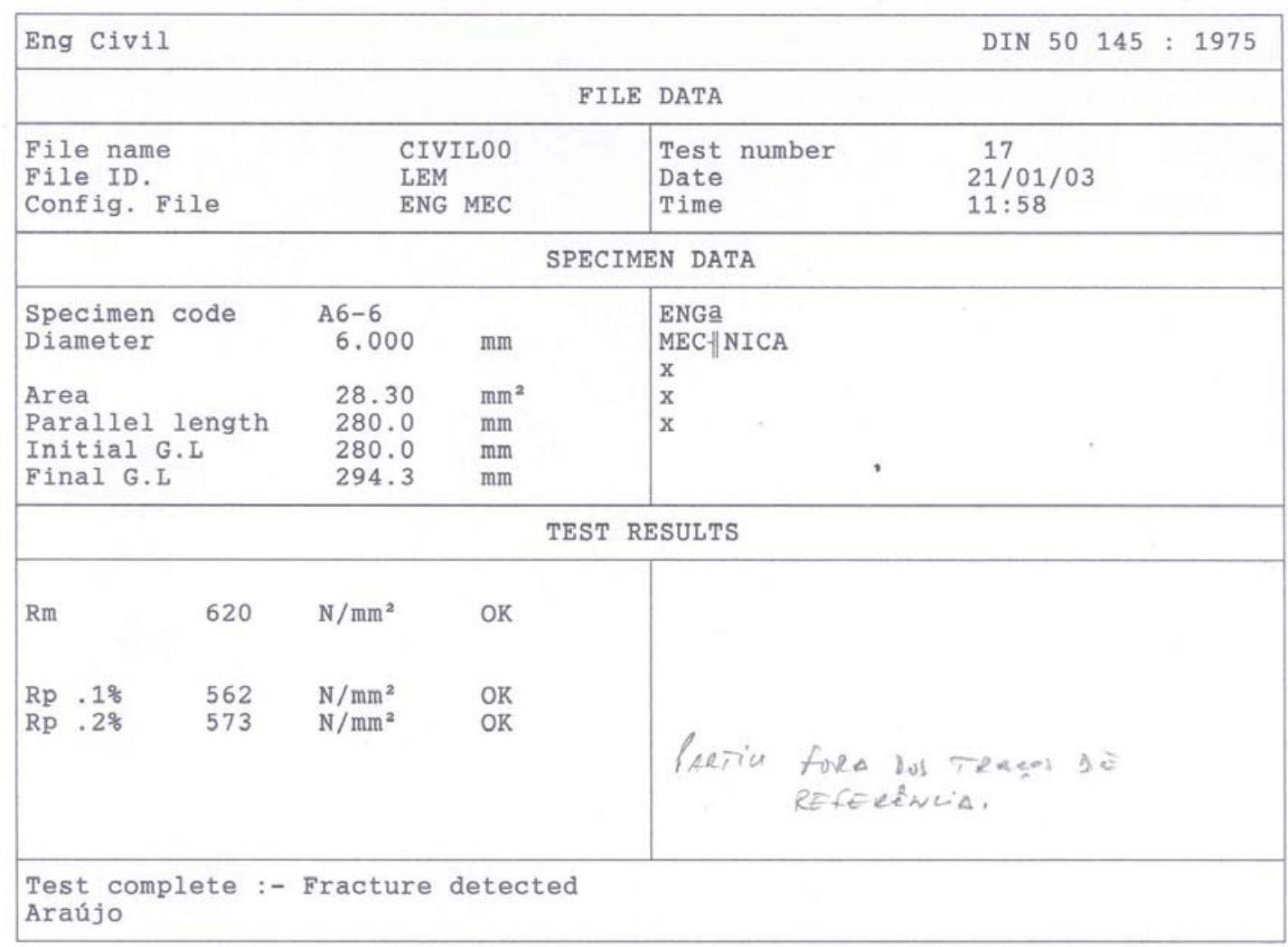

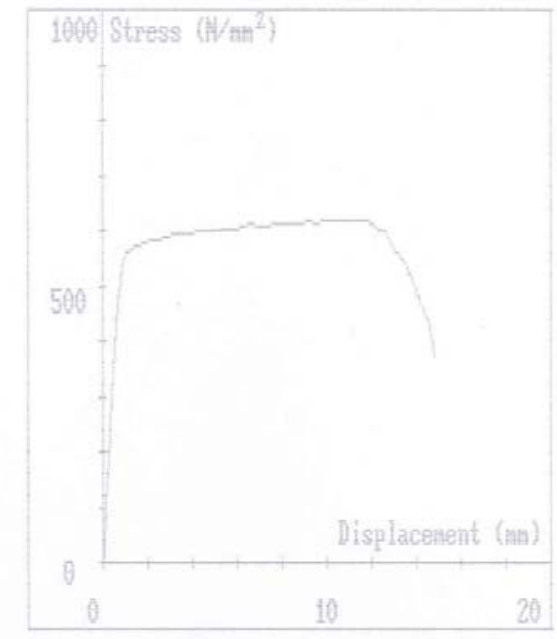

Figure 98 - Test of bar diameter $6 \mathrm{~mm}$. 


\section{ANNEX 2}




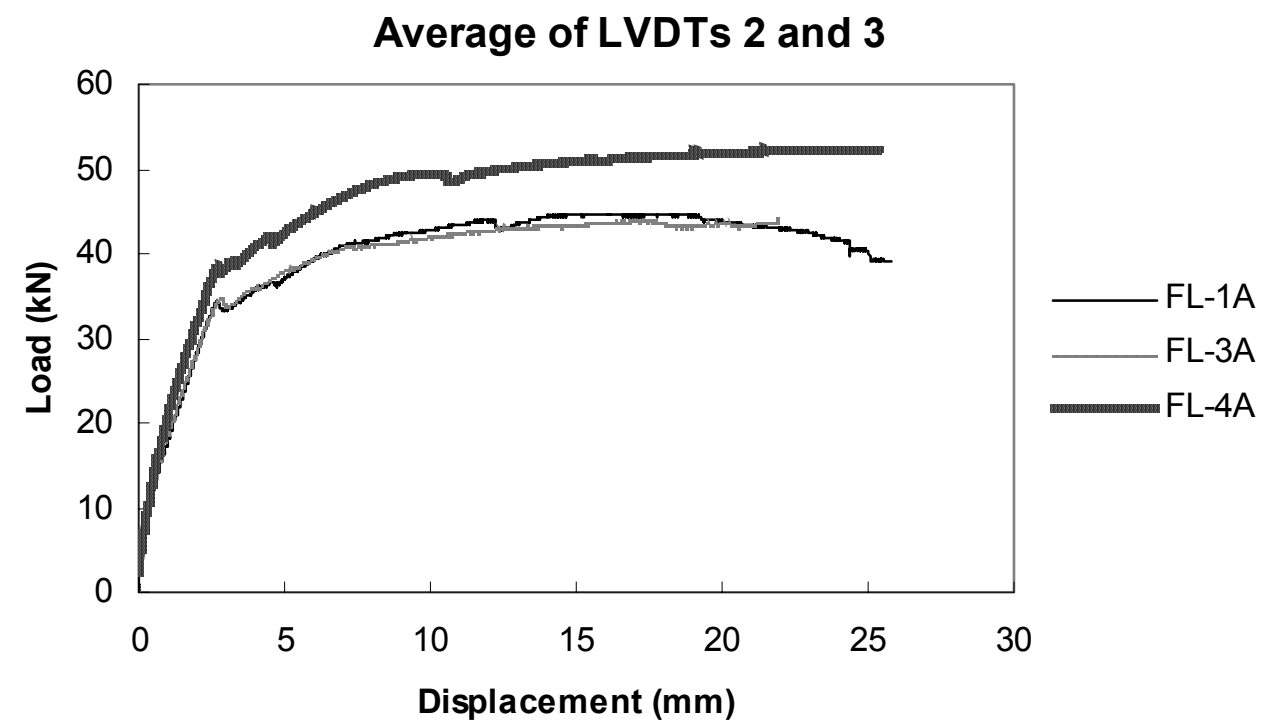

Figure 99 - Curves of displacements (average LVDT 2 and 3) $\times$ load - series FL-A.

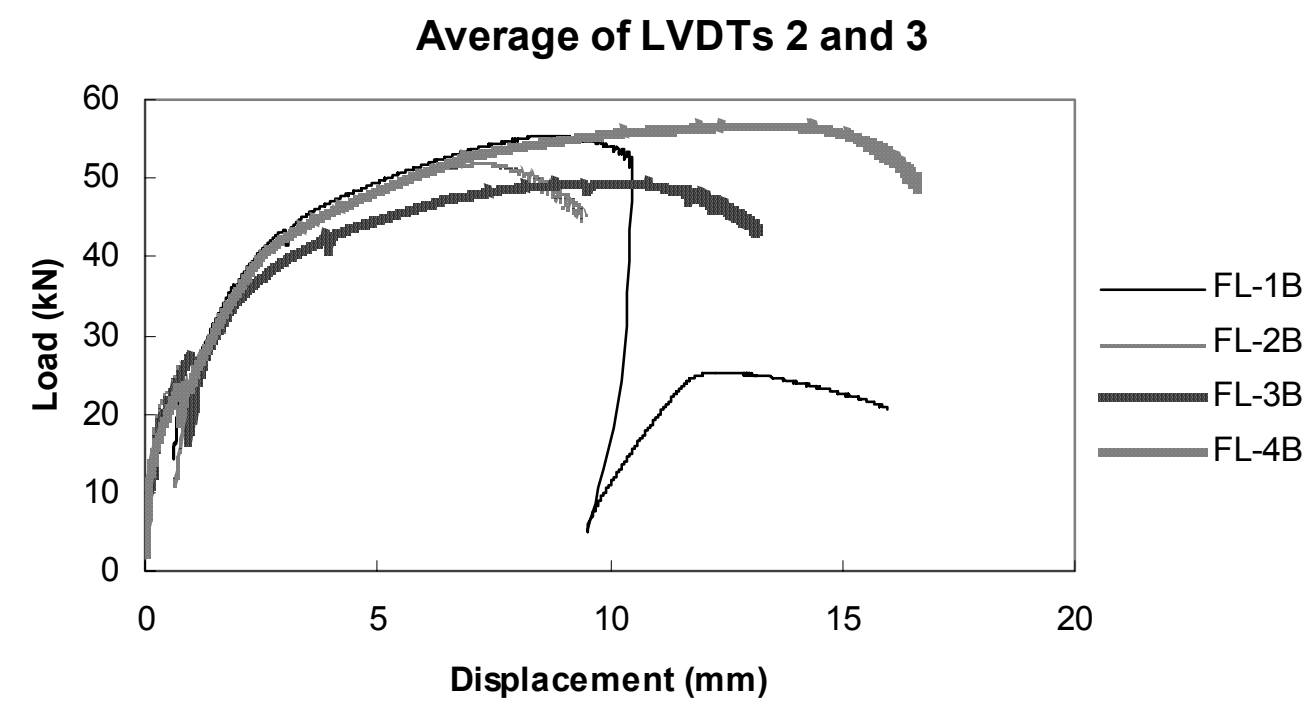

Figure 100 - Curves of displacements (average LVDT 2 and 3) $\times$ load - series FL-B. 


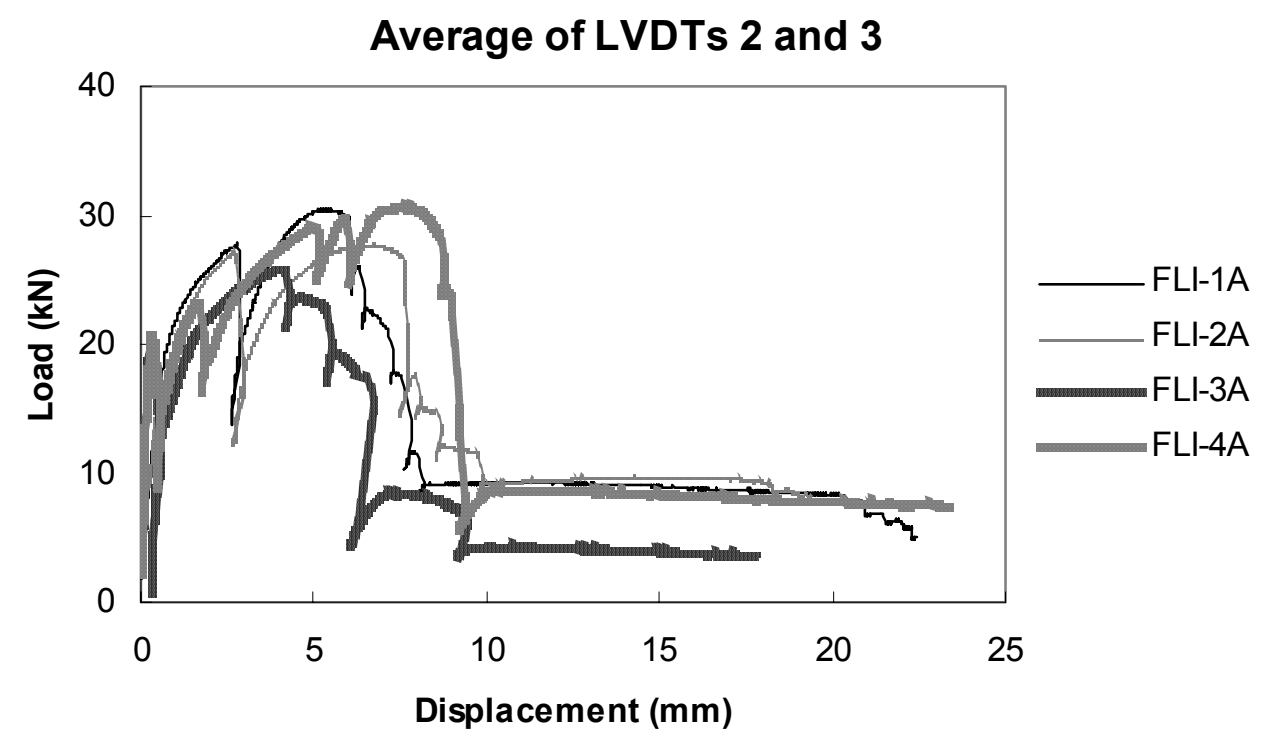

Figure 101 - Curves of displacements (average LVDT 2 and 3) $\times$ load - series FLI-A.

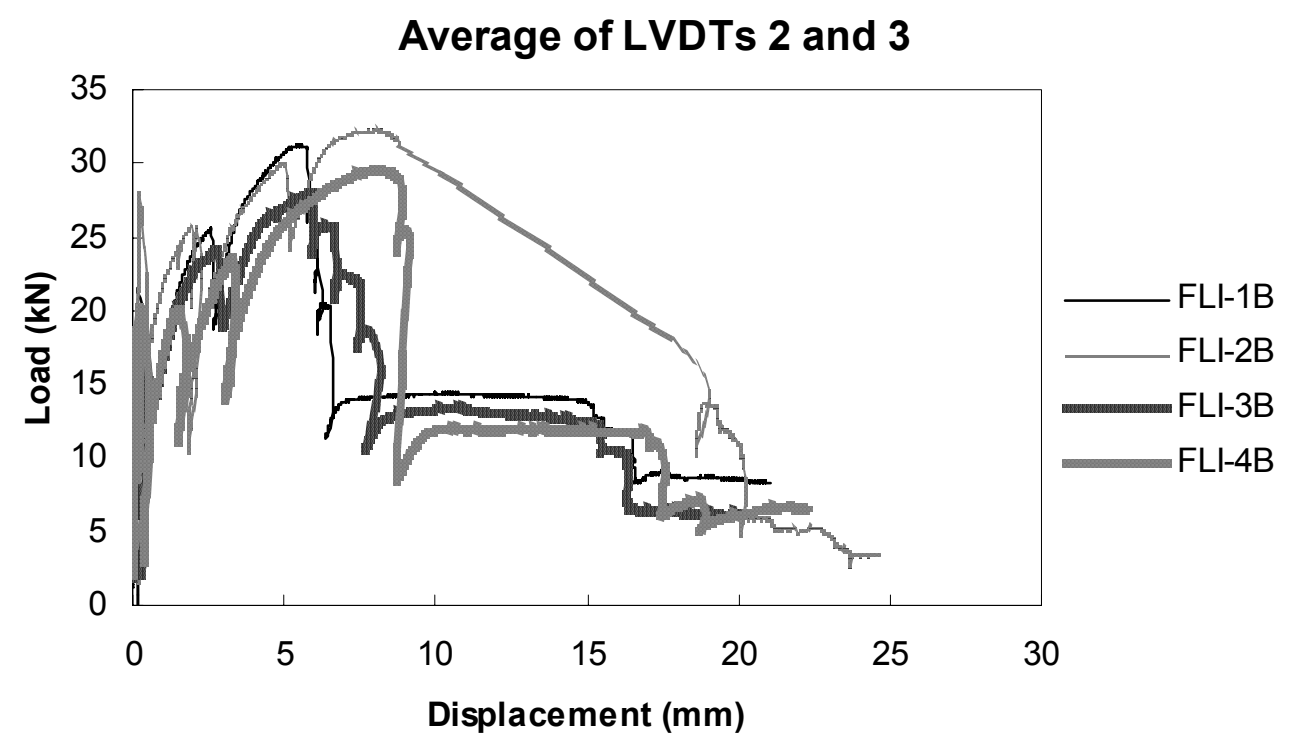

Figure 102 - Curves of displacements (average LVDT 2 and 3) $\times$ load - series FLI-B. 


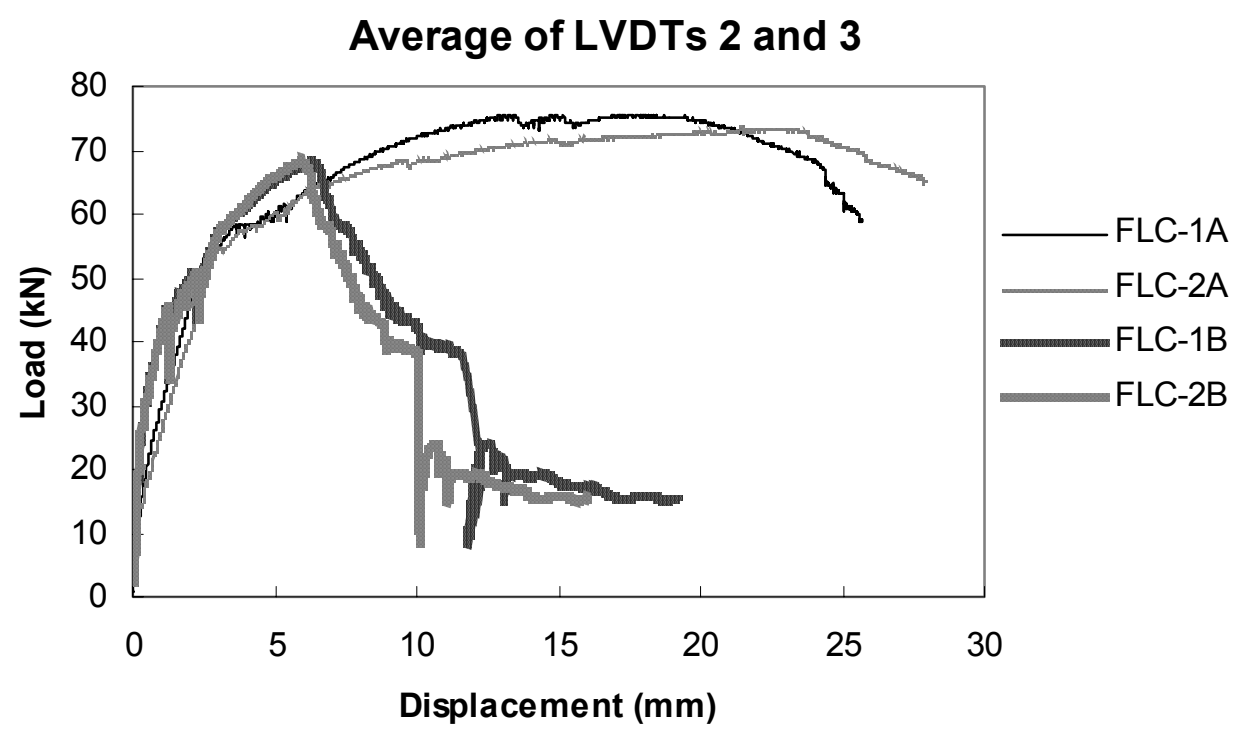

Figure 103 - Curves of displacements (average LVDT 2 and 3) $\times$ load - series FLC.

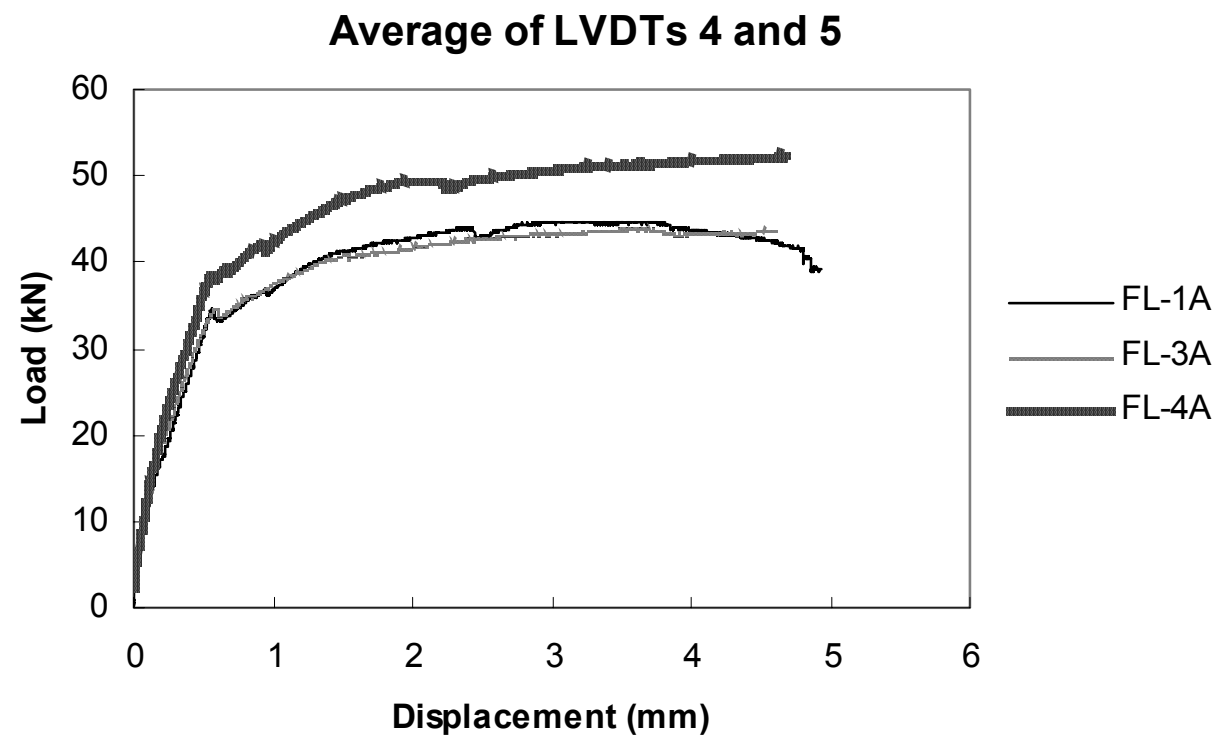

Figure 104 - Curves of displacements (average LVDT 4 and 5) $\times$ load - series FL-A. 


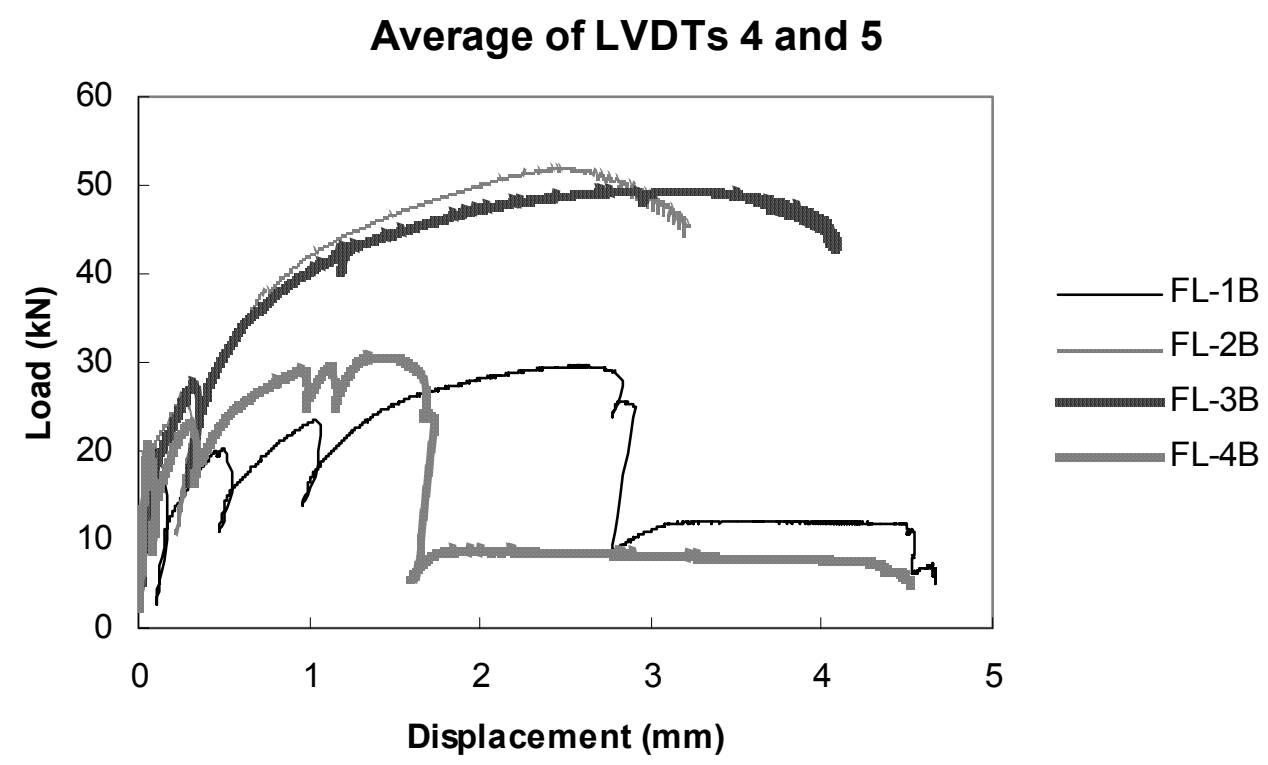

Figure 105 - Curves of displacements (average LVDT 4 and 5) $\times$ load - series FL-B.

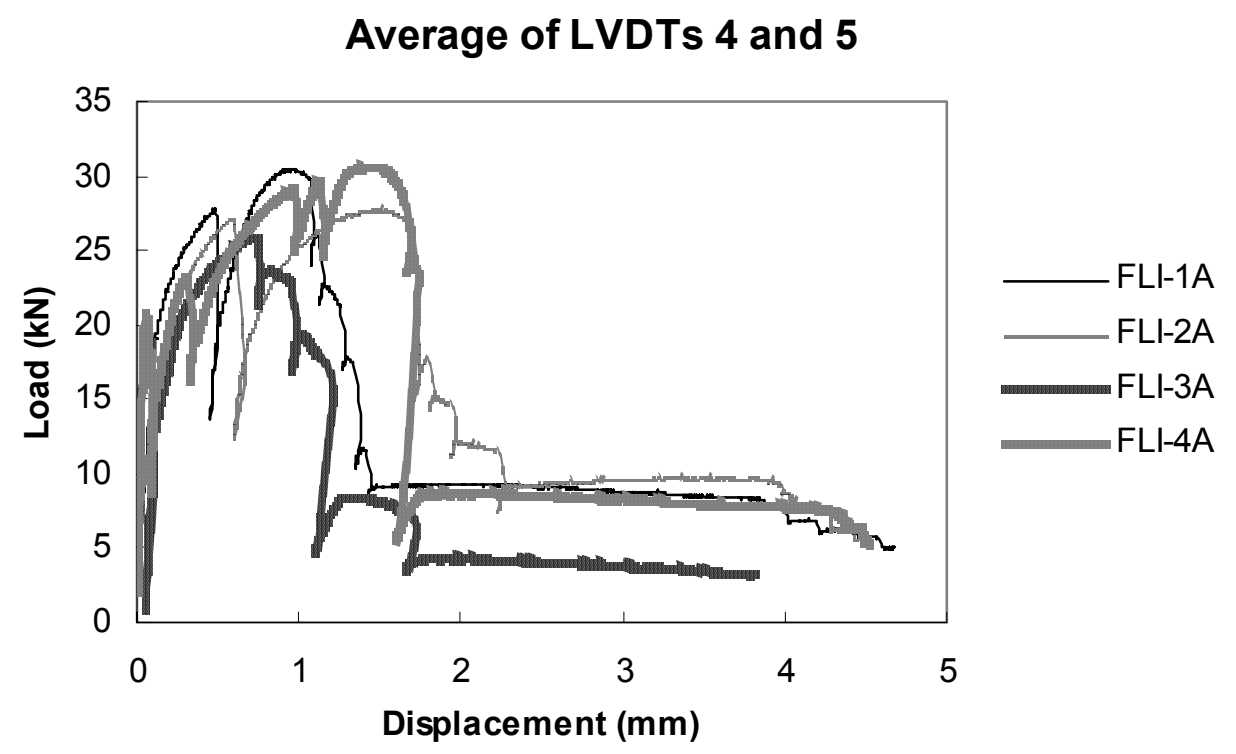

Figure 106 - Curves of displacements (average LVDT 4 and 5) $\times$ load - series FLI-A. 


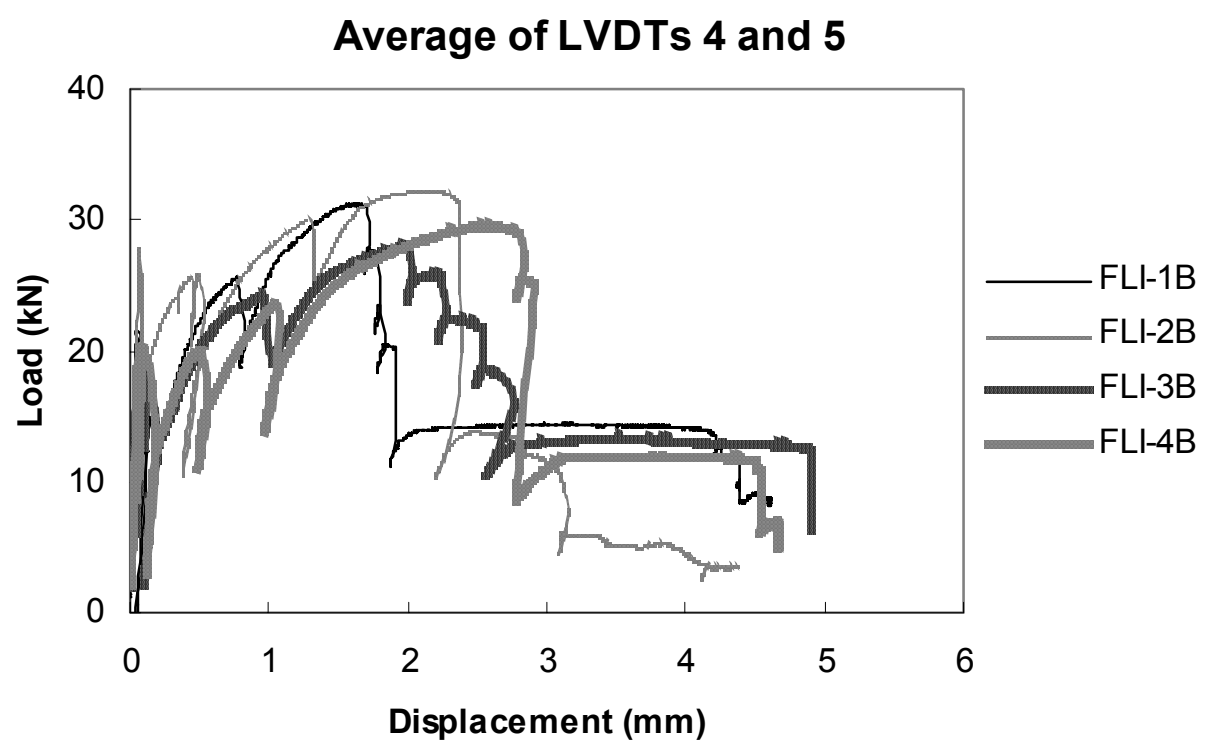

Figure 107 - Curves of displacements (average LVDT 4 and 5) $\times$ load - series FLI-B.

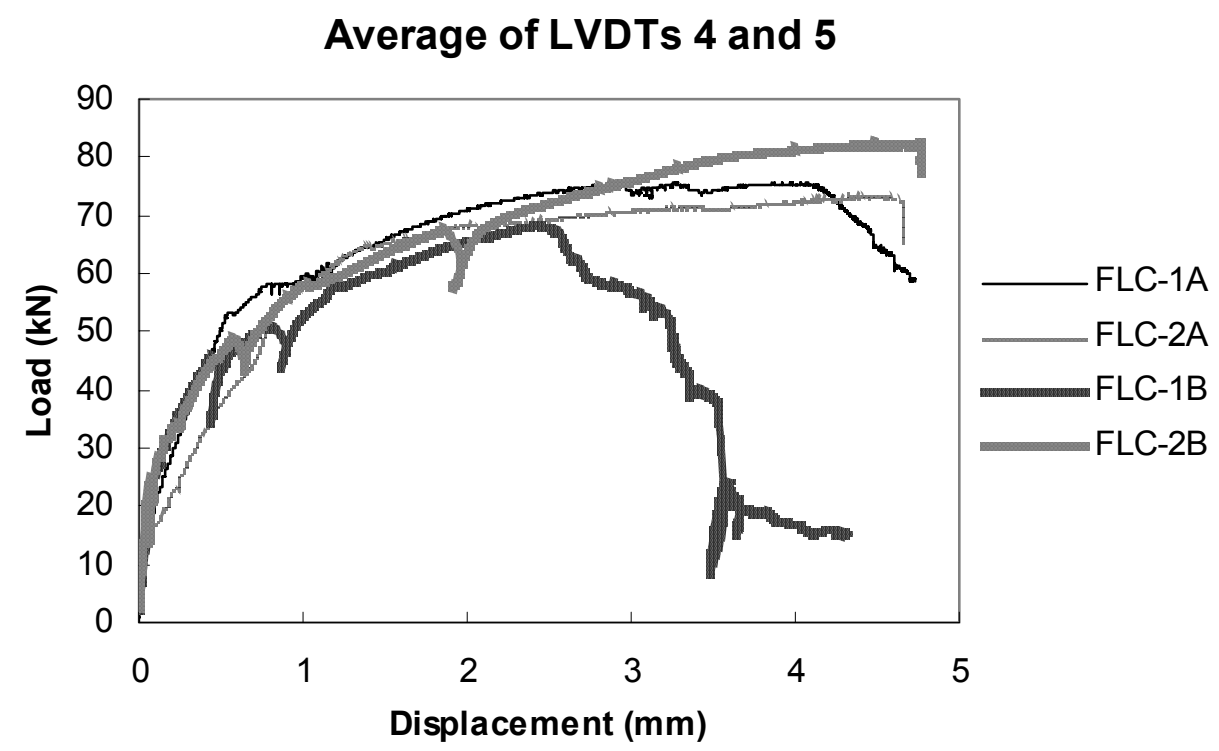

Figure 108 - Curves of displacements (average LVDT 4 and 5) $\times$ load - series FLC. 